\title{
Hybrid renewable energy systems for desalination
}

\author{
Farbod Esmaeilion ${ }^{1}[0$
}

Received: 8 November 2019 / Accepted: 19 February 2020 / Published online: 2 March 2020

(c) The Author(s) 2020

\begin{abstract}
Water and energy are two key factors in human life that always control the growth and development of human societies. Climate changes, increasing the population in urban areas and industrialization, have increased the demands for freshwater around the world. Estimates show that a small percentage of all freshwater produced in the world is from renewable sources. By developing the technology, lowering equipment prices and increasing attention to the environmental problems of fossil fuels, utilizing renewable energy is growing. By providing a wide variety of conventional desalination methods driven by various types of renewable energy technologies in the world, water and energy legislators should choose different methods to meet the needs based on the local potentials by paying attention to the desalination processes and power systems. In some cases, concentrated solar power for thermal desalination or electricity generated by the photovoltaic plants for membrane desalination systems can be used in arid areas. Definitely, the most problem of using renewable sources is their unsteady natures, which using storage systems or combining with other renewable sources can solve this problem. This chapter provides extensive information about renewables, desalination and performance analysis of power systems. Reverse osmosis technique is a practical process in desalination which $69 \%$ of desalination plants use this system. Solar energy is an important source of energy for hybrid systems. The geothermal has a steady performance at a specified depth. Ultimately, obtained results from energy and exergy analysis would have provided a better insight.
\end{abstract}

Keywords Desalination $\cdot$ Freshwater $\cdot$ Renewable energy sources $\cdot$ Hybrid energy systems $\cdot$ Exergy

\begin{tabular}{|c|c|c|c|}
\hline \multicolumn{2}{|c|}{ Abbreviations } & EDR & Electrodialysis reversal \\
\hline$A$ & Area $\left(\mathrm{m}^{2}\right)$ & EIA & Environmental impact assessment \\
\hline BAT & Best available technology & EL & Electrolysis \\
\hline bbl & Barrel of oil & ERT & Energy recovery turbine \\
\hline$C$ & The salt concentration of feedwater $(\mathrm{g} / \mathrm{l})$ & ex & Specific exergy $(\mathrm{kJ} / \mathrm{kg})$ \\
\hline$c$ & Specific heat capacity $(\mathrm{kJ} / \mathrm{kg} \mathrm{K})$ & Ex & Exergy $(\mathrm{kW})$ \\
\hline $\mathrm{CA}$ & Cellulose acetate & $\mathrm{FC}$ & Fuel cells \\
\hline CSP & Concentrated solar power & FO & Forward osmosis \\
\hline DCC & Direct capital cost & GHG & Greenhouse gas \\
\hline DEIM & Department of Energy, Information Engineer- & $h$ & Specific enthalpy $(\mathrm{kJ} / \mathrm{kg})$ \\
\hline & ing and Mathematical Models & $H$ & Enthalpy (kJ) \\
\hline DPP & Desalination pilot plant & HYB & Hybrid \\
\hline DPR & Direct potable reuse & $i$ & Interest \\
\hline DWEER & Dual work exchanger energy & IAEA & International Atomic Energy Agency \\
\hline E & Energy $(\mathrm{kJ})$ & IDA & International Desalination Association \\
\hline ED & Electrodialysis & IDA & International Desalination Association \\
\hline EDI & Electrodeionization & IPR & Indirect potable reuse \\
\hline & & LCA & Life cycle analysis \\
\hline$\triangle$ Farbod & Esmaeilion & & Mass flow rate $(\mathrm{kg} / \mathrm{h})$ \\
\hline farbode & mailion@gmail.com & MD & Membrane distillation \\
\hline & & MED & Multi-effect distillation \\
\hline $\begin{array}{l}\text { School } \\
\text { System }\end{array}$ & of Advanced Technologies, Department of Energy & MSF & Multi-stage flash \\
\hline Techn & ogy (IU & MVC & Mechanical vapor compression \\
\hline
\end{tabular}




$\begin{array}{ll}\text { MW } & \text { Molar mass } \\ \text { N } & \text { Number of moles } \\ \text { NF } & \text { Nanofiltration } \\ \text { NHR } & \text { Nuclear heating reactor } \\ \text { OECD } & \begin{array}{l}\text { Organization for Economic Co-operation and } \\ \text { Development }\end{array} \\ \text { OER } & \text { Osmotic energy recovery } \\ P & \text { Pressure }(\text { bar }) \\ \text { PV } & \text { Photovoltaic } \\ \text { PX } & \text { Pressure exchanger } \\ Q & \text { Heat transfer }(\mathrm{kW}) \\ R & \text { Recovery } \\ \text { RE } & \text { Renewable energy } \\ \text { RO } & \text { Reverse osmosis } \\ S & \text { Entropy }(\mathrm{kJ} / \mathrm{K}) \\ \text { SHDD } & \text { Solar humidification and dehumidification } \\ & \text { desalination } \\ \text { SWRO } & \text { Seawater reverse osmosis } \\ T & \text { Temperature }\left({ }^{\circ} \mathrm{K}\right) \\ \text { TCC } & \text { Total capital cost } \\ \text { TDS } & \text { Total dissolved solids } \\ \text { TFC } & \text { Thin-film composite } \\ \text { TVC } & \text { Thermal vapor compression } \\ U & \text { Overall heat transfer coefficient }\left(\mathrm{kW} / \mathrm{m}^{2} \mathrm{~K}\right) \\ \text { USD } & \text { US dollar } \\ V & \text { Volume }\left(\mathrm{m}^{3}\right) \\ \text { VP } & \text { Vapor compression } \\ W & \text { Work }(\mathrm{kW}) \\ \text { WHO } & \text { World Health Organization } \\ \text { WSI } & \text { Water stress index } \\ \text { WWP } & \text { World Water Program } \\ \text { WWTP } & \text { Wastewater treatment plant } \\ x & \text { Mole fraction } \\ \dot{Z} & \text { Capital cost rate }(\$ / \mathrm{h}) \\ & \end{array}$

\section{Greek symbols}

$\begin{array}{ll}\Delta & \text { Changes in quantity } \\ \beta & \text { Number of particles } \\ \varepsilon & \text { Exergy efficiency }(\%) \\ \eta & \text { Efficiency }(\%) \\ \nu & \text { Vapor } \\ \rho & \text { Density }\left(\mathrm{kg} / \mathrm{m}^{3}\right) \\ \Phi & \text { Maintenance factor }\end{array}$

\section{Subscripts and superscripts}

$0 \quad$ Initial state

ch Chemical

e Element

equip Equipment

f Feedwater

hpp High-pressure pump

HT Horizontal tube

i Inlet condition

k Kinetic

$\begin{array}{ll}\mathrm{m} & \text { Modified } \\ \mathrm{o} & \text { Outlet condition } \\ \mathrm{p} & \text { Pump, permeate, potential } \\ \mathrm{ph} & \text { Physical } \\ \mathrm{sw} & \text { Seawater } \\ \text { swip } & \text { Seawater and intake price } \\ \mathrm{T} & \text { Thermal }\end{array}$

\section{Introduction}

More than $70 \%$ of the Earth's surface is covered with water; however, most of it is not suitable for human consumption. The magnitude of all water resources on the Earth is approximately 1.4 billion cubic kilometers, which roughly $97.5 \%$ of it placed in the oceans and only $2.5 \%$ could be found as freshwater in the atmosphere, icebergs, lakes, rivers and groundwater and just $0.014 \%$ of the total resources are available for humans (Shatat et al. 2013; Kucera 2019; Subramani and Jacangelo 2015).

The distribution of freshwater around the world is not uniform. In this case, unbalanced distribution caused that some parts of the groundwater resources have become greatly available to several specific areas with low population and convenient access to freshwater such as the northern parts of Russia, Scandinavia, Canada, Alaska and southern parts of South America. Additionally, areas with a high population or areas with industrial growth are more vulnerable to water stress and areas that are in arid regions also have a degree of water stress based on the ratio of water consumption to the amount of available water. Obviously considering the significance of upstream water use on downstream stress has a direct effect on water distribution (Munia et al. 2016). The index of water stress is essentially linked to per capita water use. The following formulation represents a detailed picture of this relation (Veldkamp et al. 2015).

$\frac{\text { Water use }}{\text { population }}=\frac{\text { Water use }}{\text { accessibility to water }} \times \frac{\text { accessibility to water }}{\text { population }}$

Based on the defined indexes, various levels of water stress have been calculated by Falkenmark. In this classification, the water stress index (WSI) for lower than $20 \%$ represents no stress and if it becomes more than $70 \%$ expresses extreme stress (Falkenmark et al. 2007). The measure of water stress is the ratio of total water use (domestic, industrial or agricultural) to produced renewable water, including runoff in rivers and underground sources with little depth. About 2.8 billion people on the planet will face the problem of scarcity or water stress up to the year 2025, and by 2050 this value will be reached at 4 billion. In the future, some areas including South and Central America, Eastern Europe and Asia will face water scarcity (Kucera 2019). In addition to increasing 
population growth, pressure on water resources comes from increasing per capita consumption. There are different maps to determine current and predicted water stress in the future. The worldwide populace has nearly quadrupled in the course of recent years (last century), and it arrived at 6.5 billion until the end of the twentieth century. Regardless of just little varieties in per capita water utilization after this period, growth in total water utilization brought about an expansion in the population under water scarcity in the twentieth century. The following graph provides an extensive trend of water scarcity all over the world in the twentieth century (Fig. 1).

Demands for freshwater in developed countries are increasing. For example, the daily consumption per person in the USA is $400 \mathrm{~L}$. Some developed countries with the help of restrictions and regulations have reduced the consumption of water up to $150 \mathrm{~L}$. However, the studies indicated that with the difficulty of access to freshwater resources in some areas around the world, a low amount of water would be consumed. For example, the consumption per person in Africa is $20 \mathrm{~L}$ per day. The World Health
Organization (WHO) considers that consuming 15-20 L per day is necessary for human survival. On the other hand for some uses, such as hospitals and schools, consumption of $50 \mathrm{~L}$ per person per day is essential, while population growth, increasing consumption per capita and climate changes are three main stressors in the water resources. The World Water Program (WWP) estimates that by 2030 only $60 \%$ of the water needed will be available, and the Organization for Economic Co-operation and Development (OECD) has predicted that by 2050 this amount will reach $55 \%$. By the end of the century, $40 \%$ of the world's population will live in areas with water stress (Caldera et al. 2016). Overall, water demands will be doubled every 20 years (Eltawil et al. 2009; Kalogirou 2005). About 70\% of the freshwater needed is for the agriculture section, $20 \%$ for the industry sector and only $10 \%$ for houses uses (ElDessouky and Ettouney 2002). High rates of population growth and climate change have highlighted the need for new freshwater resources. Shortages of water resources are leading to a decline in the standard of living and economic growth.

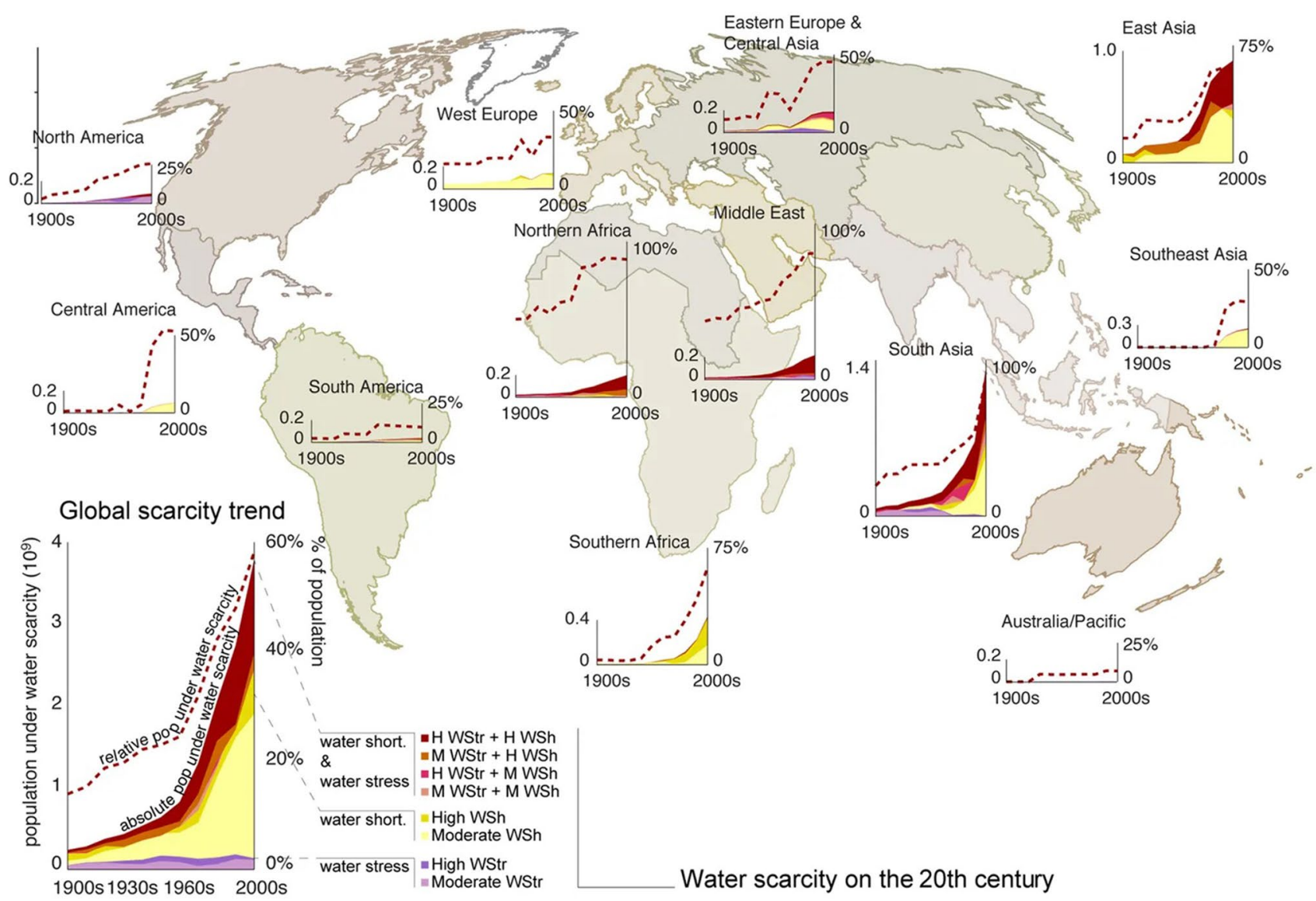

Fig. 1 Water scarcity trends for each area of the globe in the twentieth century (Kummu et al. 2016) 


\section{New freshwater resources}

Water storages besides water flows affect water accessibility for human life and ecologies. Ecosystems are affected by water management, sustainability in quantity and quality of water resources and humans activities (e.g., constructing dams and dikes). Wise developments for water resources can lead to eliminating the water scarcity concerns (Vörösmarty et al. 2015; Sterling et al. 2013). Rapid urbanization and successive transfer of wastewater to surface water and underground can cause boundless contamination of freshwater supplies with developing contaminants. Despite the fact that these matters might be available at any level, their unfavorable consequences for aquatic life, creatures and live beings are developing concerns (Pal et al. 2010). In this case, it is important to find novel ways to supply freshwater. The followings are the most important ways to access freshwater.

\section{Water transmission}

Water transmission from rich resources to arid areas is not an innovative idea. For example in the southwestern areas of the USA, water is transmitted for household, industrial and agricultural uses. Los Angeles now supplies $85 \%$ of its water requirements from outside of the region. Of course, water transfers from other areas are not always favorable, and protests against the transmission have always been a problem. In the USA, for instance, the diversion of the Colombia River for water supply in the western states has been a hot topic in Oregon for 35 years. Furthermore, in Spain, representatives of various parties are vigorously competing for water in the southeast (Kucera 2019). Additionally in the transmission systems, water quality is getting worse. Preventive potential for biological regrowth can be achieved by chlorinating the water. Even more disturbing, scheduling the control systems in water transmission lines is another concern for this strategy (Jung et al. 2015; Al-Jasser 2007).

In addition to social and political pressures, technical problems such as long distances for water transmission, especially in high-altitude areas, makes it impossible to apply this method to all areas of the earth.

\section{Protection and reuse}

Conservation of water resources is a concept that has been used for achieving optimally usage of resources. Nowadays the sustainability term represents a concept for this idea. The idea of optimal use, retrieval and reuse of resources in today's world is an acceptable indicator. These techniques are the primary option for arid and remote areas from the oceans that do not have access to freshwater resources. By considering, the Los Angeles city that placed in an arid area with precipitation equal to $40 \mathrm{~cm} / y e a r$, increases attention to conserving water resources. The city has a population of about 4 million and is projected to reach 10 million by 2020. In this metropolitan, demand for freshwater will go up to 123 million cubic meters annually. The Los Angeles Department of Water and Power (LADWP) is a very large water refinery site that is used as an effective operator for converting wastewater to purified water. The equipment was installed in 1992 after a severe drought in the late 1980s and nowadays produces about 114 cubic meters of water per day, and that 500 million USD in this site has been invested (Kucera 2019).

Two supply-side strategies that can raise the reliability of drinkable water supplies are (1) indirect potable reuse (IPR) and (2) direct potable reuse (DPR). In both cases, by using wastewater, the water supply is enlarged.

In IPR, water decontaminated to reach drinkable standards and then certified to enter the water supply through an environmental buffer. In general for IPR, wastewater treatment plant (WWTP) causes a high purification through advanced processes and then directed to an environmental buffer, such as stream or reservoir. The environmental buffer is proposed to provide an extra boundary and time gap for reducing the adverse effects with different sources (Raucher and Tchobanoglous 2014). Figure 2 represents the cycle of IPR.

DPR is an effective method that can increase the sustainability and reliability of water supplies by recovering drinking water from wastewater and sewage. It is important to note that the stability of this method in coastal areas differs from that in other areas (Scruggs and Thomson 2017). DPR system dedicates adequate time for confirmation of particular parameters for water quality before the water injects into

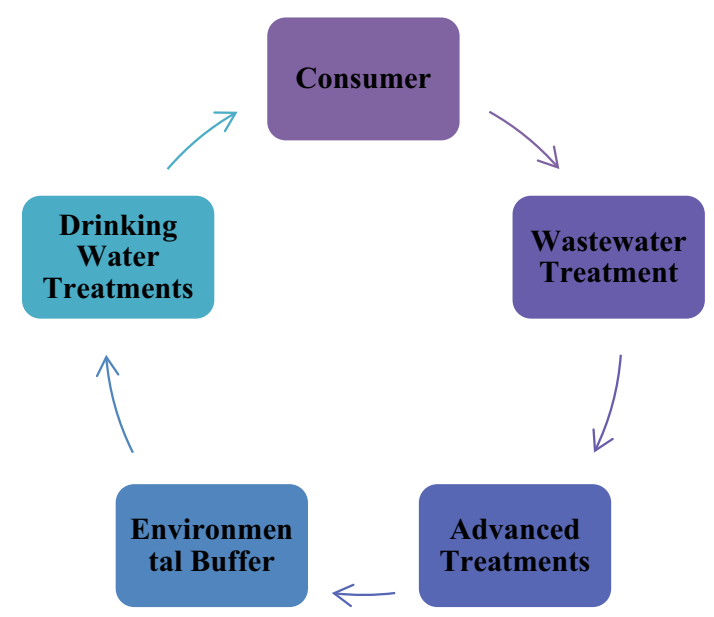

Fig. 2 Indirect potable reuse (IPR) cycle for recovering water 


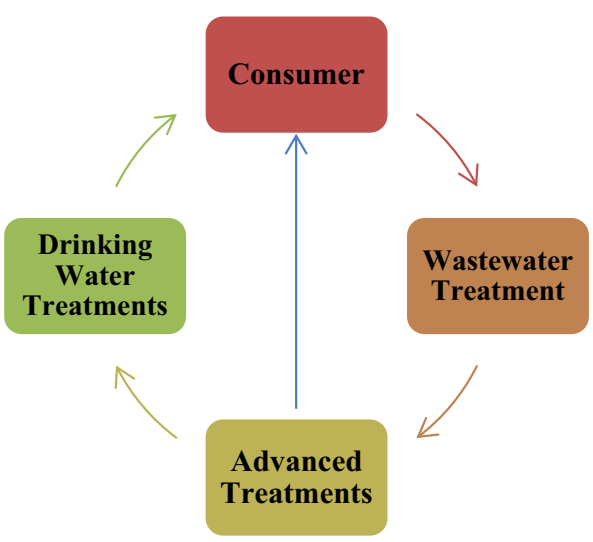

Fig. 3 Direct potable reuse (DPR) cycle for reusing wastewater

the distribution system. Figure 3 illustrates the function of DPR based on its operative factors.

Produced water has 5 properties that are used for various purposes:

- Wastewater that used for industrial and irrigation purposes

- Nitrated water for use in cooling towers

- Soft water to recharge groundwater

- Reversed osmosis water for low-pressure boilers

- High-quality reverse osmosis water for high-pressure boilers

Conservation of resource and recovery techniques can reduce the rate of need for freshwater, but generally does not eliminate the need for freshwater.

\section{Developing new resources}

Developing new resources for freshwater along with other conventional water reservoirs such as lakes, rivers and shallow wells is another way to meet the growing need of communities. These new sources include seawater, deep wells and groundwater saline aquifers (Be 2014). Nonetheless, the main drawback of the water from these sources is that it has a high percentage of mineral salts and has a negative impact on water quality. So in this case spearing this matter and recycling the water by specific processes like desalination, can improve the quality (Cipollina et al. 2009). Extensive researches into the desalination process over the last 50 years have led to technological advancements in this pathway and reduced costs for freshwater production, and in the future, this process will be a major factor in supplying water from low-quality sources.

The desalination process means separating salt from water. Technically, desalination can be the process of separating insoluble solid particles, such as salts and minerals from water. The first operational uses of the desalination process were in the sixteenth and seventeenth centuries, during which some sailors provided seawater with the aid of desalination. In the early twentieth century, desalination equipment was first used on the island of Curacao and the Arabian Peninsula. Research and development of desalination plants have accelerated in the middle of this century, and for the past 30 years, the manufacture and use of this technology have been developed rapidly (Sauvet-Goichon 2007; Sanza et al. 2007). In our time the desalination process has, in some ways, indispensable and undeniable effects on human life, which may be due to:

1. Increased demand for drinking water with rapid population growth in arid regions and low access to drinkable water.

2. Increasing per capita consumption of drinking water in industrial areas and urban communities.

Seawater has been used to feed many desalination plants all over the world (58.85\%) (Kucera 2019). The use of desalination equipment in the Persian Gulf, Algeria, Australia and Spain is growing, significantly. Seawater use is only possible for coastal areas and offshore areas, while the areas that are far from the seas have to rely on underground saltwater aquifers (Cheng et al. 2000). According to statistics from the International Desalination Association (IDA), installed desalination capacity was 5 million cubic meters per day in 1980 that increased to 80 million cubic meters per day in 2013, in which about 150 countries used this method around the world to access freshwater (Caldera et al. 2016). The worth of all desalination equipment installed in 2014 was about 12 billion USD, which increased to 21 billion USD by 2019 . For the time being the total desalination capacity of the world reached 23 million cubic meters per day (Bennett 2015).

The desalination technologies have been used for many years in arid regions of the world such as the Middle East, the Mediterranean and the Caribbean lands. The highest capacity of installed desalination plants belongs to the Middle East, accounting for $65 \%$ of total desalination capacity, due to the lack of freshwater resources in these areas and extensive access to fossil fuels. Saudi Arabia, the United Arab Emirates, the USA, Spain and China have the highest desalination capacities, and India has the highest growth in this industry since 2002 (Proskynitopoulou and Katsoyiannis 2018; Greenlee et al. 2009). Figure 4 indicates a map of areas with desalination units. As explained, the Middle East has the highest share of seawater utilization which North America mostly uses brackish water.

Demands for freshwater have risen above its sustainable consumption level, and using desalination is the best way to deal with the shortage of water resources. Nearly 400

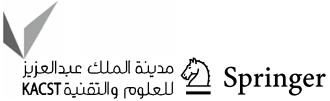




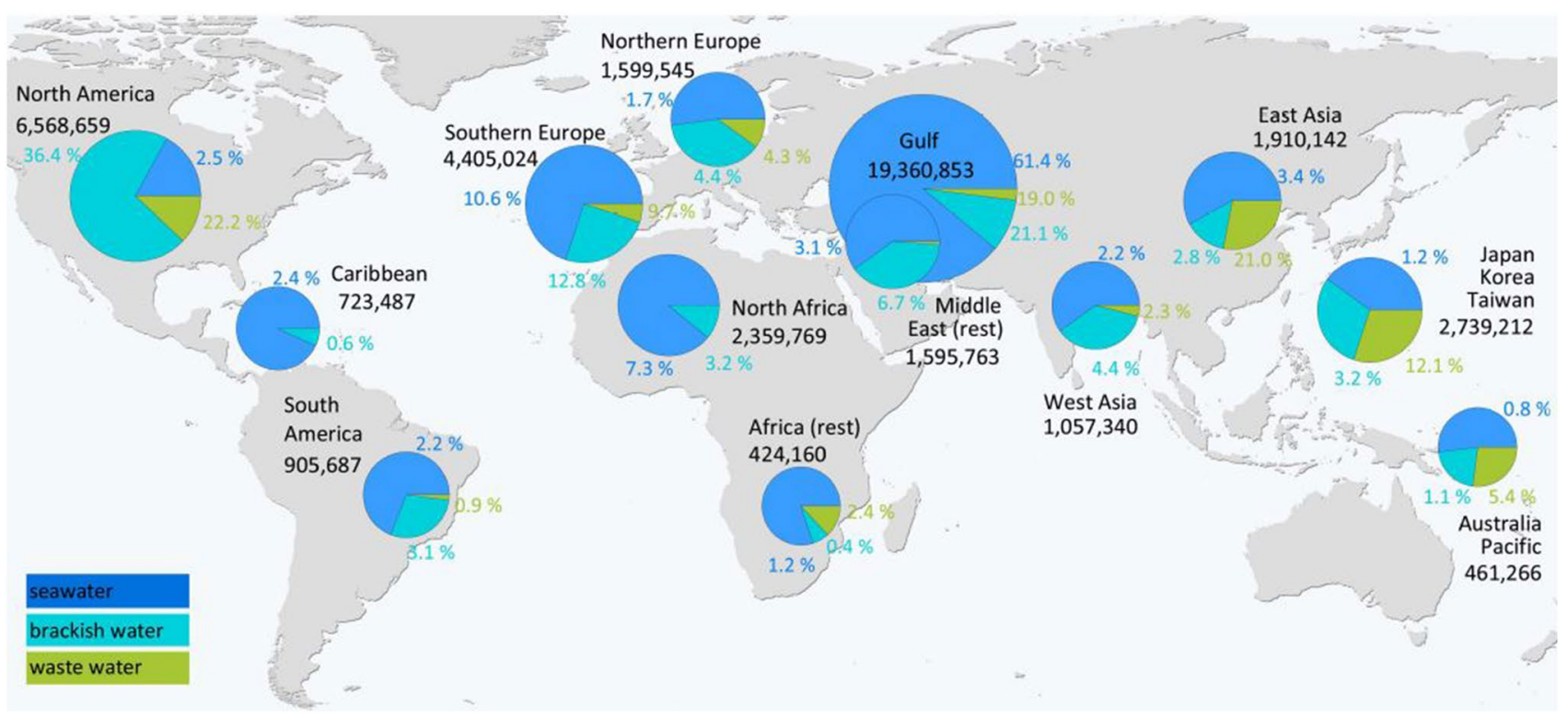

Fig. 4 International desalination capacity $\left[\mathrm{m}^{3} / \mathrm{d}, \%\right]$ and which the Middle East has the largest share (Latteman 2010)

million individuals used desalinated water in 2015, and it is projected that by 2025 , about $14 \%$ of the world's population will have to use desalinated water (Chandrashekara and Yadav 2017). On the other hand, we need to find ways to convert industrial wastewater into freshwater. Recovered water has high levels of insoluble solid particles that can be reduced or eliminated by desalination methods.

\section{Desalination resources}

The sources of water for the desalination are varied, and as mentioned, these sources can range from seawater to saline groundwater or even wastewater. Although the seawater contributed the most among other resources, since 2000 the shares of other resources such as brackish water, underground saltwater aquifer and recovered water have been growing (Abrams 2018). Figure 5 represents the variations in the shares of water resources from 2010 to 2011. As mentioned before, the most proportion belongs to seawater. It is reasonable to note that during this period the amount of seawater contribution decreased specifically. Moreover, during this period, utilizing brine has been eradicated.

According to WHO documents, the salt limit is around $500 \mathrm{ppm}$ and can only be increased to $1000 \mathrm{ppm}$ for specific situations. However, most of the water on Earth has salts above 10,000 ppm (Eltawil et al. 2009; Kalogirou 2005). The word "freshwater" is used to refer to water with a salinity of 100-500 ppm. Roughly 3-5\% of the world's water falls into the category of freshwater (Reif and Alhalabi 2015). Table 1 shows all water-insoluble solid particles (g/l) (note that total
Fig. 5 Shares of water resources for the desalination process for 2010 (a) and 2011 (b) (Abrams 2018) (b)

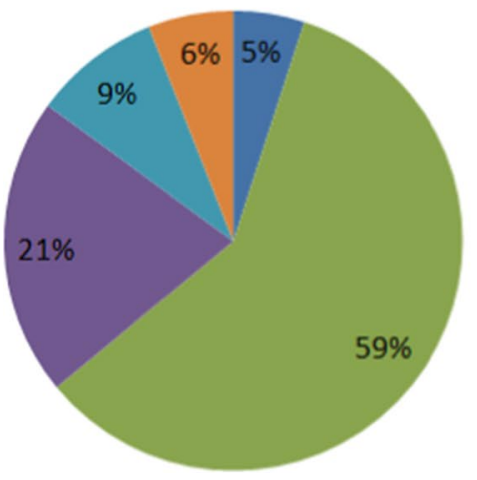

(a)

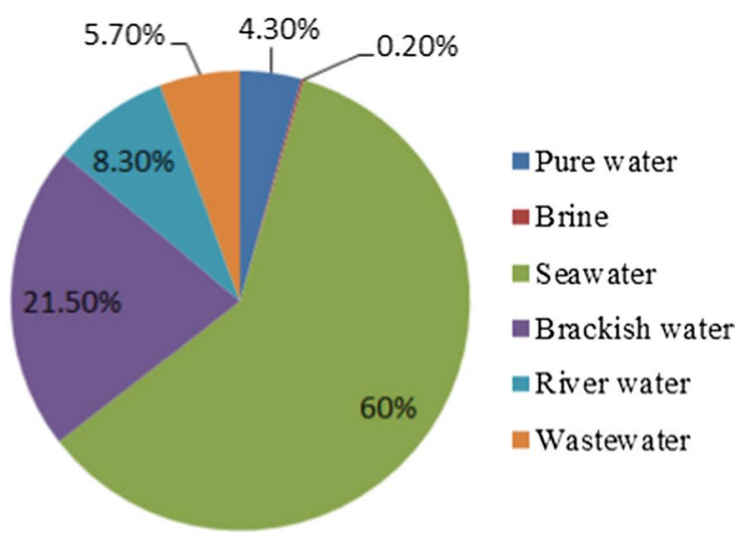


Table 1 The classifications of water by total dissolved solids (DeZuane 1997)

\begin{tabular}{ll}
\hline Type of water & TDS $(\mathrm{g} / \mathrm{l})$ \\
\hline Drinking water & $<0.5$ \\
Agricultural water & $0.5-1.5$ \\
Groundwater & $1.5-3.5$ \\
Seawater & $>3.5$ \\
\hline
\end{tabular}

dissolved solids (TDS) represent the sodium chloride $(\mathrm{NaCl})$ value and each gram per liter is $1000 \mathrm{ppm}$ ) (DeZuane 1997).

Groundwater resources, depending on drainage and surface soil conditions, have a wide range of TDS. The brackish water is blue with salinity between freshwater and seawater (about 5000-35,000 ppm but usually in the range of $10,000-15000 \mathrm{ppm}$ ) which about $23 \%$ of the world's water is of this type. The salinity of seawater is in the range of $35000-45,000 \mathrm{ppm}$ that has a share equal to $58 \%$ of the world's water. Other shares of the world's water resources are wastewater (approximately 5\%), river water (almost $7 \%$ ) and others. Unfortunately, much of the wastewater in advanced societies goes straight into the river, which in turn reduces the share of freshwater resources. Too much salt in the water causes problems such as taste changes and digestive problems for humans. The ultimate objective of desalination from brackish water or seawater is to provide pure water with less than $500 \mathrm{ppm}$ salt content (El-Ghonemy 2012). Despite the different quality of different water sources, each of them has a high amount of salinity and TDS. These high TDS sources are not suitable for consumption and industrial uses. So reducing TDS contents should be part of the desalinating task. Table 2 shows the water compounds depending on the sources (Kucera 2019).

The most significant sector in the use of desalinated water belongs to urban consumption which contributed about twothirds of the total desalination capacity for drinking uses. A third of the capacity belongs to industry and energy sections (Fig. 6). Only about $6 \%$ of the desalinated water is used

Table 2 Different compounds in water resources (Kucera 2019)

\begin{tabular}{llll}
\hline Compound type (ppm) & Seawater & $\begin{array}{l}\text { Groundwater } \\
\text { (well water) }\end{array}$ & $\begin{array}{l}\text { Wastewater } \\
\text { (graywater) }\end{array}$ \\
\hline TDS & 35,000 & $350-3200$ & 650 \\
Chloride & 19,345 & $4-1400$ & 67 \\
Sodium & 10,752 & $40-750$ & 66 \\
Sulfur & 2710 & $110-300$ & 200 \\
Magnesium & 1295 & $16-40$ & 34 \\
Calcium & 416 & $50-180$ & 88 \\
Nitrate & 3 & $0.1-1.7$ & 4.4 \\
Iron & 0.0034 & 0.01 & 1.3 \\
Arsenic & 0.003 & - & - \\
\hline
\end{tabular}

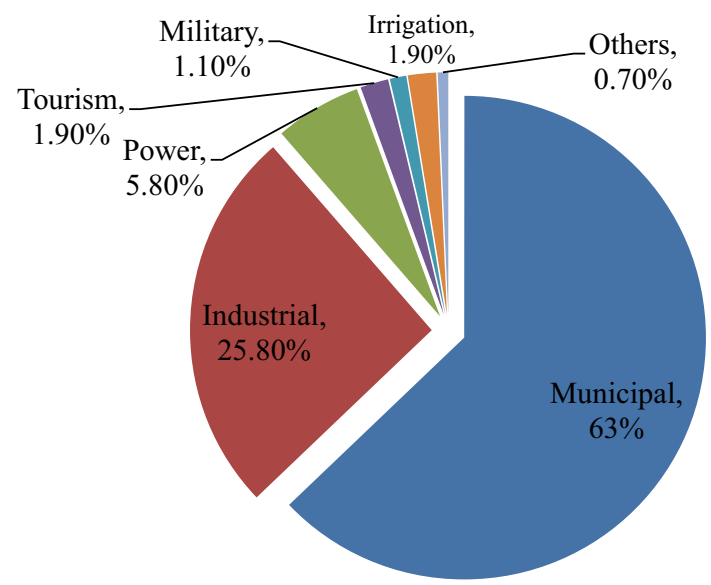

Fig. 6 Shares of freshwater consumption produced in different sectors (Xevgenos et al. 2016)

for tourism, military and agricultural purposes (Yearbook 2010).

\section{Methods of desalination}

At present desalination plants are very expensive and high energy consumption, which proposing innovative methods that will reduce the costs would make them more affordable and economical. For this reason, researches are ongoing to increase the efficiency of desalination plants to reduce the costs. Some areas of development are:

- Energy: The use of renewable energies such as wind or solar to drive desalination plants, reduces the costs of energy in these methods. Today's share of renewable energy (RE) use in the desalination process is about $1 \%$ (Kalogirou 2018).

- Materials: The use of new products for the manufacture of thermal desalination devices is to reduce the phenomenon of corrosion as well as reduce the dimensions and weight of the assembly which will, in turn, reduce construction costs. Considering the type of materials used in plant construction plays an effective role in system productivity (Darre and Toor 2018; Hernandez et al. 2018).

- Chemicals: Antifouling materials on both membrane and thermal methods should be developed to increase the freshwater production capacity of these devices.

The total capacity of the world's desalination in 2019 reached about 95.37 million cubic meters per day. In this case, there are 15,906 working desalination plants all over the world. Lately, desalination plants mainly utilized thermal technologies that they are located in oil-rich areas that have

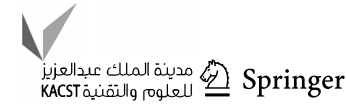


Fig. 7 Noticeable increase in the number of desalination plants and desalination capacity over the last two decades (Jones et al. 2019)

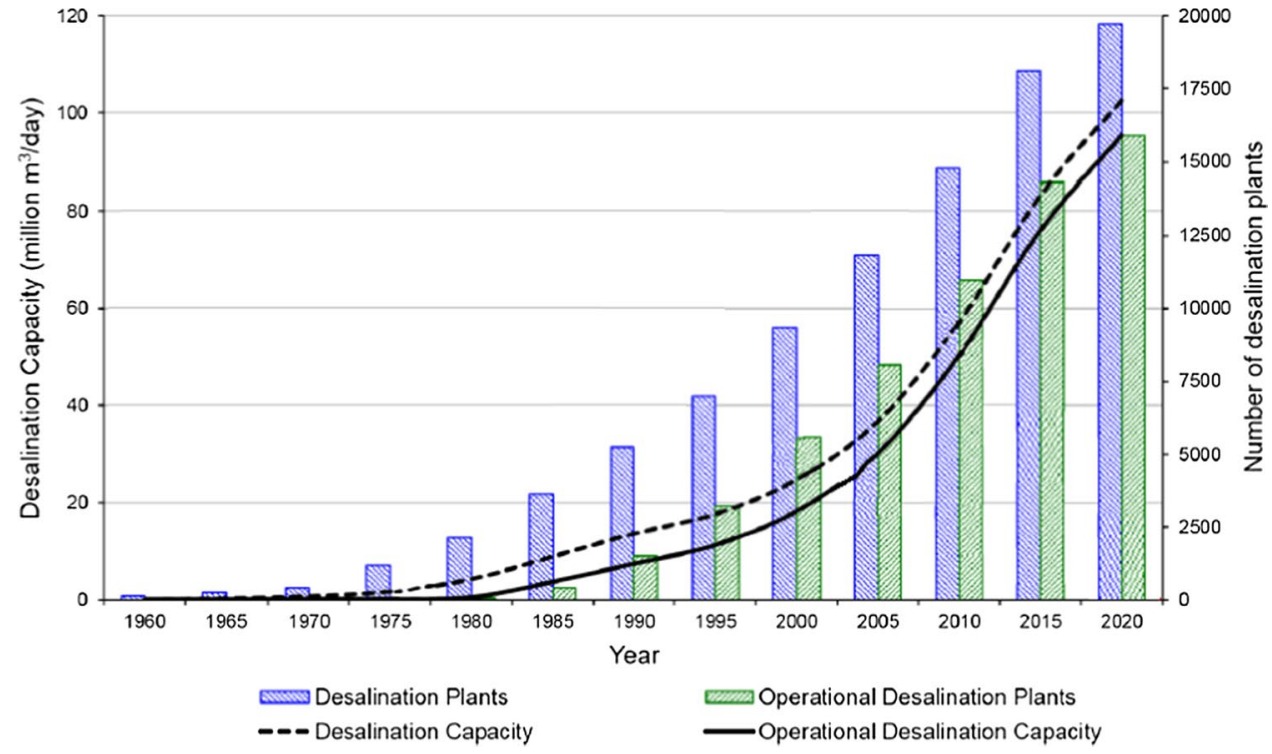

East region, due to the low cost of energy in this region that is widely popular (Wetterau 2011).

\section{Membrane desalination}

This technology is based on the capabilities of the semipermeable membrane to let certain ions pass through it. The three main driving forces can be used in membrane separation, including pressure, electrical potential difference and concentration difference. The reverse osmosis (RO) method is based on pressure, electrodialysis (ED) and electrodialysis reversal (EDR) operated on the basis of the difference of electrical potential and forward osmosis (FO) is based on the concentration difference. Of the membrane separation methods, reverse osmosis is the most commonly used. Although all types of electrodialysis are well-known technologies, the use of these methods for seawater desalination is not economical. Also, direct osmosis is an innovative and complementary technique that is recently being commercialized for use in high desalination capacities (Wetterau 2011; Amy et al. 2017). It is important to mention that there are other methods for desalination, named: multi-stage flash (MSF), multi-effect distillation (MED), nanofiltration (NF), electrodeionization (EDI), hybrid (HYB) and vapor compression (VP).

The contribution shares of different desalting methods are shown in Fig. 8. Installed capacity by membrane systems is nowadays more than traditional thermal methods. Until 1980, membrane systems had less than one-third of desalination. A distinctive feature of this trend is in the Middle 


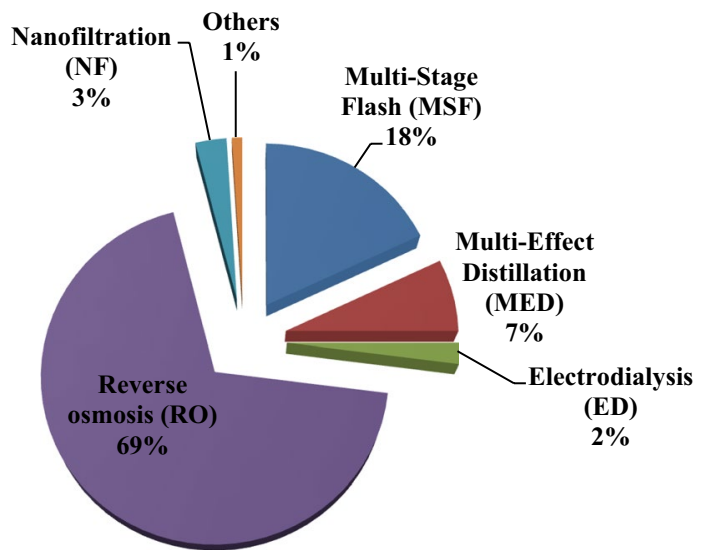

Fig. 8 The contributions of desalination methods all over the world

desalination capacity, but today they approached just under two-thirds of the total installed capacity. Membranes are growing in several markets such as Australia, Spain and Algeria; nevertheless, there is a high opportunity for thermal strategy in the Middle East where energy costs are low. Saudi Arabia has $34.8 \%$ of total thermal desalination capacity (5.9 million cubic meters per day). In a close competition, United Arab Emirates (UAE) produces 5.8 million cubic meters per day, followed by Kuwait, Qatar, Libya, Bahrain and Oman with 0.5-2.1 million cubic meters per day. The USA took ninth place for thermal treatment (about 0.35 million cubic meters per day), but it ranked first in use of membrane desalination at 7.5 million cubic meters per day, while Saudi Arabia ranked second with less than 5 million cubic meters per day (Yearbook 2010).

\section{Reverse osmosis}

The growth in the utilization of membrane separation methods and in particular reverse osmosis has been very high in recent years which, nowadays, reverse osmosis is one of the most widely used methods for desalination (Widiasa et al. 2009). Due to the low energy requirements and associated costs, reverse osmosis has been known as the major desalination method. The reverse osmosis method works by overcoming the natural phenomenon of osmotic pressure. This occurs when a semipermeable membrane separates two solutions with different concentrations of ions. The osmotic pressure is based on the difference in concentration and the flow of water from the dilute solution to the concentrated solution. This process continues as long as the chemical balance is maintained between the two solutions. The flow of water can be reversed by an external factor such as hydraulic pressure, provided that the applied pressure is greater than the osmotic pressure. Figure 9 represents the function of osmosis and reversal osmosis processes by considering the semipermeable membrane.

In reverse osmosis, water with inorganic salts (minerals), soluble and insoluble organic matters, insoluble gases under pressure and aquatic microorganisms are passed through the semipermeable membrane. A semipermeable membrane is a membrane that allows water to pass at a faster rate and flow than other materials and compounds. Depending on the size and electrically charged particles in the water, these particles remain in the inlet portion of the reverse osmosis membrane, while fresh and desalinated water passes through the membrane surface. Since the gases particles have small molecular sizes, the membrane does not block them well. In terms of the size of the reverse osmosis membrane, it can easily hold solid particles with a size larger than 1 Angstrom. This means that the membrane can absorb suspended solids, protozoa, bacteria, viruses and other substances that are harmful and detrimental to the human body in drinking water (Voutchkov 2012). Hence, each range of membrane layers prevents a specific kind of particles. Figure 10 illustrates a functional range of reverse osmosis membranes.
Fig. 9 Schematics of osmosis and reverse osmosis process (Widiasa et al. 2009)

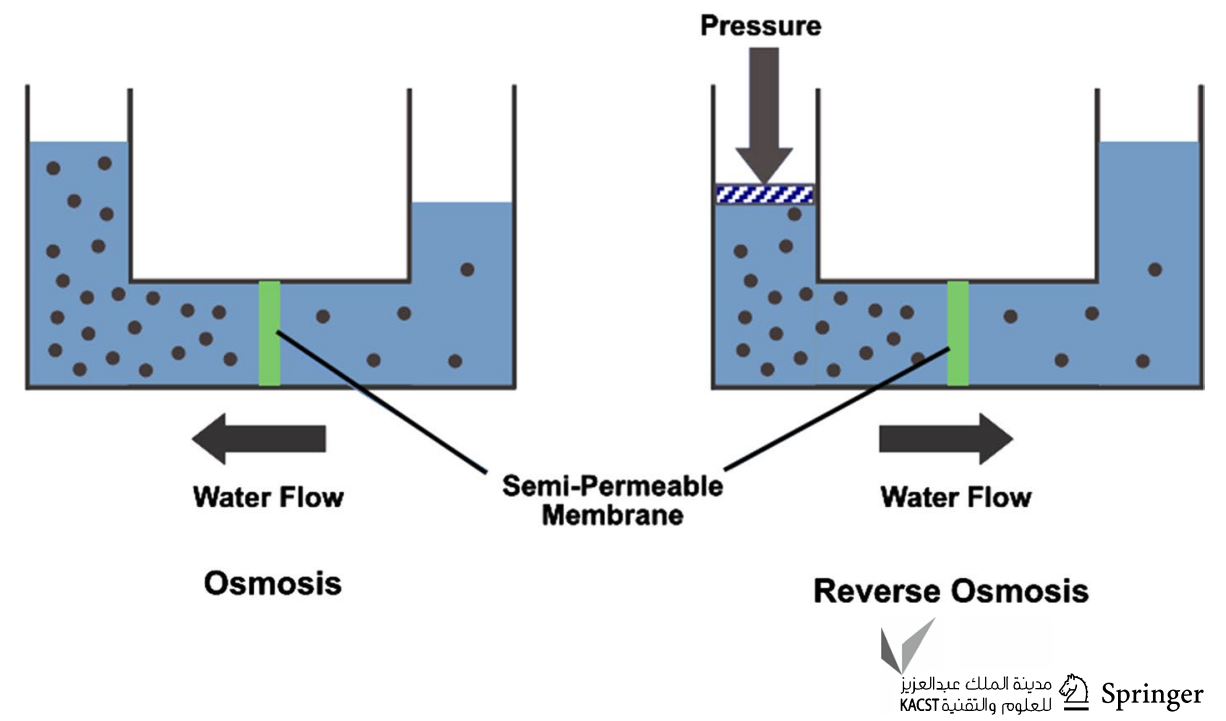


Fig. 10 Ranges of isolated materials by reverse osmosis membrane (Voutchkov 2012)

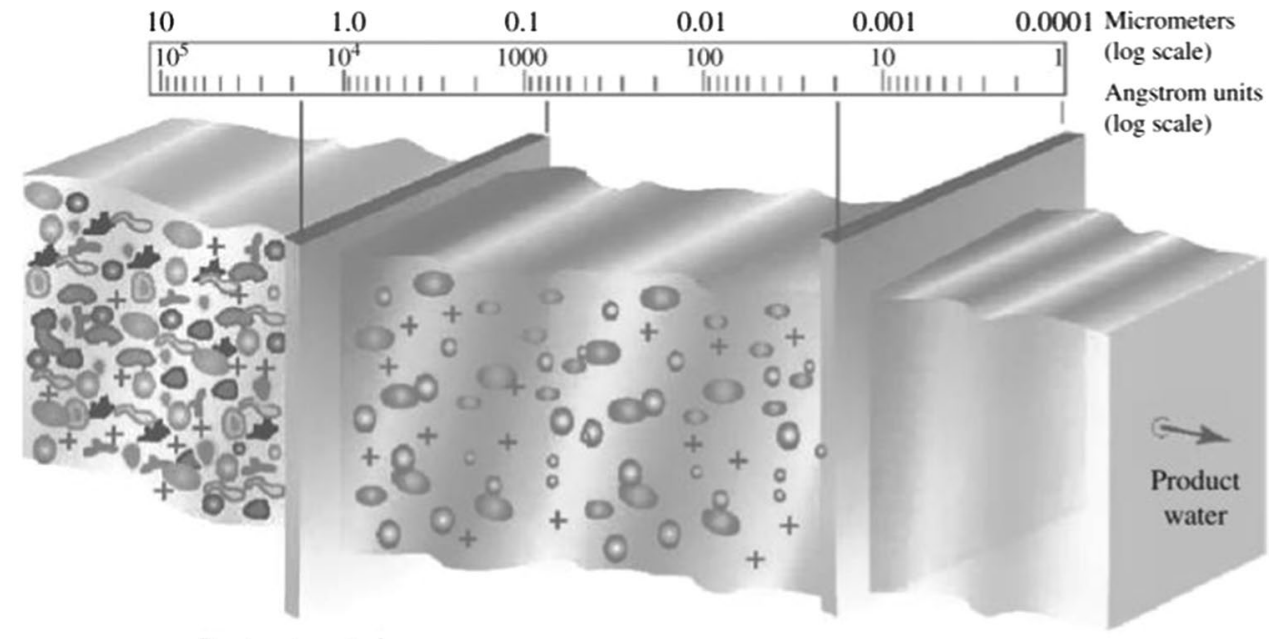

Pre-treatment via microfiltration or

Reverse osmosis pressure filtration

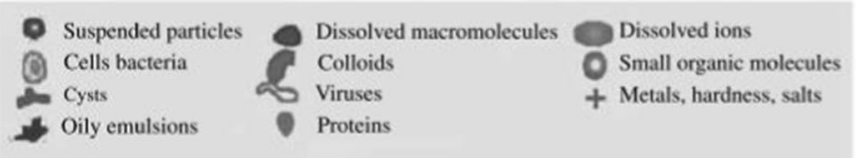

The microstructure of the membrane is a very important factor that depends on its manufacturing procedure. The most commonly used polymer in reverse osmosis is cellulose acetate (CA). Asymmetric cellulose acetate membranes were manufactured in the 1960 s that were less permeable than composite membranes. Therefore, higher pressure was needed to use this type of membrane. On the other hand, salt absorption and entrapment properties in the previous generation of membranes were lower than those of current membranes (Ali et al. 2018). Another commonly used material in this field is the thin-film composite (TFC). The film consisted of a super-thin layer of polyamide, often made of polymer or cross-linking. Composite membranes are a mixture of several layers of different materials. This type of membrane has a higher salt content and producing more water at a fixed surface. This type of membrane operates in a wide range of $\mathrm{pH}(2-11)$ up to $45^{\circ} \mathrm{C}$. Different types of membranes are used as flats and tubes for water desalination operations where the choice of membrane shape is dependent on economic issues and operating conditions (Ali et al. 2016).

The required pressure in the reverse osmosis system must overcome the total osmotic pressures of salts, minerals and the resistances created by the material in the membrane and other resistances in the device (joints, pipes, valves, etc.). These membranes typically operate at a feed pressure of 800-1000 psi. Membranes are capable of separating impurities and contaminants up to $0.1 \mathrm{~nm}\left(1 \times 10^{-9} \mathrm{~m}\right)$. In reverse osmosis, all molecules with molecular weights above $150 \mathrm{Da}$ (1 $\left.\mathrm{Da}=1.660 \times 10^{-27} \mathrm{~kg}\right)$ and more than $99 \%$ of molecules with molecular weights of 25-150 Da are normally separated (Micale et al. 2009). The amount of obtained water by reverse osmosis is about $35-60 \%$ of the volume of water entering the machine, and industrial machines can separate 99.5-99.8\% of the TDS. However, very small compounds such as boron may not be separated from freshwater. The important point is the optimal and effective control of the solubility and polarity of the membrane. In reverse osmosis, several desalting steps are generally used. Typically a singlestep reverse osmosis machine has a recovery rate of $10-15 \%$ (Micale et al. 2009). It is essential to note the feedwater temperature in typical reverse osmosis component effects on the system performance. The recommended range for this temperature is $15-40{ }^{\circ} \mathrm{C}$ to enhance the energy savings in this unit (Koutsou et al. 2020).

Multi-stage flash (MSF) desalination is used to increase the quality of the final freshwater, which is the easiest way to place the modules in series. New membranes with more boron removal potential have eliminated the need for multistage reverse osmosis. The most important problem with this type of arrangement is the discussion of membrane deposition and the increase in pressure drop in the series circuit. At large desalination sites, several parallel branches of the desalination plant are coupled together to increase the freshwater discharge. The structure of the reverse osmosis membrane is such that it cannot collect and remove the residual material on its surface and accumulates solids over it and then precipitates rapidly on the surface. This problem destroys the membrane's steady-state conditions, so suspended solids in the feedwater must be removed from the 
saline stream before reaching the membrane. The reverse osmosis membrane is sensitive to changes in $\mathrm{pH}$, oxidizers, a wide range of organic matter, algae and bacteria, as well as other particles and sediments. Therefore, there are several precautions to prevent extra charges in system performance. Especially from the final amount the purified water, $60 \%$ of it, will be released into the saltwater environment. One of the biggest challenges of reverse osmosis is the sediment formation on the membrane. The use of acids and antifouling agents can be added to the inlet water to reduce the alkali content and reduce the phenomenon of sediment formation. In general, reverse osmosis requires prepreparation, providing the appropriate chemical conditions for the project to succeed.

\section{Prepreparation processes in reverse osmosis}

In the reverse osmosis process, pretreatment of water is crucial to extend the life and efficiency of the membrane. These processes prevent the formation of all kinds of sediments. There are several chemical and physical processes for preparing water before entering the reverse osmosis system. These processes are as follows:

1. Coarse-grained sieve

2. Increasing the acid content to adjust $\mathrm{pH}$

3. Separating chlorine and adding antifouling materials

4. Multi-stage filtration

On the other hand, membrane cleaning is an important factor in increasing its efficiency and service life. As a general rule, membrane cleaning should be performed once changes in operating parameters are 10-15\%. For example, the decrease in produced freshwater, the increase in path pressure drop and the quality of produced water in the device are among the operational parameters under control. Membrane cleaning is done in 4 ways:

1. Mechanical

2. Hydrodynamic

3. By water or air

4. Chemical

In the mechanical method, a large shear force is applied to the surface of the membrane (e.g., by increasing the velocity of the passing fluid or the reverse flow of the current) due to the mixing of wind and air by turbulent flows that cleanse the membrane. Chemical methods are used to remove sediments and algae. These chemicals can be acidic or alkali that each one has its applications (Madaeni and Samieirad 2010; Ang et al. 2006).

It should be pointed out that post-treatment processes should also be performed on water, including the addition of calcium and sodium to the water to stabilize its $\mathrm{pH}$ and the removal of insoluble gases such as $\mathrm{CO}_{2}$ (Reif and Alhalabi 2015).

\section{Energy recovery in the reverse osmosis process}

Electricity has the highest share of reverse osmosis desalination costs. The outflow water from the reverse osmosis process has a large amount of energy applied to the desalination unit by high-pressure pumps to the feedwater in the process. The optimization of energy consumption in the RO unit for achieving latent energy in water flow is great progress in this field. There are several technologies to recover this energy, and some of them are as follows (El-Ghonemy 2012):

1. Energy recovery turbines (ERT): Mostly based on the Pelton wheel.

2. Pressure exchanger (PX): An isobaric device used to rotate a ceramic rotor and allow the direct impact of the feed and brine flows.

3. Dual Work Exchanger Energy (DWEER): It is an isobaric device and uses a piston and valve to separate feedwater and saline.

4. Turbo charger: A turbine to drive the centrifugal pump.

Table 3 shows the increase in efficiency by applying different methods of energy recovery to the reverse osmosis system.

Regarding the energy consumption in the RO unit is unequivocally subjected to various site construction factors, for example, the quality of water resources; associated cost with materials and chemical matters; associated power costs; membrane costs, etc. In this way, all-inclusive parameters in this field have direct impacts on the energy optimization procedure (Proskynitopoulou and Katsoyiannis 2018). Therefore, for reducing the energy use in RO, several suggestions have been presented. High productivity/low energy membrane elements, hybrid membrane configuration, low-recovery plant design, split-partial twopass RO system design, three-center RO system design, large-size high-efficiency pumps and energy recovery by pressure exchangers are practical strategies to reach the

Table 3 The amount of energy recovery in reverse osmosis by different processes (El-Ghonemy 2012)

\begin{tabular}{ll}
\hline Energy recovery system & Efficiency (\%) \\
\hline Francis turbine & 76 \\
Pelton turbine & 87 \\
Turbo turbine & 85 \\
Work exchanger & 96 \\
Pressure exchanger & 96 \\
\hline
\end{tabular}




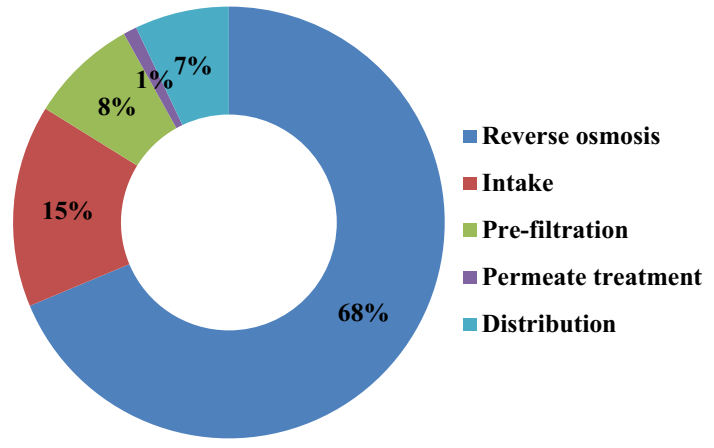

Fig. 11 The power consumption across applications or across different stages of SWRO

minimum energy use in these systems (Voutchkov 2018). By studying the power consumption in various sections of the RO unit, it has been determined that which stage has the most power consumption in comparison with other phases. Figure 11 shows the power breakdown for different stages of seawater RO (SWRO). As it is obvious, the RO process has the most share in power consumption accounting for 68\% (Kadaj and Bosleman 2018).

Finally, it can be concluded that this method, in addition to the ability to refining a wide range of pollutants, consumes less energy and does not have thermal effects on the water or the environment. With the advances in membrane manufacturing and energy recovery methods, the overall process efficiency in this method has increased, so the desalination costs have decreased with this method. In Fig. 12, the largest reverse osmosis complex in the world with a capacity of $624000 \mathrm{~m}^{3} / \mathrm{d}$ has been indicated. This plant has been operating in Israel since October 2013. The unique feature of this unit is the use of 16-inch membranes in vertical pressure vessels (Bennett 2014).

\section{Nanofiltration}

Nanofiltration method is commonly used to soften water and eliminate by-products created during water decontamination. Nanofiltration is not generally used for seawater desalination. However, two-step models of this technology have been successful for this purpose. Nanofiltration uses a semipermeable membrane, and its thrust force is hydraulic pressure. Nanofiltration membranes have removed high percentages (90-98\%) of diatomic ions such as calcium and magnesium, non-soluble organic matter and some substances that are effective in odor and water hardness formation. But monatomic ions are not inhibited so well. Due to the high concentration of monatomic ions, the osmotic pressure is lower than the reverse osmosis pressure that reaches to a certain range (500-700 psi). Based on this advantage, the Long Beach Water Department (California, USA) has developed a twostage nanofiltration project for seawater desalination (Micale et al. 2009; Yuan et al. 2017). Also, this method is different from RO in terms of the separation mechanism. The crosssectional area of the membrane in this method is between 2 and 70 angstroms. The membrane charge can be positive or negative which is effective in the membrane separation property due to the effects among the charged ions.

An innovative hybrid FO-NF system designed for brackish water desalination has been investigated systematically. The introduced system has a wide range of benefits, e.g., lower hydraulic pressure, less flux decline caused by membrane fouling and more flux recovery after the cleaning process (Zhao et al. 2012). The obtained result from another study indicated that using ultrahigh permeance and high
Fig. 12 The largest reverse osmosis site in the world with $624000 \mathrm{~m}^{3} /$ day capacity (Bennett 2014)

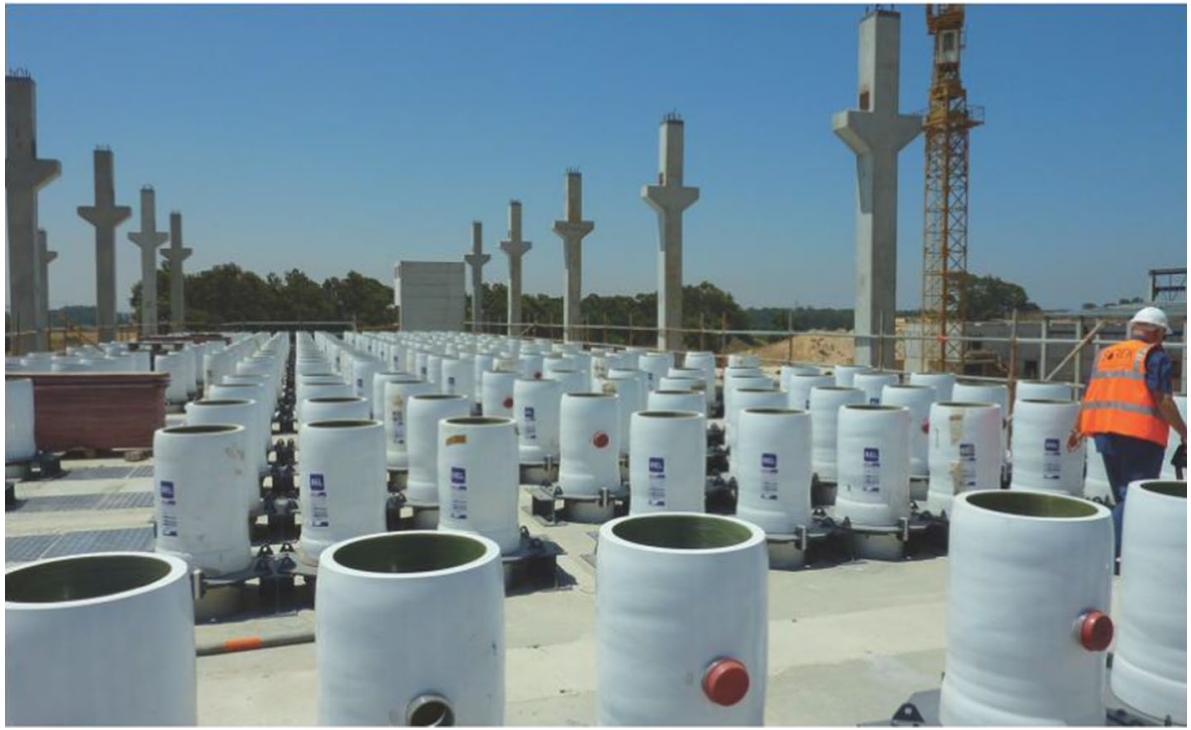


rejection features is highly beneficial for efficient desalination and wastewater treatment in NF membranes (Wang et al. 2018). In Pérez-González et al. 2015, the separation process of polyvalent and monovalent anions, like sulfate and chloride, has been reported. The experimental performance and modeling of this process in NF are investigated.

\section{Electrodialysis/reverse electrodialysis}

The commercial use of the electrodialysis method began in 1952 for the desalination of brackish water in the Arabian Desert and 10 years earlier than the reverse osmosis method. The electrodialysis and reverse electrodialysis methods use ion-selective membranes to separate charged particles from water. In this method, the separation of minerals from freshwater occurs by the direct application of electricity in the feedwater. Electrodialysis consists of a stack of anion and cation membranes (between 300 and 600) separated by a number of spacers that prevent them from sticking to them, and saline water passes through them. An anode and a cathode are located at the two ends of the stack, when the electrodes in the salt solution are connected to an external direct current source such as a battery the electric charge passes through the solution and directs the ions to the opposite charge electrode (positive ions to the cathode and negative ions to anodes) (Tado et al. 2016). The anions can easily pass through the nearest anionic membrane, but in their path to the anode they collide with the adjacent cationic membrane, so the cation moves in the opposite direction and passes through the nearest cationic membrane; however, it gets stuck in the next layer behind the anion membrane (Fig. 13).

With this arrangement, diluted and concentrated salt solutions placed in the space between the membranes. This method can be used solely for brackish water with

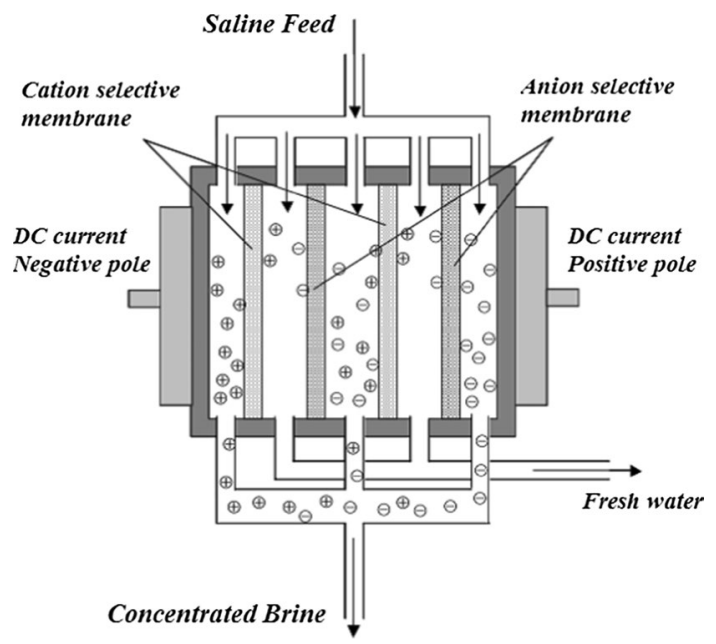

Fig. 13 Schematic of the electrodialysis process for producing freshwater and concentrated brine (Miller 2003) an insoluble solid particle content of $1000 \mathrm{ppm}$. It should be noted that in order to increase the efficiency of electrodialysis and to increase the salt uptake, more groups of membranes must be clustered together; thus, in this case achieving 95\% recovered freshwater becomes available (Miller 2003). When different ions are accumulated on the surface of the electrode, the sediment forms over time and must be cleaned to maintain stable conditions. One way to overcome this problem is to oscillate the electrode poles (about 2-4 times per hour). The ED process, which involves the periodic shift of the electrode polarity, is called electrodialysis reversed (EDR). Today, all commercial electrodialysis machines are from EDR type. By preventing the accumulation of ions on the surface of the membranes in the reverse electrodialysis method, these types of devices can dehydrate at higher capacities (Voutchkov 2012).

The energy required for this method is directly proportional to the amount of water salinity. Generally, this method can remove the appropriate form of high-charge particles such as monatomic and polyatomic salts, silicates, nitrates and radium, but these devices can be used to absorb low-charge particles such as organic matter and organisms such as bacteria. The following table presents a comparison of particle outflow efficiencies in the recovering process by ED and RO methods. The important issue to notice from this table is that ED extracts fewer amounts of useful minerals for humans and this makes the desalination process more attractive than reverse osmosis or thermal distillation (Table 4).

Hydrolysis and sediment formation are two major problems for this method. Consequently, the membrane used in this method is subjected to clogging deposition, so some precaution actions must be applied to the inlet water. The rate of recovery with this method is over $90 \%$ and is very economical to set up and use for balanced TDS. However, ED and EDR membranes are highly resistant to acidic and alkali environments. This process is more resistant to chloride and sediments (compared with RO) and is significantly thinner than RO membranes (Micale et al. 2009).

Table 4 Comparison of particle separation from water by reverse osmosis and electrodialysis/reverse electrodialysis methods (Cotruvo et al. 2010)

\begin{tabular}{lll}
\hline Substances in water & Reverse osmosis \% & $\begin{array}{l}\text { Electrodialysis/ } \\
\text { reverse electrodi- } \\
\text { alysis \% }\end{array}$ \\
\hline TDS & $90-99.5$ & $50-90$ \\
$\begin{array}{l}\text { Harmful substances for } \\
\text { human health }\end{array}$ & $99.99<$ & $<5$ \\
Nitrate & $94-90$ & $60-69$ \\
\hline
\end{tabular}




\section{Thermal desalination}

All methods of thermal treatment are based on distillation, in which the water vapor entered into the system and, after condensation, is converted to less saline water. The thermal method is very suitable for the desalination of water with high salinity. This is one of the most important reasons that Middle East countries such as Saudi Arabia, Oman, Qatar, United Arab Emirates, Bahrain and Kuwait are profoundly using this method because the water resources in these areas are among the saltiest types on the planet (Red Sea, Persian Gulf and the Indian Ocean). At the moment, about $75 \%$ of thermal desalination sites are installed in Arab countries, and half of them are active in Saudi Arabia.

Thermal methods are multi-stage flash (MSF), multieffect distillation (MED) and vapor compression distillation (VC). In the MSF and MED, usually, direct heat exchangers are used to providing the needed thermal energy for water evaporation, while the VC method uses heat from the steam condensation as a heat source. Thermal desalting methods can produce freshwater with very low concentrations of salts $(10 \mathrm{mg} / \mathrm{L}$ or less) from saline water with high TDS of $60,000-70,000 \mathrm{mg} / \mathrm{L}$. The produced freshwater also contains very low levels of harmful substances to health (pathogens) and other pollutants such as boron, bromide and organic matters (Cotruvo et al. 2010). Each of these methods has a history that is between 40 and 60 years, and during these years, their productivity and production capacity have been increased continuously. According to the water properties, the performances of these methods would have differed. The oldest method is multi-stage flash, and this process requires a great deal of steam at high temperatures. MED and VC are newer methods, and their efficiencies have been improved by lowering the boiling temperature at lower pressures. In the MED method, the feedwater evaporates at a lower temperature and pressure in comparison with the MSF. In the VC method, the pressure is lower than the other ones, and this allows these systems to process evaporation by internally produced steam rather than requiring an external source. The ratio of the amount of freshwater produced to the mass of required steam for desalination is called the gained output ratio (GOR). Depending on the used technology in the thermal desalting method, the environmental conditions of the desalination site and the quality of supplying feedwater, the value of productivity varies from $4 \%$ to $40 \%$. The higher GOR would represent higher efficiency (Voutchkov 2012). The thermal method is based on the evaporation of saline water by the application of heat and condensation of steam for the preparation of freshwater. In this method, the system pressure is usually lowered to reduce the boiling temperature of the water. Industrial systems based on this method have several reservoirs with different boiling points designed to reduce the temperature and pressure in succession. One of the limitations of this method is the energy supply for evaporation. The high percentage of salt increases the boiling point temperature, and the energy required to evaporate seawater is in the range of $50-100 \mathrm{~kW}$ per 1000 gallons of freshwater. It should be noted that this heat energy is in addition to the needed electrical energy. Sometimes large desalination sites are combined with steam or gas power plants and use lowlevel energy to use as their inputs (Micale et al. 2009).

Thermal desalination methods are highly dependent on local conditions in terms of investment costs and current costs due to the high energy requirement of these methods. It is practical to combine these types of sites for generating electricity and water, simultaneously (Bennett 2015). This type of recovering is more widely used in the Middle East, where the costs of fossil fuels are low (as well as the costs of owning land and installing extensive equipment). Also in these regions, there are not any strict environmental constraints. The tendency to use solar energy as a source of heat has been considered in these approaches. Thermal desalination units have desirable performances to operate about 10-15 years (Chandrashekara and Yadav 2017). The main technical issues in these methods are sediment and corrosion. Due to the severe corrosion properties of seawater, special alloys such as copper nickel, aluminum and titanium alloys are the most used materials for this type of process, but it should be noted that the use of these alloys greatly increases investment costs. Especially for desalination at high capacities, larger cross sections will be required. Lowgrade soluble salts at high temperatures precipitate inside pipes and other equipments, which is a major problem that reduces heat transfer capacity and increases the final cost of energy. Another important point about this method is when the produced concentrated water by desalination discharged into the environment has a higher temperature than the initial seawater conditions. While the final costs of desalination by the thermal methods are higher than reverse osmosis, it requires much less preparation and preprocessing, and the obtained water has a higher quality and does not require post-treatment processes such as boron, chloride or bromide removal.

\section{Multi-stage flash}

The MSF was invented in the early 1950s. Nowadays, more than $80 \%$ of the produced freshwater by the thermal method is produced at MSF sites. In this method, the water is heated in several stages, and at each stage, the pressure and temperature decrease compared to the previous stage. Typically, MSF includes 15-28 levels or stages. The latest MSF 
technology has reached 45 stages that can compete with RO in terms of capacity and energy consumption. Inlet brine is heated to $90-115{ }^{\circ} \mathrm{C}$ in the heater tank, and the water vapor is produced. The pressure level in the first stage is slightly lower than the saturation pressure of water vapor (Voutchkov 2012). When a stream of saturated water passes by means of a pressure convertor, the pressure suddenly decreases, forming the so-called sudden evaporation (flashing) phenomenon. As the water enters each step, some of the water suddenly evaporates and enters the vapor phase as it passes through the pressure-reducing nozzle. The vapors formed on the condenser tubes are distilled and then collected in special trays. As the steam phase changes to the liquid, some latent heat is released, which is used to preheat the saline water before entering the first stage. The MSF method is performed at each step by lowering the pressure and producing some amount of steam that will be distilled at the same stage. Conveniently, the amount of seawater recovered by this method is about 10-30\% (Kim et al. 2016) (Fig. 14). The produced brine at each stage is pooled together, and at a later stage, a share of it is added to the desalination cycle to reduce the total volume of feedwater. The amount of salt in produced freshwater is less than $10 \mathrm{ppm}$ (Micale et al. 2009). The typical GOR for the MSF process is 8, but in the newer systems, it is as high as 9. The MSF method is most appropriate when the feedwater conditions (temperature, salinity, insoluble matters and high percentages of contaminations) are unfavorable. The typical energy consumption of MSF units is $250-330 \mathrm{~kJ} / \mathrm{kg}$ of freshwater, and the amount of electricity required for processing is in the range of $3-5 \mathrm{kWh} / \mathrm{m}^{3}$.

Large MSF units are often combined with gas or steam power plants. The generated steam at high temperature and high pressure is first expanded in the turbine of the power plant to generate electricity, and then, the intermediate to low-pressure steam leaves the turbine to be used in the thermal desalination unit. MSF units are usually located at the bottom of steam power plants with a temperature range of $90-120^{\circ} \mathrm{C}$ to be used to heat the saline water in the unit. In this combined system by using heat loss as an energy resource in the desalination process, the requirement for condensers in these power plants is eliminated due to the use of turbine exhaust steam for desalination (El-Ghonemy 2012).

MSF is widely used to desalinate water in the Middle East region (especially Saudi Arabia, the United Arab Emirates and Kuwait) that contributed to $40 \%$ of the worldwide desalination capacity. In the Persian Gulf, large MSF sites operate alongside gas or steam turbines to take advantage of their low-temperature energy. New schemes on this device have reduced the need for acid cleaning and shut down during the maintenance process. At the moment, MSF sites can operate for about 2-5 years without any major overhaul. Ventilation is a very important process in MSF systems that drive insoluble gases into the feed stream (such as oxygen, nitrogen and carbon dioxide). Besides, oxygen and carbon dioxide can cause corrosion in various parts of the system.

Ras Al Khair is the world's largest desalination plant with approximately $10^{6} \mathrm{~m}^{3} / \mathrm{d}$ capacity, which in this site RO and MSF contributed 30\% and 70 of desalination capacity, respectively. The complex also generates $2400 \mathrm{MW}$ electricity which supplies freshwater for large metropolitan areas. Generally, the use of the MSF method for desalination due to low efficiency, high costs and high environmental impacts in the future, can be ignored compared to MED and RO (Bennett 2014; Ghaffour et al. 2014).

\section{Multi-effect distillation}

The multi-effect distillation process has been used in various industries such as sugar, paper production, dairy industry, desalination. Small MED sites with a total

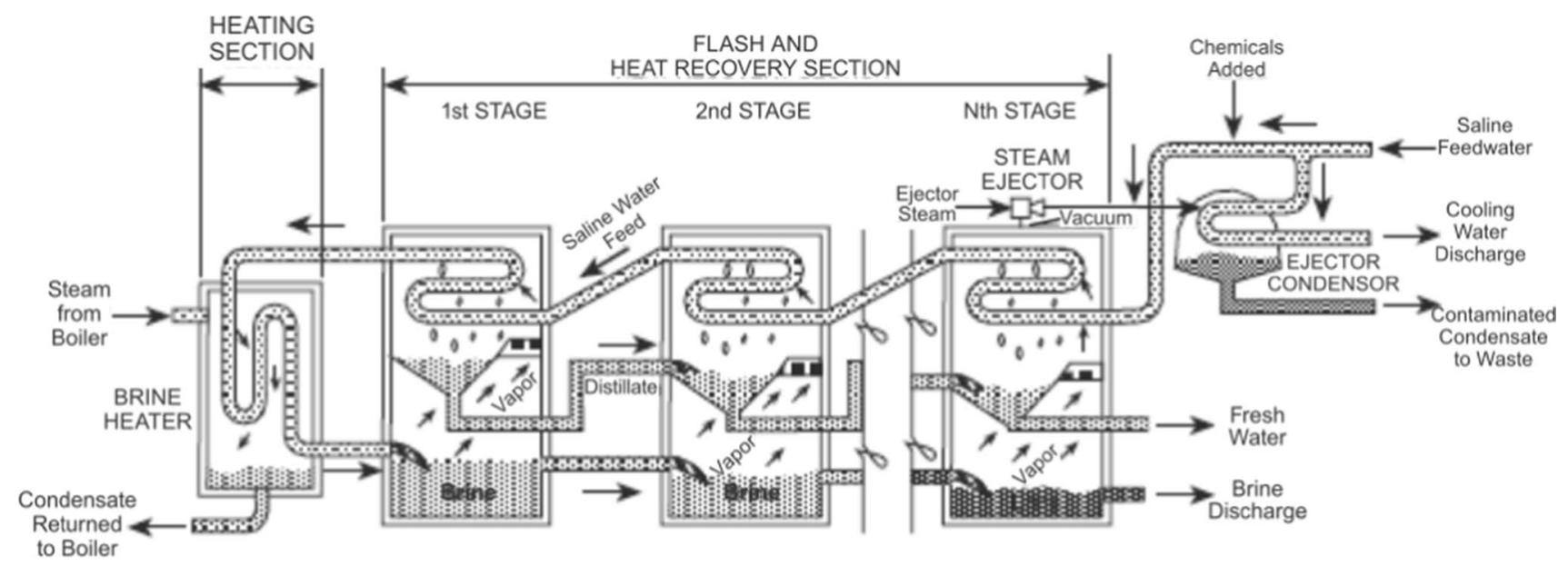

Fig. 14 The multi-stage flash (MSF) process for producing freshwater (El-Ghonemy 2012) 
capacity of less than 500 cubic meters per day were built in the 1960s. Subsequent improvements over the years have expanded the recovering capacity of this method. In 2006, the capacity of MED sites increased to $36,000 \mathrm{~m}^{3} / \mathrm{d}$ (Micale et al. 2009; Al-Othman et al. 2018). This method also uses several steps or levels where each step takes place in a separate tank and the pressure in each step is gradually reduced. For multi-stage distillation, 8-16 steps are typically used to minimize energy consumption. The water on the evaporator pipe surfaces is spread out as a thin film, which causes the water to evaporate rapidly. The produced steam is distilled on a cool external surface. Here, the latent heat from the distillation water is used to heat the saline water at lower temperatures and pressures, which means that after initial heat in the first stage, there is no need to heat the water in other stages. In summary, the latent heat from the condensation at each stage is used to evaporate the water at a later stage. This reduces the total energy consumption for water desalination. Therefore, the energy costs in the MED method are lower than the MSF technique (Ortega-Delgado et al. 2017). The pressure reduction process at each step allows for lowering the evaporation temperature of the feedwater without any need for external heat supply. Only the first-stage steam must be produced from an external source. The most important difference between the MED and MSF methods is that in the MED method steam is generated by spraying water on a tube heat exchanger and absorbing heat from the steam that passes through the generator (Fig. 15).

The produced steam in the final stage is very low in terms of temperature and pressure, so it is distilled in the external condenser and rejects the latent heat to its environment. The energy required for the multi-effect distillation method is as follows:
1. Formation of steam with proper pressure to initiate the process in the first stage

2. Vacuum pump to reduce pressure in later stages

3. Pumping the salt solution at each stage

4. Cooling the steam to turn it to water in the last step

The usual amount of freshwater in this method is about $20-35 \%$ of the water that entered into the system (Voutchkov 2012; Micale et al. 2009). Newly designed sites are looking for ways to avoid the effects of sediment. In some MED plants, the maximum boiling temperature is $55^{\circ} \mathrm{C}$, which reduces the effects of sediment and corrosion on the system and using recovered heat from other adjacent processes is available. The input energy to the system can be supplied from various sources such as mechanical vapor compression (MVC) and thermal vapor compression (TVC). The combination of MED and TVC systems has very high thermal efficiency and reaches about $17 \%$, while a combination of MED and heat pump (with water lithium bromide absorber) reaches $21 \%$. By comparing the MSF and MED methods, it is evident that the MED method has higher efficiency and has lower thermal and electrical energy consumption and, on the other hand, the MED operating temperature is lower, thus requires steam at lower temperatures and pressures (Miller 2003). Another advantage of the low-temperature MED process is the manufacture of relatively inexpensive materials, including aluminum alloys for epoxy laminated carbon steel pipes for evaporator shells.

The largest MED-RO hybrid complex is built in the UAE's Fujairah project (second phase), capable of producing $2000 \mathrm{MW}$ of electricity and $591,000 \mathrm{~m}^{3} / \mathrm{d}$ of freshwater. The first phase of the Fujairah project, which, launched in 2004, is a combination of MSF and RO methods and has a desalination capacity equal to $455,000 \mathrm{~m}^{3} / \mathrm{d}$ (Bennett 2014) (Fig. 16).

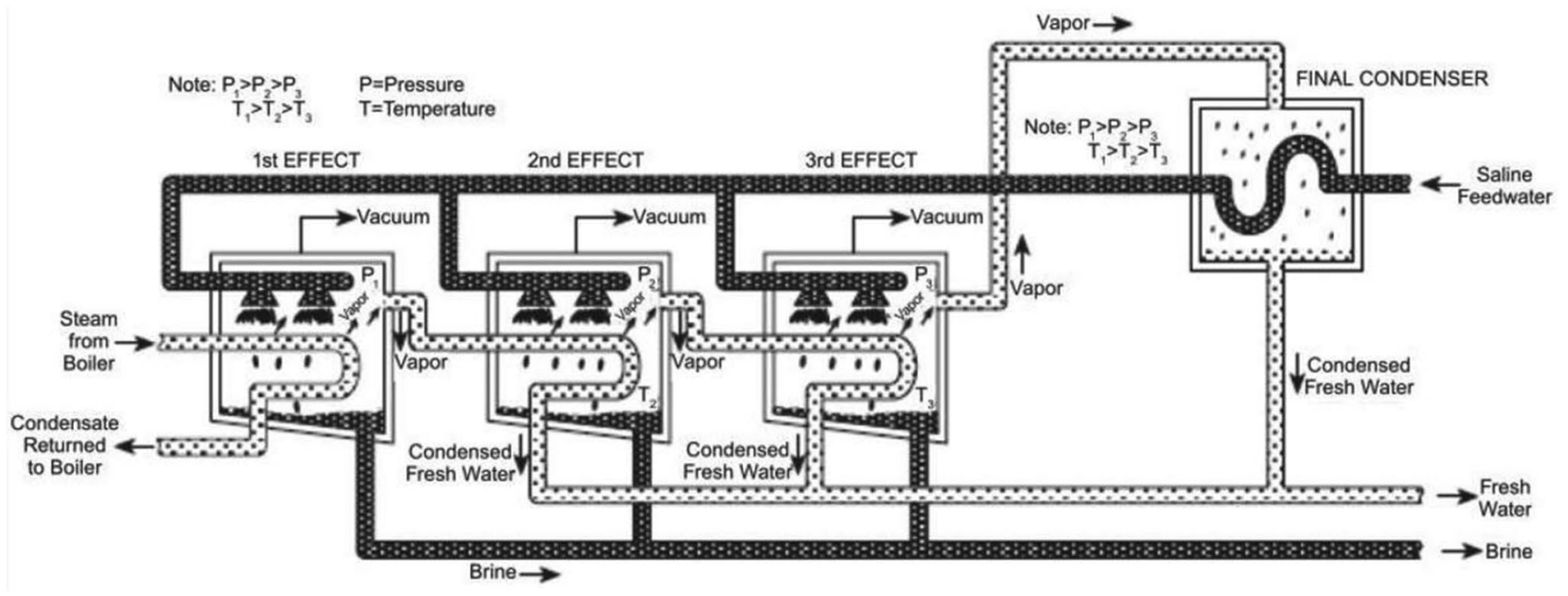

Fig. 15 The multi-effect distillation process for recovering saline feedwater (El-Ghonemy 2012)

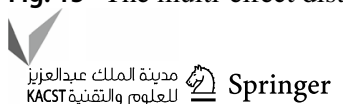


Fig. 16 Fujairah MSF-RO hybrid site in UAE (Bennett 2015)

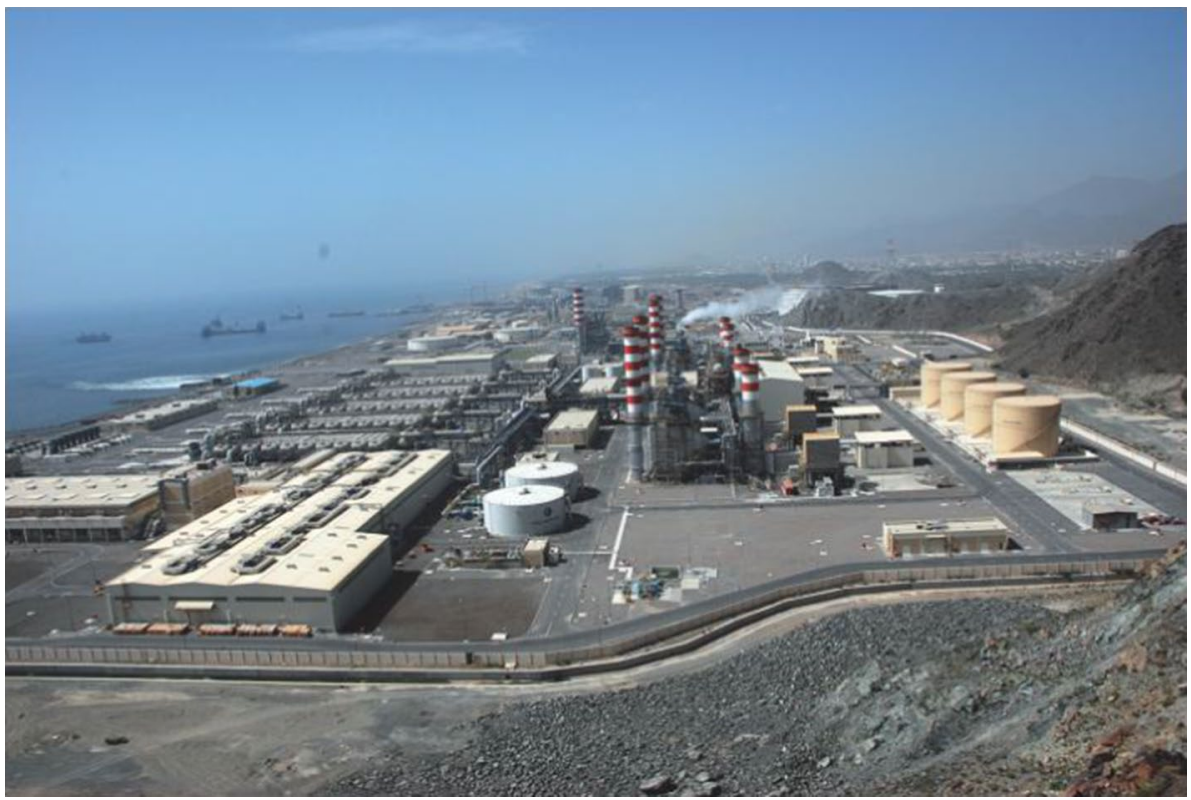

In Saudi Arabia, the Shoaib desalination plant will become the world's largest MED unit. Considered capacity for this plant is $912,000 \mathrm{~m}^{3} / \mathrm{d}$ that enjoys high efficiency equal to $160 \mathrm{~kJ} / \mathrm{kg}$ (Bennett 2015).

\section{Vapor compression}

In the vapor compression method, the water vapor is fed to the evaporator and the steam goes to the compressor. The steam is compressed at this point, and its temperature rises to evaporate the sprayed feedwater on the heat exchangers. Preheating the feedwater is used to start the process and reach the evaporation temperature (Fig. 17). The required heat to evaporate water in this method is provided by two methods:

1-Mechanical vapor condensation (MVC) using electrical energy

2-Thermal vapor compression (TVC) using high-pressure steam

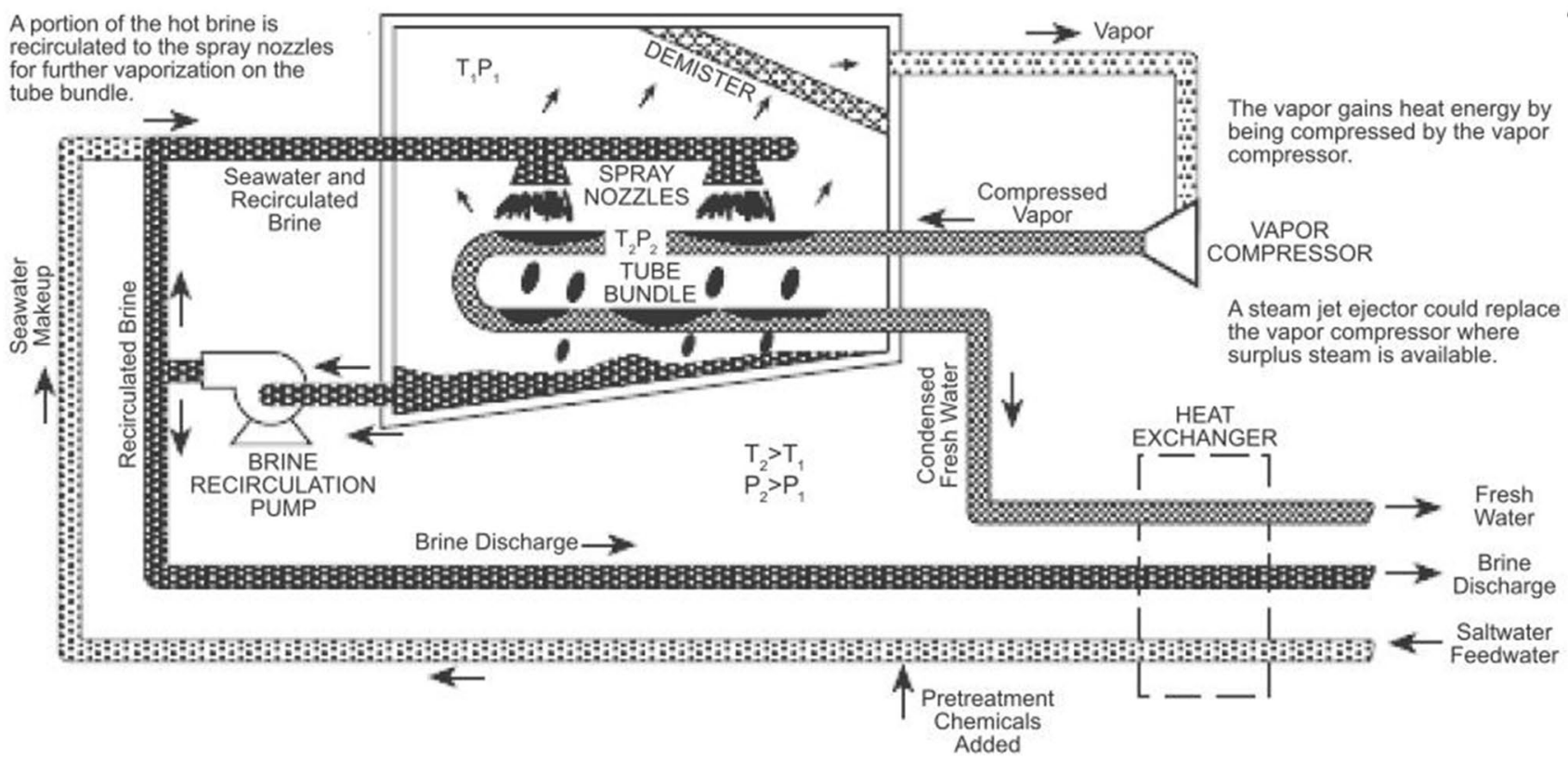

Fig. 17 The vapor compression method (Voutchkov 2012) 


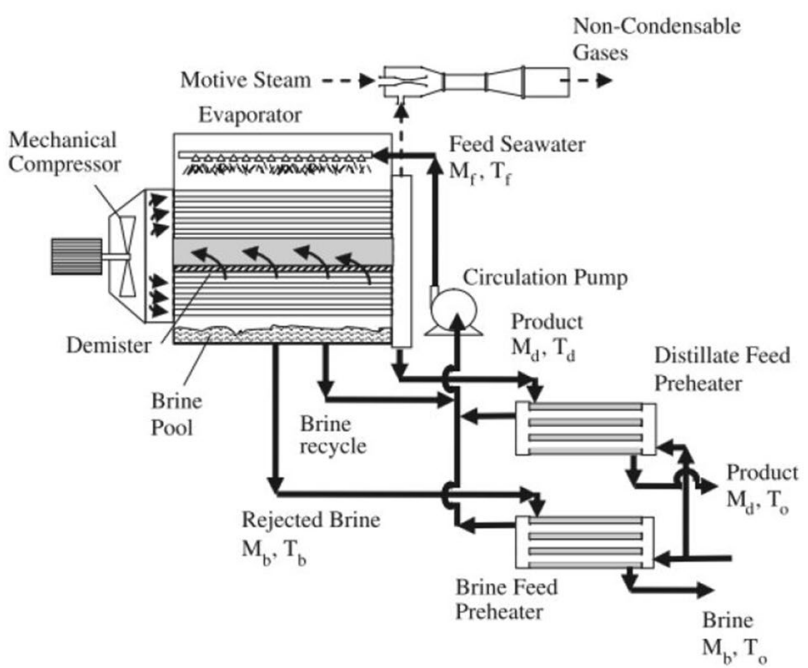

Fig. 18 Single-stage mechanical vapor compression (MVC) process (El-Ghonemy 2012)

The VC desalination method is used in a wide range of applications. The total required energy to provide mechanical compression is between 8 and $12 \mathrm{kWh} / \mathrm{m}^{3}$ of freshwater. This method can typically recover about $40-50 \%$ of the incoming water (Voutchkov 2012). The MVC process was introduced in the 1980s. The original idea behind this method was to use electrical energy for the thermal distillation process. The MVC process is in competition with new RO technologies. However, the passage of time has shown the complete dominance of the reverse osmosis system, and on the other hand, the reliability of this method in contradiction with other heat distillation methods such as MSF and MED has been slightly improved.

As shown in Fig. 18, the system has a horizontal evaporator tube, water spray nozzle, steam compressor, pump and preheating unit. Hot steam or condensate vapor flows through the pipes and the brine is sprayed onto the surface of the pipe. The maximum temperature for condensed vapor is about $70{ }^{\circ} \mathrm{C}$ to reduce the amount of formed sediment on the surface of the pipes. The incoming saline water is preheated in two heat exchangers located in conjunction with the outlet saline. The following is a combination of steam compression with a multi-effect distillation method to increase its efficiency. This process is based on the reuse of produced steam in the distiller as a steam heater after compression. The generated steam at each stage is compressed to an extent in the compressor and used for heating the first unit. Mechanical vapor compression (MVC) and thermal vapor compression (TVC) are used for condensing the steam.

In the TVC method, the required steam is supplied by lateral processes such as power cycles or industrial processes. Two small-scale factors, as well as the use of electrical energy, are raising concerns about combining this system with renewable energy resources. Typically, MVC requires about $10-14 \mathrm{kWh} / \mathrm{m}^{3}$ of electrical energy. Therefore, with the aid of 2-3 MW power, the production of 5000 cubic meters is accessible. This process can be achievable by renewable energy.

The mechanical vapor compression (MVC) method is used for small to medium desalination units. The conventional capacity of MVC units is $3000 \mathrm{~m}^{3} / \mathrm{d}$, while the capacity of TVC units can reach. The increase in temperature and pressure values by mechanical methods is limited, and therefore, the capacity created by this method is restricted (El-Ghonemy 2012).

\section{Overall comparison}

The share of reverse osmosis systems has grown tremendously over the last 10 years, due to the dramatic advances in membrane technology and the possibility of using recovered energy. In these systems, the cost of freshwater production is reduced. Table 5 demonstrates the functional range of each method in terms of the amount of water-insoluble particles.

The cost of desalinated water is subjected to various factors, including capacity and type of desalination process; location and type of inlet water (seawater or brackish water); type of energy consumed and manpower cost. Recent improvements in materials used in membrane fabrication as well as the use of energy recovery technology have significantly reduced the energy consumption by RO desalination. It should be noted that the membrane desalting costs vary according to the type and composition of the inlet water. Economic studies of seawater desalination in recent years show that costs related to desalination are decreasing. A review of these studies shows that the use of membrane methods is an optimal approach for this purpose even at high capacities, and this is due to the decrease in membrane energy consumption because of recent developments in membrane production and technology (Baxter et al. 2008; Karagiannis and Soldatos 2008).

In Europe, Australia and the USA, RO is the most widely used desalination method, but it still consumes a great deal of energy (3-4 $\mathrm{kWh} / \mathrm{m}^{3}$ ) compared to groundwater and wastewater treatment $\left(0.5 \mathrm{kWh} / \mathrm{m}^{3}\right)$ (Reddy and Ghaffour 2007). Sydney's RO unit emits about 954 tons of $\mathrm{CO}_{2}$ per

Table 5 The function of each desalination method based on the TDS of inlet water

\begin{tabular}{ll}
\hline Desalination method & TDS (mg/L) \\
\hline Thermal methods & $20,000-100,000$ \\
Reverse osmosis & $50-46,000$ \\
Electrodialysis & $200-3000$ \\
\hline
\end{tabular}


day with a production capacity of $250,000 \mathrm{~m}^{3} / \mathrm{d}$, and its energy consumption is about $3-4 \mathrm{kWh} / \mathrm{m}^{3}$ (Lattemann et al. 2010).

In Saudi Arabia, it is expected to reach 1.6 million cubic meters in the coming years. Most of the produced freshwater in this country is from thermal desalination methods, specifically MSF with a production capacity of 5.6 million cubic meters per day, but MED and RO methods which require less energy are becoming more popular, gradually (Ghaffour et al. 2014). Modern RO systems can meet the energy requirements for less than $2.5 \mathrm{kWh} / \mathrm{m}^{3}$, depending on the available types of equipment. However, the required energy in operational conditions can be higher. For example, the required energy for desalination of water with a salinity of $40,000 \mathrm{ppm}$ and a temperature of $20{ }^{\circ} \mathrm{C}$ with recovering efficiency at $41 \%$ is $3.8 \mathrm{kWh} / \mathrm{m}^{3}$. For water prepurification, the energy required is $0.2-0.8 \mathrm{kWh}$ (Ludwig 2010; Council 2008). The energy required for distillation is far greater than the RO process, but these methods are still the first option in Middle Eastern countries for political, economic, technical reasons.

\section{Economic aspects}

Economic and environment parameters are significant constraints in every system, which desalination units are not excluded from this issue. Generally, the costs involved in the desalination process can be divided into two categories:

\section{Investment costs}

2. Current costs

Numerous factors can affect the cost and choice of desalination methods. Various studies show that investment, operation and maintenance costs are directly dependent on on-site conditions (Shatat et al. 2013; Balfaqih et al. 2017; Darwish et al. 2016; Pinto and Marques 2017; Younos 2005). The construction cost and production capacity of the various types of desalination methods are shown in Table 6 (Mentis et al. 2016).

Table 6 Production capacity and construction cost of some desalination plants (Mentis et al. 2016)

\begin{tabular}{lcc}
\hline Desalination method & $\begin{array}{l}\text { Production capacity }\left(\mathrm{m}^{3} /\right. \\
\text { day) }\end{array}$ & $\begin{array}{l}\text { construction } \\
\text { cost }\left(€ / \mathrm{m}^{3} / \text { day }\right)\end{array}$ \\
\hline MSF & $1000-60,000$ & $1000-2000$ \\
MED & $500-20,000$ & $850-1750$ \\
RO & $0.4-70,000$ & $650-4400$ \\
ED & $15-50,000$ & $1000-5000$ \\
\hline
\end{tabular}

Current costs are highly dependent on project conditions. Using the SWRO method is very economical in terms of operating costs $\left(0.47 \mathrm{USD} / \mathrm{m}^{3}\right)$ followed by the MED $\left(0.54 \mathrm{USD} / \mathrm{m}^{3}\right)$. The cost of using the MSF method is $0.65 \mathrm{USD} / \mathrm{m}^{3}$ that puts it at the bottom of the selection queue, and this will make many obstacles to construct new units (El-Ghonemy 2012).

Studies have shown that the cost of desalination with fossil fuel energy is lower than renewable energy (RE). Generally, the cost of freshwater production has fallen in recent years due to the development of technology, but it must be acknowledged that using renewable energy rises the costs (Shatat et al. 2013). Table 7 illustrates that in the case of RE use, the investment cost is the highest, but the fuel cost is the lowest (Al-Hallaj et al. 2006).

The cost of membrane desalination water varies according to the method and conditions of the inlet water. In high-capacity desalination units, brine desalination costs $0.27 \mathrm{USD} / \mathrm{m}^{3}$. (The TDS is about $5000 \mathrm{ppm}$.) The cost of seawater desalination with RO is $0.56 \mathrm{USD} / \mathrm{m}^{3}$ (while the capacity is $94,600 \mathrm{~m}^{3} /$ day). Similarly, in thermal desalination processes, water production costs in high-capacity units such as $91,000-320,000 \mathrm{~m}^{3} /$ day are in the range of $0.52-1.01 \mathrm{USD} / \mathrm{m}^{3}$ (Shatat et al. 2013). By using renewable energy sources, costs increase up to $16 \mathrm{USD} / \mathrm{m}^{3}$. Of course, this increase in costs can be ignored by environmental benefits. Using the RO method is the most efficient and cost-effective method of using the sun for desalination, and its costs are approaching the use of fossil fuels. Therefore, the combined use of photovoltaic and RO could be the second priority for desalination of brackish water (Shatat et al. 2013). Figure 19 shows water product cost per production capacity for considered methods. However, the costs of producing freshwater with fossil fuels are only slightly reduced by capacity variations.

Related costs to water supply, including production, transmission and storage, vary from 0.65 to 3.1 USD per cubic meter in 2030 depending on renewable resources and water transmission distances. Until this year, the total global cost of investment is up to 10,770 billion USD (Caldera et al. 2016). Obtained results represent that using seawater as the water resource has a more associated cost for fuel in comparison with brackish water (Karagiannis and Soldatos 2008).

Table 7 Contribution of investment, operating and energy costs in different methods of desalination (Al-Hallaj et al. 2006)

\begin{tabular}{llll}
\hline $\begin{array}{l}\text { Desalination } \\
\text { method }\end{array}$ & $\begin{array}{l}\text { Investment cost } \\
(\%)\end{array}$ & $\begin{array}{l}\text { Operating cost } \\
(\%)\end{array}$ & Fuel cost (\%) \\
\hline RO & $22-27$ & $14-15$ & $59-63$ \\
MSF & $25-30$ & $38-40$ & $33-35$ \\
RE & $30-90$ & $10-30$ & $0-10$ \\
\hline
\end{tabular}




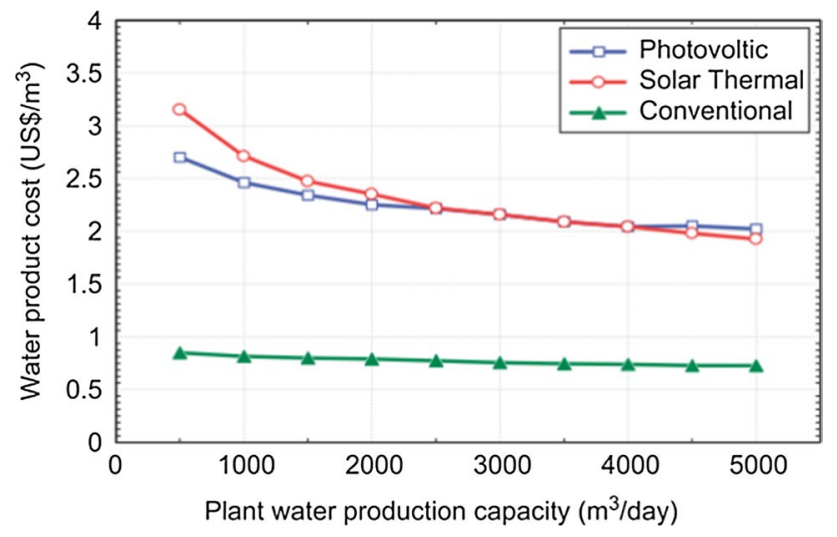

Fig. 19 Water product cost per water production capacity for considered methods (Shatat et al. 2013)

As reported by in Voutchkov 2016, each section in seawater desalination has a determined contribution in economic conditions. Cost breakdowns for seawater desalination for O\&M, energy, capital and indirect capital sections are in $15-30 \%, 20-35 \%, 30-40 \%$ and $10-20 \%$ ranges, respectively. Furthermore, management costs for produced water are subdivided into subcategories. Transportation, resources, disposal and treatment are the main topics in this field that water treatment has the most variable range equaled to $0.2-8.5 \mathrm{USD} / \mathrm{bbl}$ for various water treatments (Dahm and Chapman 2014).

For calculating associated costs with the RO process, Table 8 presents substantial formulations for this purpose (Nafey et al. 2010). In this table, DDC is direct capital cost, TCC is the total capital cost, CC is the capital cost, swip is the seawater and intake price, hpp is the high-pressure pump, $\mathrm{e}$ is the element, $\mathrm{p}$ is the pump, and equip is the equipment.

\section{Environmental effects}

For achieving sustainable design in desalination plants, employing and analyzing the system performance in different terms can bring new aspects to the obtained results. These evaluation methods are environmental impact

Table 8 Costs related to the RO process

\begin{tabular}{ll}
\hline $\mathrm{DCC}$ (USD) & TCC (USD) \\
\hline $\mathrm{CC}_{\text {swip }}=996 \times M_{\mathrm{f}}^{0.8}$ & $\mathrm{TCC}=1.27 \times \mathrm{DCC}$ \\
$\mathrm{CC}_{\mathrm{hpp}}=393,000+10,710 \times \Delta P_{\mathrm{f}}$ & \\
$\mathrm{CC}_{\mathrm{e}}=F_{\mathrm{e}} \times P_{\mathrm{p}} \times N_{\mathrm{p}}+F_{\mathrm{e}} \times P V_{\mathrm{p}} \times n_{\mathrm{v}}$ & \\
$\mathrm{CC}_{\text {equip }}=\mathrm{CC}_{\text {swip }}+\mathrm{CC}_{\mathrm{hpp}}+\mathrm{CC} \mathrm{e}$ & \\
$\mathrm{CC}_{\text {site }}=0.1 \times \mathrm{CC}_{\text {equip }}$ & \\
$\mathrm{DCC}=\mathrm{CC}_{\text {equip }}+\mathrm{CC}_{\text {site }}$ & \\
\hline
\end{tabular}

assessment (EIA), life cycle analysis (LCA) and best available technology (BAT), economic analysis and social impact analysis (Lior 2017). Desalination methods can have detrimental effects on the marine and terrestrial environment. For the sustainable development of desalination processes in the world, these environmental impacts must be controlled. Most of the investigated studies have focused on the shortterm potential impacts on the environments. Nevertheless, long-term evaluations in environmental impacts for various terms such as construction, high salinity brine discharge, chemicals and GHG emissions, can increase the accuracy of the results (Shemer and Semiat 2017). The following represents two major effects:

- Highly concentrated outlet saline: During operation, high concentrated saline water is produced and the insoluble solids in the outlet can reach up to $100,000 \mathrm{ppm}$. In addition, the effluent is opaque and has a high temperature in thermal desalting methods and may also contain some chemical additives such as polymers, acids and anticorrosive substances. The important thing is to safely dispose these wastes in an environmentally friendly manner, while not costing too much. Saltwater produced from desalination equipment is now often dumped in the seas. There has been much debate about the detrimental effects of salinity, turbidity and temperature on the life of animals in the seas, and in some cases, they have been forced to migrate from the specific area. Offshore desalination sites have another method for saline release, including surface water release $(45 \%)$, drainage $(27 \%)$ and deep good injection (16\%), drainage in evaporative ponds (4\%) and other methods (8\%). Each of the mentioned methods has environmental problems related to high salinity and other undesirable components in saline (Miller et al. 2015).

- Carbon production and air pollutants: Table 9 lists the pollutants produced for fossil energy desalination methods. The amount of carbon dioxide produced in the thermal desalination processes is much higher than the membrane. Environmental impacts of thermal desalination methods, when combined with other industrial processes

Table 9 Contributions of air pollutants produced by different desalting methods

\begin{tabular}{|c|c|c|c|c|c|}
\hline \multirow{2}{*}{$\begin{array}{l}\text { Desalination method } \\
\text { Energy resources }\end{array}$} & \multicolumn{2}{|l|}{ MSF } & \multicolumn{2}{|l|}{ MED } & \multirow{2}{*}{$\begin{array}{l}\text { RO } \\
\text { Fossil }\end{array}$} \\
\hline & Fossil & $\begin{array}{l}\text { Thermal } \\
\text { recovery }\end{array}$ & Fossil & $\begin{array}{l}\text { Thermal } \\
\text { recovery }\end{array}$ & \\
\hline $\mathrm{CO}_{2}(\mathrm{Kg})$ & 24 & 2 & 18 & 1.1 & 1.8 \\
\hline NOX (g) & 28 & 4.1 & 21 & 2.4 & 3.9 \\
\hline $\operatorname{SOX}(\mathrm{g})$ & 28 & 15 & 26 & 16 & 1.1 \\
\hline
\end{tabular}


as well as the use of recycled energy, can be significantly reduced (up to 75\%) (Reddy and Ghaffour 2007).

The most important environmental and public health concerns about desalination plants are the release of air pollutants into the atmosphere, most notably $\mathrm{CO}_{2}$ emissions, acid rain gases $\left(\mathrm{NO}_{\mathrm{X}}, \mathrm{SO}_{2}\right)$ and particulate matter. The emission of these pollutants can also come directly from the desalting process itself, for example, fossil fuels are used to generate heat in thermal desalination processes (Miller et al. 2015). Greenhouse gas emissions and air pollutants generally depend on the type of fossil fuels, the efficiency of the power plant that generates electricity and the pieces of equipment for pollutant collection at the plant's output. The presence of $\mathrm{CO}_{2}$ at the plant's outputs is inevitable due to the presence of carbon in fossil fuels. (The methods of $\mathrm{CO}_{2}$ collection at the plant's output are not yet universal). To account for all the gases that contribute to climate change that emit from the combustion process of fossil fuels (such as $\mathrm{CO}_{2}$, methane, $\mathrm{N}_{2} \mathrm{O}, \mathrm{SF}_{6}$, fluorocarbons, etc.) all of these gases can be based on the equivalent of $\mathrm{CO}_{2}$ that is $\mathrm{CO}_{2}$-e is expressed. This parameter can be defined as the equivalent amount of $\mathrm{CO}_{2}$ gas that can have the same effect on global warming as other non- $\mathrm{CO}_{2}$ gases. To assess the environmental impact of various projects in Australia, the amount of $\mathrm{CO}_{2}$ emissions was calculated. The average value of this parameter is $1.16 \mathrm{~kg} / \mathrm{kWh}$ for the Gold Coast desalination project in Queensland, Australia. The RO site in Melbourne has an average value of $1.31 \mathrm{~kg} / \mathrm{kWh}$, which is the highest in the whole of Australia due to the high percentage of coal usage (Ghaffour et al. 2014).

By comparison, if the energy required for reverse osmosis desalination is $4 \mathrm{kWh} / \mathrm{m}^{3}$, the $\mathrm{CO}_{2}$-e emission from desalination will be $4.6 \mathrm{~kg} / \mathrm{m}^{3}$ and $5.2 \mathrm{~kg} / \mathrm{m}^{3}$ in Queensland and Melbourne, respectively. The total energy required for the Queensland desalination unit, including all operating and pumping processes, is estimated to be $24.5 \mathrm{MW}$ for a capacity of $125,000 \mathrm{~m}^{3} / \mathrm{d}$, which is about $4.7 \mathrm{kWh} / \mathrm{m}^{3}$. The amount of greenhouse gas (GHG) emissions required to produce the process is estimated to be about 679 tons of $\mathrm{CO}_{2}$-e per day, equivalent to $5.43 \mathrm{~kg} / \mathrm{m}^{3}$ of $\mathrm{CO}_{2}$-e. The lowest GHG emissions and energy required for desalination in Australia's Perth area were reported to be $3.43 \mathrm{~kg} / \mathrm{m}^{3} \mathrm{CO}_{2}$-e for all site processes, resulting in 325 tons of space gas being released into space from this site daily. The worst conditions for air pollution are in the Persian Gulf. In Kuwait, for example, $90 \%$ of the water required is from hybrid processes, and the energy required for these systems is derived from oil. Kuwait has been ranked fourth in seawater desalination capacity and accounts for $6 \%$ of total desalination capacity. In 2004, the sites produced 42 million megawatts of electricity and 443 million cubic meters of water and consumed 462 million gigawatts of energy. The $\mathrm{CO}_{2}$ emission factor was $0.7 \mathrm{~kg}$ /
$\mathrm{kWh}$ for power generation and $15.7 \mathrm{~kg} / \mathrm{m}^{3}$ for seawater desalination. Therefore, the total $\mathrm{CO}_{2}$ emissions in this area are approximately 19,000 tons per day (Darwish et al. 2008). As mentioned before, each desalination process has a specific environmental impact. For MSF and MED, discharged water is $10-15^{\circ} \mathrm{C}$ hotter than ambient temperature, and by this process, TDS enjoys an increase equal to $15-20 \%$. On the other hand, in RO, brine discharges at ambient temperature. However, the TDS value increases in the range of 50-80\% (Sommariva et al. 2004; Mezher et al. 2011).

By using microfiltration or ultrafiltration that used fewer chemicals than conventional seawater pretreatment (like sand), the environmental impact of discharged concentrate streams could be reduced. Practical pretreatment will also reduce the fouling rate and frequency of cleaning by chemicals (Elimelech and Phillip 2011). Using filtration systems for preventing disturbing factors from flowing to the oceans can moderate physicochemical characteristics and improve marine ecosystems (Kwon and Yoon 2017). SWRO method has several environmental impacts related to the construction and process of intake systems and the discharging of concentrate. The crucial effect of conventional open ocean intake systems is the impingement and entrainment of marine organisms. Concentrate disposal can locally impact benthic creatures (by poorly diluted discharge to the marine bottom). This impact can be minimized by using an accurate design of diffuser systems (Missimer and Maliva 2018).

\section{Renewable energy}

In recent years, the world has faced many problems due to the increased consumption of water and energy. These problems are primarily related to rising energy and water demand from developed countries such as the USA, the European Union and Japan. However, demands for these two cases are also growing in populated countries such as China, India and Brazil. Unfortunately, most countries' energy and water policies today are based on the widespread use of fossil fuels and available water resources, which disrupt the sustainability of resources and can lead to demands for access to new sources in the coming decades. In recent years, most OECD countries have realized that new facilities are needed for the sustainable use of energy resources (Resch et al. 2008; Lund et al. 2011). On the other hand, unfortunately, there is little effort to make proper use of water resources, which has led to severe water restrictions in some parts of the world. This issue has been studied by Koutroulis and colleagues who have been looking for a link between water resources and climate changes. The same study for the South African region was carried out by Kusangaya et al., and a similar study for the Mediterranean region by Manios et al. All these studies have shown that in the future, access to water could

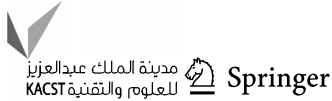


become a solemn problem than access to the fossil fuels. Consequently, the problem of energy and water scarcity must be addressed at the same time, and the solution must be to develop technologies that will sustain both factors (Koutroulis et al. 2013; Kusangaya et al. 2014; Manios and Tsanis 2006).

In this field, a lot of research has been accomplished in recent years that have increased the share of renewable energy use. Although advanced energy conversion technologies from traditional fuels are now economical options, the use of renewable sources is becoming more competitive and economical with governmental aids. The cost of using fossil fuels has also risen, as well as the investment costs in the renewable energy sector. Therefore, the intense competition of these renewable energies with fossil fuels will be conceivable in the coming years. As long as fossil fuels are used for the production of freshwater, these processes are operationally expensive and polluting and will have a wide impact on the environment. In stark contrast, the use of fossil fuels is not very economical for remote areas, even for coastal areas that have access to seawater. Many areas are deficient in fossil fuel and water resources, at the same time. The use of desalination or water treatment sites by renewable sources would be highly desirable for these areas. It should be noted that efforts to reduce GHG emissions will lead to greater investment and the use of renewable sources (Gilau and Small 2008). Renewable energy is part of the engineering field that has received a lot of attention. It is clearly foreseeable that a high proportion of human energy will come from various renewable sources. Renewable energy can be used in a variety of processes, which solar thermal energy, wind energy and geothermal energy are widely used in various thermal projects such as air and water heating and desalination sites (Foster et al. 2009; Tabak 2009). The contribution of renewable energy in total primary energy supply would rise from $14 \%$ in 2015 to $63 \%$ in 2050 (by 2050, wind and solar account for over $70 \%$ of total renewables generation), while $\mathrm{CO}_{2}$ emissions from energy section increase by $33 \mathrm{Gt}$ in 2015-35 Gt in 2050 (Ummel and Wheeler 2008; Gielen et al. 2019). Figure 20 indicates the projected power generation by energy resources.

Latorre et al. explained that because of the unpredictability of prices and the availability of fossil fuels, there is a high demand for renewable energy for desalination. Using these resources would be very suitable for areas with low fossil fuels and a lack of water resources (Latorre et al. 2015). Saudi Arabia has seen the growing population and industries, seriously dependent on seawater as a water resource. In addition, despite the high cost and energy demand for desalination methods, water transfers to crowded areas in central Saudi Arabia, as well as to rural and remote cities, have greatly increased these costs (Zhou and Tol 2005). The need for water in many remote coastal rural areas as well as in remote rural and urban areas has provided the novel potential for the use of renewable energy for desalination in small seawater capacities (Al-Karaghouli et al. 2009; Doukas et al. 2006).

Saudi Arabia, like many Arabian countries, has areas with high levels of solar radiation and has considered the use of solar energy as a renewable energy source. On the other hand, the use of wind energy will be very popular, especially in coastal areas (Mokheimer et al. 2013). The use of renewable energies for desalination is not very common in the world (only $0.02 \%$ of the total desalination capacity driven by renewable energy resources). But it must be acknowledged that the use of these resources is appropriate for the desalination of seawater for several reasons. The first is the diversity of these types of energy, the other being the cost of setting up, maintaining and running renewable energy systems against other traditional energy sources, making it a desirable option for remote areas. In addition, the majority of desalination units are in coastal areas where abundant renewable energy sources are found. The use of fossil fuels will require the transportation of fossil energy carriers, which is very costly due to the lack of development of energy distribution networks in these areas (Ghaffour et al. 2015; Ismail et al. 2016). There are two strategies for using renewable energy, off-grid and on-grid systems.
Fig. 20 The trend of world net electricity generation by different energy resources (EIA 2019)

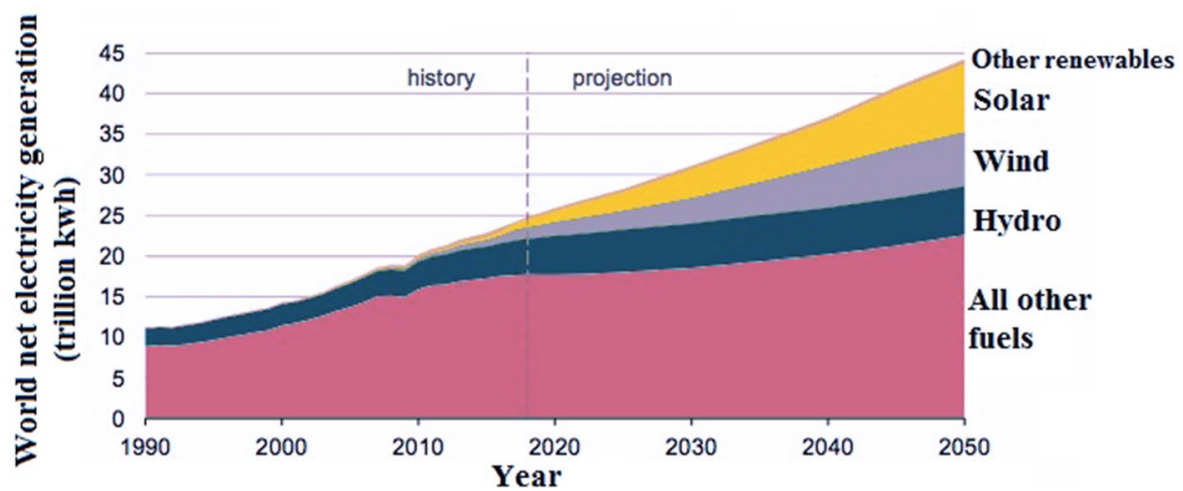


In the first scenario, there is no need to connect to the electricity distribution network, and the electricity needed for the complex is supplied by itself. In this strategy, it is necessary to allocate energy-saving components to meet the needs of the complex at all times of the year, as access to renewable sources fluctuates throughout the year that complicates the design. Also, by overestimating the capacity of the devices, we will need a wider terrain to locate the equipment that makes this scenario costly (Mentis et al. 2016). Microgrid generation units can be considered as a small-scale power grid that includes the production, transmission and storage sectors and can meet local needs. There are several distribution plants in the world that use renewable energy, and their performance demonstrates the benefits of on-site renewable energy production (Soshinskaya et al. 2014). Stand-alone units have been installed in some countries around the world such as China, Mexico, Kenya and Bangladesh to supply electricity to remote areas. These energy systems often include photovoltaic cells with storage battery sets or even diesel generators as backup power. Although these units are mostly installed in non-industrial rural areas, there are also several interconnected micronetworks that can meet the needs of residential and commercial complexes (Urmee et al. 2009). For example, the microgrid in Japan is capable of supplying electricity to five universities, a nursing home and a high school by photovoltaic cells, fuel cells and storage batteries. In the second scenario, if the desalination units and the renewable energy resource are both connected to the power grid, the amount of energy generated by renewable energy and the energy required for desalination can be monitored at any time by the central control system.

For the sustainable development of freshwater production, the use of energy sources as a primary option is a concern. For example, due to the problems and costs of transmitting electricity to remote areas, it would make sense to use hybrid wind and solar systems for areas with high radiation levels and appropriate wind potential. The use of stand-alone hybrid systems can be used in urban and rural areas that can be used for a variety of applications such as lighting, water transfer, water treatment (Liu and Wang 2009; Ashok 2007).

Solar and wind energies have the highest share of all types of renewable energies to provide desalination energy. However, methods such as biomass, hydroelectric power and ocean energy will also be used in fewer proportions and are used to generate power for smaller desalination plants. The great disadvantage of solar and wind resources is their unpredictability and dependence on weather and climate. For this reason, one must accept the fact that renewable sources cannot meet the demand for energy systems alone. Batteries are commonly used for this purpose. Low storage life, high maintenance costs and the environmental damage of these batteries are major problems for these storage systems (Nagaraj et al. 2016; U. R. Energy 2012; Spyrou and Anagnostopoulos 2010). Recently, researches have been combined fuel cell with electrolyzing that is both reliable and environmentally friendly (Maleki and Askarzadeh 2014; Askarzadeh 2013). Generally, renewable energies that have significant roles in the desalination process are solar, wind and geothermal energies (Shatat and Riffat 2012). It is necessary to optimize the size and capacity of the system, for using renewable energy economically with higher efficiency (Fig. 21). Capacity optimization provides efficient renewable energy at the lowest investment cost (Ayoub and Malaeb 2012; Ahmadi et al. 2019). Figure 22 demonstrates the contribution of renewable energy resources in desalination processes for producing freshwater.

\section{Nuclear energy}

The International Desalination Association (IDA) planned to reach 120 million $\mathrm{m}^{3} /$ day desalination capacity until 2020, while nuclear energy provides proper opportunities. Progress in nuclear plants and desalination system is growing considerably, and numerous countries are getting involved in it. There is no restriction for choosing nuclear reactors for the desalination process, and any reactor has potential coupled with desalination systems (Belkaid et al. 2012; Khan et al. 2017). Nuclear energy can also be used for thermal desalting. The heat used in the nuclear reactor is used for this purpose. The cost of desalinizing seawater with nuclear energy is roughly equivalent to fossil energy. The first nuclear-powered MSF-RO unit was built in India. This unit is based on MSF technology developed in India and has a capacity of about $6300 \mathrm{~m}^{3} / \mathrm{d}$ (Dittmar 2012). Intending to design and develop hybrid systems including nuclear and desalination systems, can increase the capacity of freshwater production. These interests have been increased significantly among the members of the International Atomic Energy Agency (IAEA) for the last two decades. Table 10 lists some of the world's leading nuclear-desalination sites (Mansouri and Ghoniem 2017; Sleem 2010).

There is numerous integration of nuclear systems with small-size desalination units (Wu et al. 2000; Wu and Zheng 2002; Wu and Zhang 2003; Belessiotis et al. 2010; Khan et al. 2018). An innovative combined system consisted of the nuclear heating reactor (NHR) with low-temperature MED + RO and NHR with low-temperature MED/ $\mathrm{VC}+\mathrm{MED}$, has been presented (Kim and No 2012). Results from performance analysis indicated new aspects of the combination of the MED process with NHR. Investigated results from (Misra and Kupitz 2004; Misra 2003) have designated the role of nuclear desalination for the utilization of potable water needs in arid areas. The research also reported a bunch of nuclear reactors coupled to different desalination plants. Recently, attention was rising to a couple of reactors.

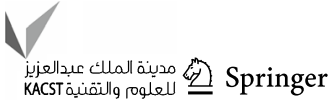




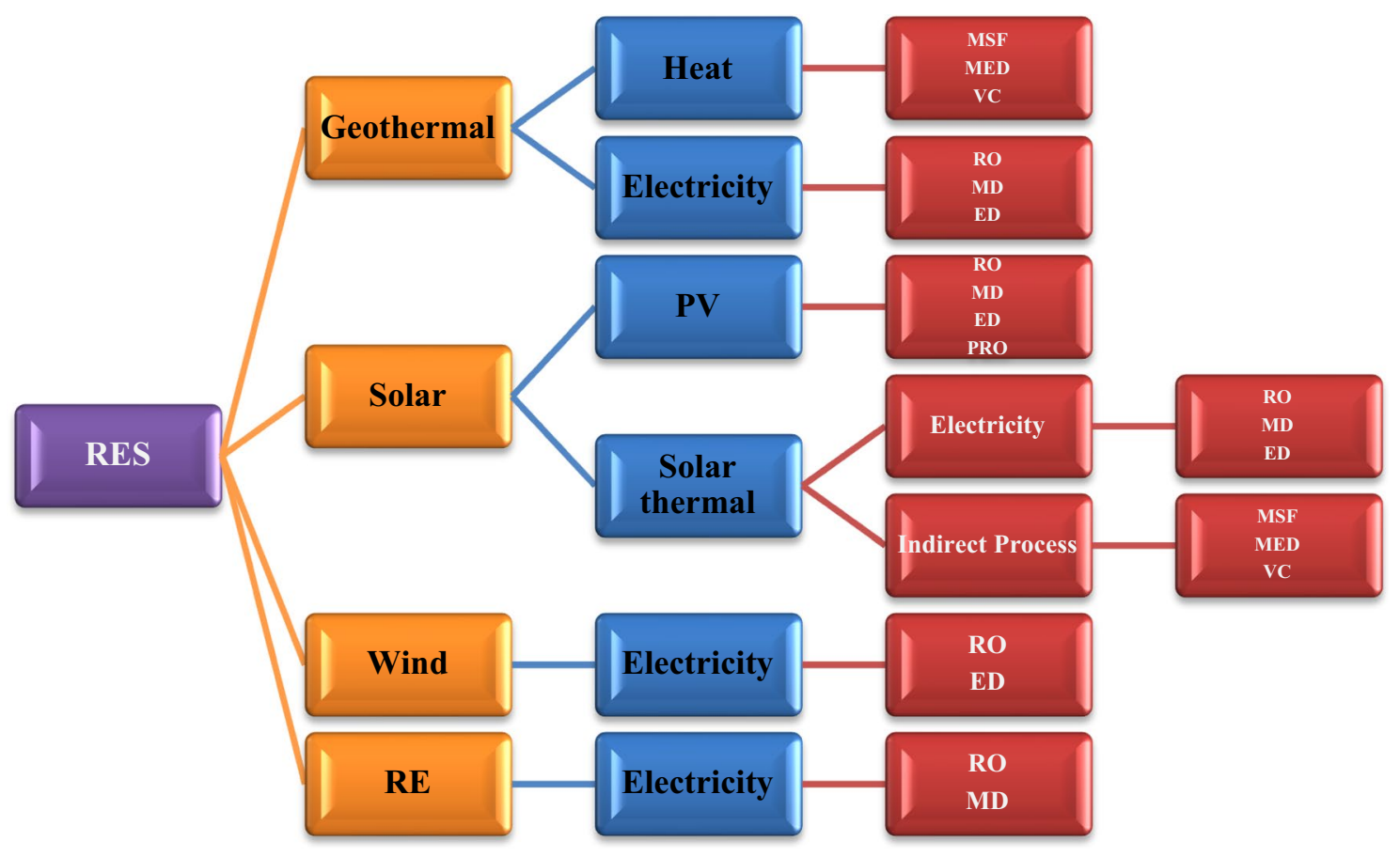

Fig. 21 Chart of combining different desalination methods with renewable energy resources. $P V$ photovoltaic, $R E S$ renewable energy source, $R E$ reverse electrodialysis, $R O$ reverse osmosis, $M D$ mem-

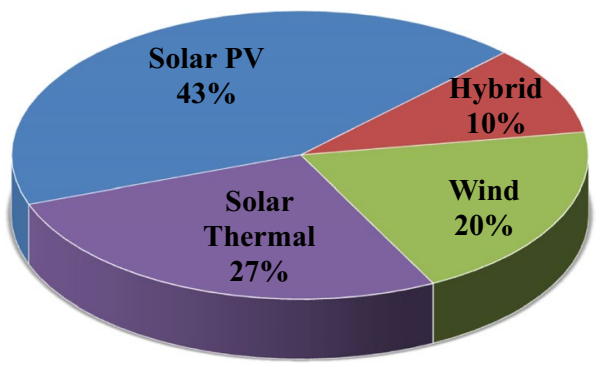

Fig. 22 The contribution of renewable energy resources in desalination (Ayoub and Malaeb 2012) brane distillation, $E D$ electrodialysis, $P R O$ : pressure-retarded osmosis, $V C$ vapor compression (He et al. 2015; Brauns 2010; Tufa et al. 2019; Tufa et al. 2015)

For example, the feasibility analysis of a coupled system comprised of RO and an existing nuclear plant (Karameldin et al. 2007). In Egypt, an advanced hypothetical model for calculating the effective parameters of the RO process is cogenerating with a considered nuclear reactor (Kavvadias and Khamis 2010). The cost of freshwater production by nuclear desalination was expected to be in the range of $0.4 \mathrm{USD} / \mathrm{m}^{3}-1.8 \mathrm{USD} / \mathrm{m}^{3}$ based on the reactor type and the desalination process (Al-Othman et al. 2019). Figure 23 represents a flow chart of the coupling desalination unit with a nuclear power plant. The diagram contains a RO and a
Table 10 Some of the world's leading nuclear power desalination sites

\begin{tabular}{lllll}
\hline Site name & Location & Power (MW) & Waster capacity $\left(\mathrm{m}^{3} / \mathrm{d}\right)$ & $\begin{array}{l}\text { Type of reactor } \\
\text { and desalination }\end{array}$ \\
\hline Shevchenko & Aktau/Kazakhstan & 150 & $80,000-145,000$ & LMFR/MED, MSF \\
Ikata-1,2 & Ehime/Japan & 566 & 2000 & PWR/MSF \\
Ikata-3 & Ehime/Japan & 800 & 2000 & PWR/RO \\
Ohi-1,2 & Fukui/Japan & $2 \times 15$ & 3900 & PWR/MSF \\
Ohi-3,4 & Fukui/Japan & $2 \times 10$ & 2600 & PWR/RO \\
Genkai-4 & Fukuoka/Japan & 1180 & 1000 & PWR/RO \\
Genkai-3,4 & Fukuoka/Japan & $2 \times 10$ & 1000 & PWR/MED \\
Takahama-3,4 & Fukui/Japan & $2 \times 8$ & 1000 & PWR/RO \\
NDDP & Kalpakkam/India & 170 & 6300 & PHWR/MSF-RO \\
LTE & Trombay/India & 40 & 30 & PHWR/LTE \\
Diablo Canyon & San Luis Obispo/USA & $2 \times 1100$ & 2180 & PWR/RO \\
\hline
\end{tabular}


Fig. 23 Schematic of a nucleardesalination process (Abdoelatef et al. 2015) ( $H X$ heat exchanger, $H P P$ high-pressure pump)

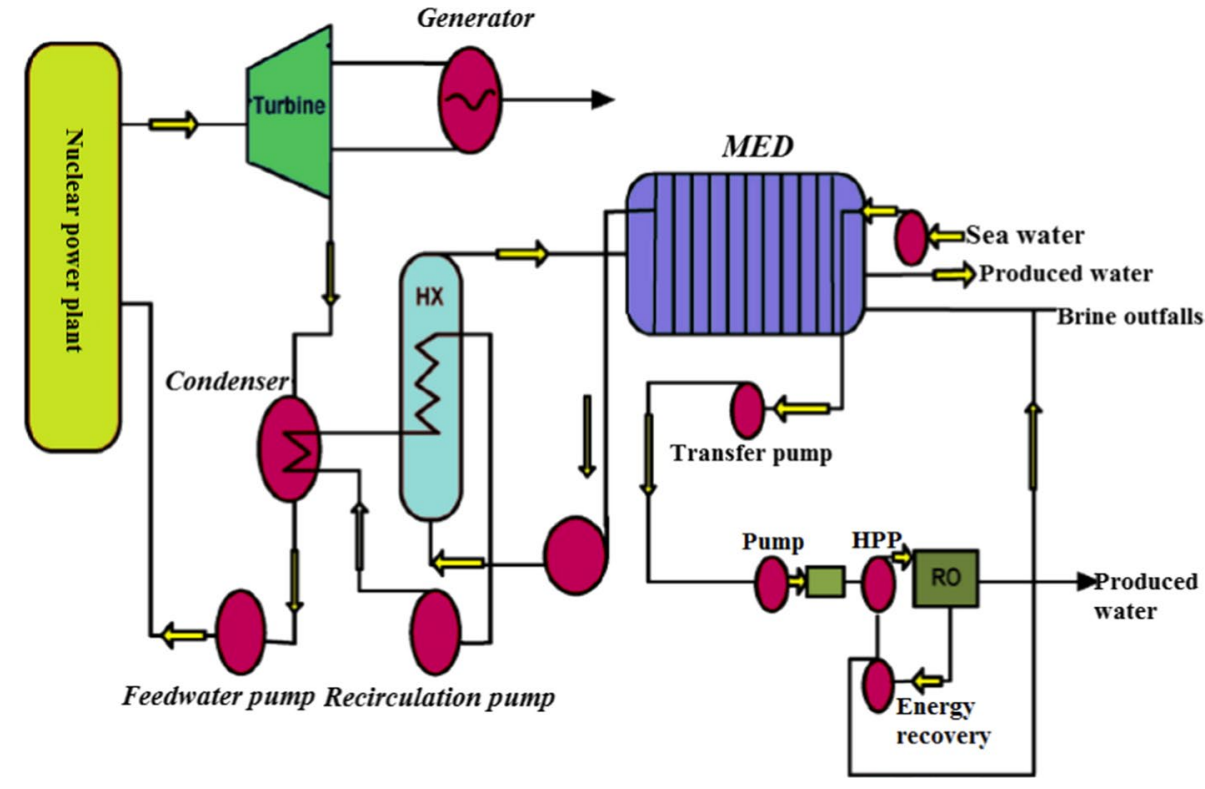

MED that integrated with an on-site nuclear-desalination plant. The purpose is to generate power (for RO) along with utilizing the waste heat to produce steam for feeding into the MED unit (Abdoelatef et al. 2015).

An energy-economic examination on various coupled systems has been carried out. In this case, the performance of the coupled system of heat pump for the space cooling purpose (Belessiotis et al. 2010) and appraisal ground source heat pump system (Fiorenza et al. 2003) has been evaluated.

\section{Solar energy}

At the moment, the use of solar energy for the purpose of the desalination process has the highest share among all types of renewable energy. Today's human needs for electricity can be met by covering only $1 \%$ of semiarid or arid regions with solar systems. For example, each square meter of land in the Middle East and North Africa receives between 5 and $7 \mathrm{kWh}$ of solar energy per day. It can be estimated that many areas in this part of the world receive 1.7-2.2 MWh per square meter of solar energy per year (Sukhatme and Nayak 2017; Hosseini et al. 2005). In this field, the use of solar energy for the desalination process is growing. Using this method in rural and remote areas can have a great impact on the health, welfare and economic development of the people. However, there are several factors including the efficiency of the complex, the variable level of energy received from the sun per year and the lack of infrastructure as constraints on the use of this energy in large-scale desalination capacities (Shatat et al. 2013). Semiarid regions are mostly located in the Middle East and Africa. There are solutions to the problem of water scarcity in these areas, either by transferring potable water from other areas or even producing water by the air. But these methods are very costly. Dry areas often have great potentials for solar energy use, so using this energy could be beneficial for these areas. Taking advantage of this environmentally friendly energy will ultimately reduce GHG effects and global warming.

Cost-effectiveness is one of the most important factors in establishing desalination plants, although the best desalination method is based on several technics and economic criteria such as water conditions (TDS, temperature, heavy metals and quality), remote control, access to the grid network, infrastructure and the type of solar energy technology. Nowadays, attentions have been focused on increasing the efficiency of solar energy conversion systems, desalination technology and the optimal combination of these two factors, so that the system can be used economically for medium- and small-size desalination plants. In Fig. 24, the contribution of different desalination methods combined with solar energy has been illustrated. Figure 25 represents the different strategies for the desalination process based on solar energy. Generally, there are two types of solar energy systems:

1. Photovoltaic (PV) systems that receive the sun's energy and convert it into power. It has been used in RO and electrodeionization systems.

2. Solar thermal systems that convert solar energy received into heat energy, which can be used directly or indirectly to supply energy. Thermal type can be used in solar distillers, solar collectors and solar ponds. 


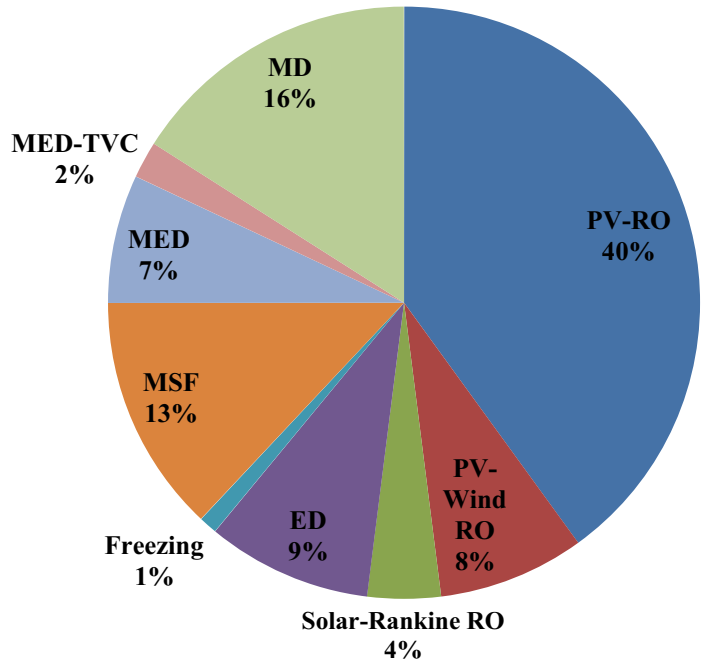

Fig. 24 Contribution of different desalination methods combined with solar sources (Ayoub and Malaeb 2012)

\section{Solar distiller}

Solar distiller has been used for decades, which has many different types. The device runs a small natural hydrology cycle as the sun's rays pass through the device's light shield and trapping it over the saltwater pool. The shield includes a glass and plastic panel that is sloping above the basin (like a greenhouse). The pond is usually black in order to absorb the longest wavelengths of sunlight (Valdez Salas and Schorr Wiener 2012). The sun's rays are spread over a steep slope, and the greenhouse effect increases the saline water temperature in the pond. The saline water in the basin is evaporated upward, and the steam generated moves upward to condense on the sloping surface and the droplets move downstream. These droplets of water are collected and removed from the

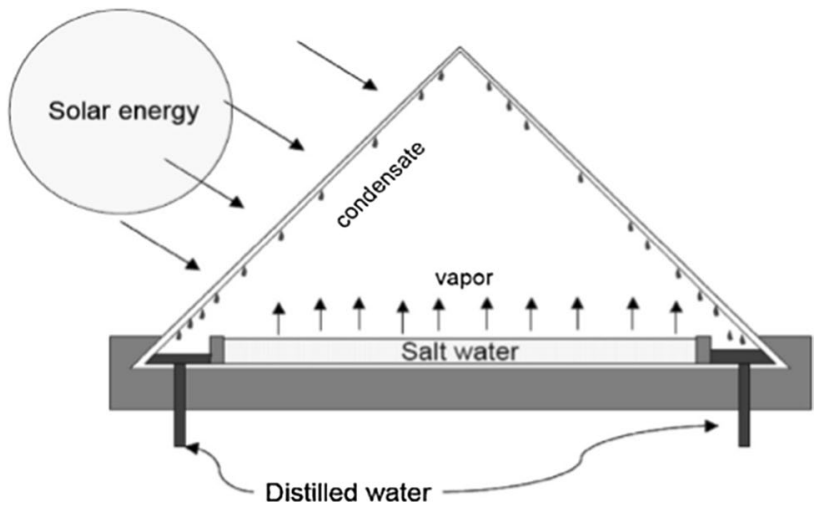

Fig. 26 Solar distiller structure and associated performance (Moh'd A et al. 2016)

specified path. The water produced by this method is purified, and a partial amount of minerals and salts is added to it to reduce the corrosive properties of its metals (World Health Organization 1993). It is cheap in terms of manufacture and has low maintenance costs, but the main problem is the low rate of freshwater production (Moh'd A et al. 2016) (Fig. 26).

This system can produce 3-4 L of freshwater per square meter per day. This method can be used for large areas with low land prices and low demands for potable water (Valdez Salas and Schorr Wiener 2012). Solar distillers have low efficiency and low production capacity besides traditional solar desalination devices can be operated under two conditions:

1. Low evaporation rates in the pond

2. Low condensation rates on the glass surface

The efficiency of the solar distiller is influenced by environmental factors, device design and operating parameters.
Fig. 25 Different strategies for using solar energy in desalination process (Caldera et al. 2016)

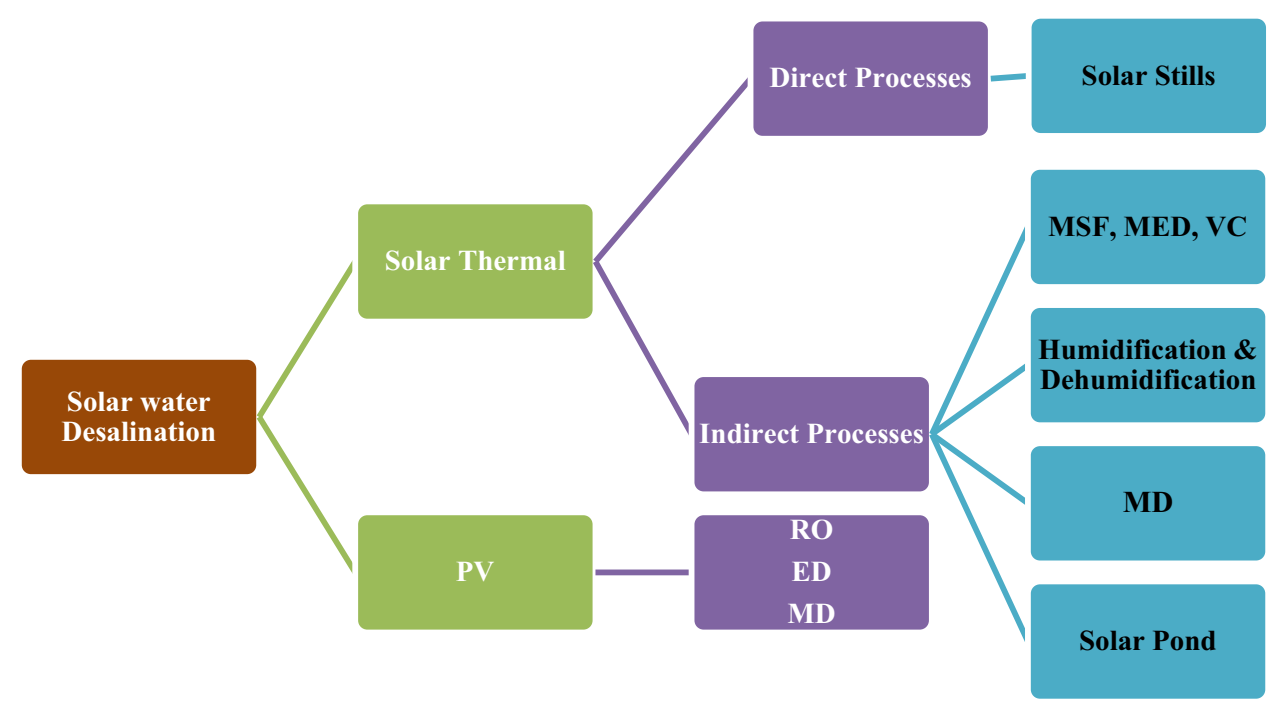


The efficiency of the system is directly related to the amount of sunlight, ambient temperature, relative humidity, wind speed, cloud and mist on the glass. On the other hand, the efficiency of the solar distiller is directly related to the level of evaporation and inversely to the depth of the basin. The glass cover of the solar distiller should have the highest angle in winter and the lowest angle in summer. The efficiency of these devices can be increased in combination with flat collectors or solar vacuum tubes. Collectors are used to preheating feedwater to a solar distiller. In addition, the use of forced circulatory systems instead of the natural circulation of the thermosyphon is very effective in increasing the efficiency of the system. Photovoltaic cells can be used to drive the pumps to create pressure, while thermal collectors are used for heating water (Moh'd A et al. 2016). Other suggested techniques to increase the efficiency of this device are to recycle evaporative latent energy and optimize water flow to increase heat transfer (Valdez Salas and Schorr Wiener 2012). The highest efficiency of solar distillers has reached $50 \%$. The efficiency of these devices would be reduced in any case of insulation failure (up to 14.5\%). Then again, increasing wind speeds of up to $3.6 \mathrm{mph}$ can reduce the efficiency of the device up to $2 \%$. This device is effective for areas with poor water quality and high solar radiation (Moh'd A et al. 2016).

Al-Hinai et al. have performed parametric studies on binary solar distillers and calculated the efficiency of the device for optimal design conditions. Their calculations show that the device can produce freshwater at an average of $4 \mathrm{~L}$ per square meter per day (Al-Hinai et al. 2002). Rajaseenivasan et al. have suggested using a multi-stage solar distiller to increase the efficiency of the complex. Innovative designs have used heat losses caused to heat water at the latter stages (by latent heat) (Rajaseenivasan et al. 2013). With all these efforts, it is not possible to use this method for desalination on a large scale (Valdez Salas and Schorr Wiener 2012).

\section{Solar humidification and dehumidification desalination (SHDD)}

The use of this desalination method has been studied by various researchers over many years, and it has been proven that this method is capable of producing freshwater at high capacity at optimal efficiency. This desalination method is combined with a vacuum tube collector system to optimize the seawater temperature desalination process. The device is based on the principle of dehumidification and the use of the energy available in the psychometric process to convert saline to freshwater. It includes a vacuum tube collector, storage tank, circular pump, fan and some other types of equipment. In this method, brine is evaporated by thermal energy and then condensed into moist air (usually at atmospheric pressure) to produce freshwater continuously. Air is capable of absorbing large amounts of vapor, and this ability increases with raising temperature (Shatat and Riffat 2012).

The seawater evaporates in the evaporator and then slowly drips downward. The air transfers in the opposite direction to the brine and reaches saturation. Partial evaporation cools the brine, leaving the device with a higher concentration percentage, while saturated water condenses on the plate converter. The condensed droplets are then collected in a special basin. The latent heat of condensation process is transferred to the seawater by moving upward in a plate converter. Consequently, the saline water temperature rises from 40 to $75^{\circ} \mathrm{C}$. Subsequently, preheated brine should be heated to the evaporator at an inlet temperature (about 80-90 ${ }^{\circ} \mathrm{C}$ ), provided by the solar collector (Shatat et al. 2013).

The experimental model of this mechanism placed in Tunisia. A new variant of the system has been proposed with multi-stage humidification that can produce an average of $355 \mathrm{~kg} / \mathrm{d}$ of freshwater in August. Higher relative humidity results in increased freshwater production under the same conditions of cooling and airflow. It is recommended that this system is installed near the seaside (Chandrashekara and Yadav 2017). The cycle of SHDD consisted of solar collector, desalination unit, driven pump, distillate and saline water tank is illustrated (Fig. 27).

\section{Solar ponds}

Solar ponds can be considered as thermal batteries that are used for desalination processes. These ponds can also be used for steady freshwater production, even at night. A 3000-square-meter solar pond has been built next to

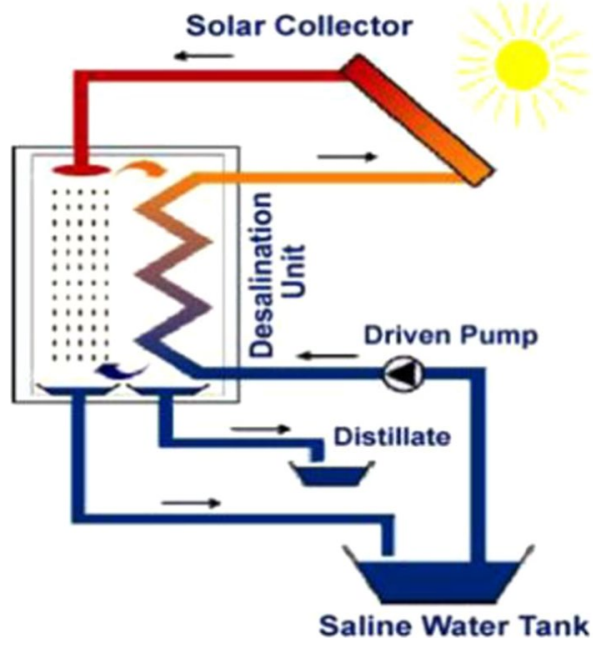

Fig. 27 Schematic of the SHDD process (Valdez Salas and Schorr Wiener 2012) 
the Dead Sea, and it can produce $4.3 \mathrm{~L} / \mathrm{min}$ of freshwater annually (Saleh et al. 2011). Solar ponds are the types of equipment that manufactured by preventing convection and changing density, raise the temperature of salty water. In the last decades, different kinds of salt gradient solar ponds in solar hybrid devices, thermal applications, power generators and desalination have been used. At the present time, various types of minisolar ponds have been released. Based on the demands, there are several categories of solar ponds. In this work, different angles of influential and substantial parameters in design, analysis, optimization, simulation and measurement of solar ponds are studied (Velmurugan and Srithar 2008).

Solar ponds have the unique ability to store solar thermal energy throughout the year (even in the cold months of the year), and it is a feature that sets it apart from other solar methods. In these ponds, the solar thermal energy enters and heats the lower zones of the pond. This convective flow is usually continuous, and the pond temperature remains constant. Solar ponds can be used to power various applications. Small ponds are used for heating the environment and domestic hot water, while larger ponds can be used for industrial processes such as heating, electricity generation and desalination. The salt circulation in the pond will store energy in it. While the temperature of water layers near the surface is close to the ambient temperature, the temperature at the bottom where the salt concentration is high is considerable (about $90^{\circ} \mathrm{C}$ ). The difference between the high and low temperatures of the pond will be large enough to start up the desalting process. The organic rankine cycle is used for this purpose. External heat is applied to organic fluids (fluids that contain carbon in their chemical formulas such as toluene and hydrocarbons). The organic fluid makes it possible to use low-temperature sources in the cycle, such as solar ponds in the range of $70-90^{\circ} \mathrm{C}$. Certainly, the efficiency of this cycle is low due to the low temperature of the hot storage, but on the other hand, due to the low costs, this low efficiency is justified (El-Sebaii et al. 2011) (Fig. 28).

The annual energy efficiency of these ponds is about $10 \%$ to $15 \%$ for setting up desalination plants, which is suitable for water supply in villages and small towns. Large solar ponds can be used for continuous desalination. Solar pondbased desalination is reportedly easier and cheaper than other solar methods. From an operational and economic point of view, freshwater supply is constantly important and solar ponds provide freshwater throughout the year, even at night and in cloudy weather (Shatat and Riffat 2012). Based on obtained results for desalinating seawater, producing each cubic meter of seawater needs $1000-4000 \mathrm{~m}^{2}$ surface of solar pond per day (Salata and Coppi 2014). A pioneering concept of solar ponds coupling with RO has been presented. In this design, the efficiency of the system was $1.5 \%$. Considerable hypothesis for this strategy was that the efficiency of the solar pond has equal to $15 \%$ and coupled ORC efficiency was 10\% (Delgado-Torres and GarcíaRodríguez 2012; García-Rodríguez 2007; Wright 1982). The improvement in salinity gradient (SGP) based on reverse electrodialysis (SGP-RE) could become a vital alternative approach for storing solar power as osmotic energy in highly concentrated salt solutions. The function of SGP could be demonstrated from the free energy of mixing two solutions at different concentrations. For using this integration, a SGP-RE battery is presented. The battery is made from consecutively mounting several cell pairs. There are two
Fig. 28 Solar pond construction which contained different zones (Ding et al. 2018)

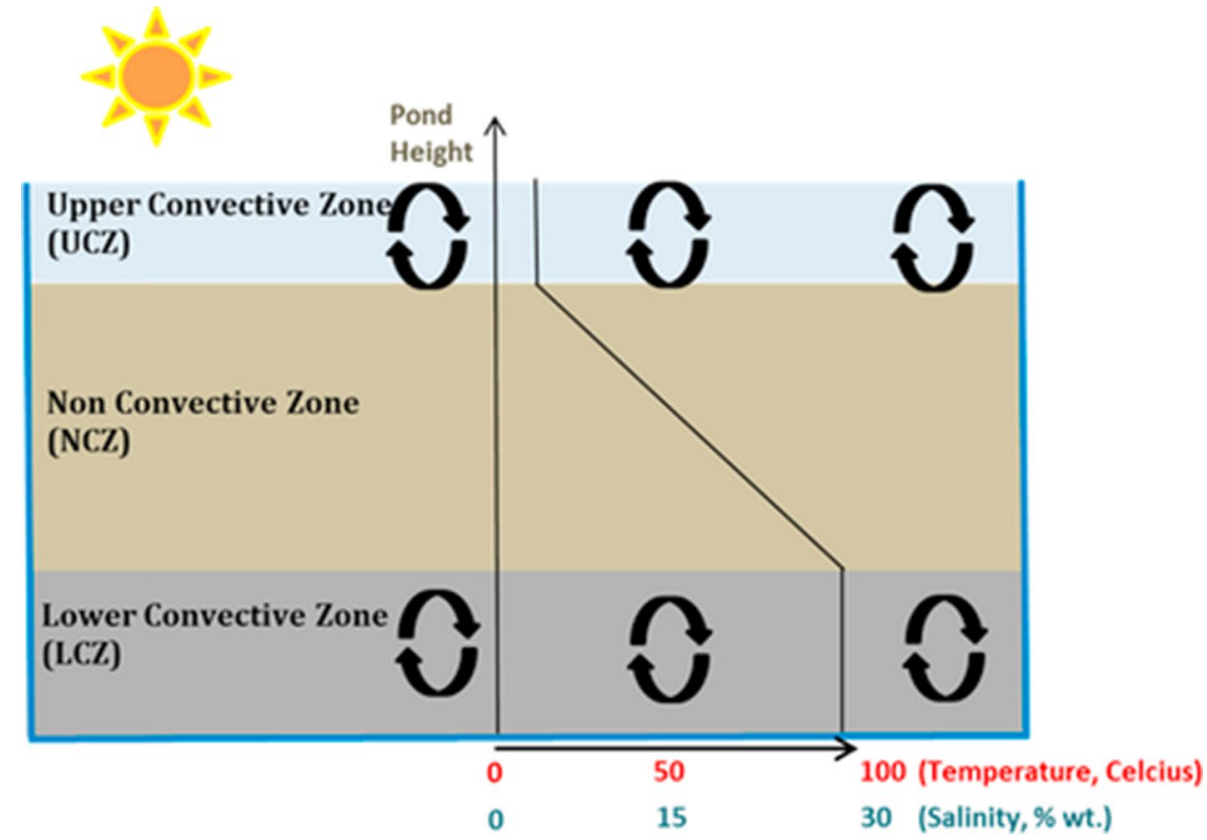


concentrated brine electrolytes (high and low). Accordingly, due to the difference in ion concentration streams, ions will move through the ion conductive membrane. This ion migration causes an electric current that can be converted at the SGP-RE battery electrodes. This DC voltage and DC current can directly drive an electric load (Brauns 2010; Catrini et al. 2017; Vermaas et al. 2012; Brauns 2019).

\section{Collector and photovoltaic}

The solar collectors are in various types such as flat plate, vacuum tube or central concentrator that can be combined with a wide variety of thermal desalination units. Furthermore, the photovoltaic (PV) panels can be powered and used for desalination by RO or ED. In the PV method, solar energy is converted directly into electricity by silicon solar cells. Backup batteries should be used to stabilize the RO system and prevent the detrimental effect of changes in solar energy levels at different times. The main drawback of using solar systems is that it can only supply the energy needed for the process in the presence of daylight, but desalination units need to operate continuously, so large storage tanks are needed. In addition, one of the major disadvantages of using solar collectors in desert areas is the presence of dust on collectors, which drastically reduces their heat capacity (Šály et al. 2006; Pietruszko and Gradzki 2003).

Solar cells are made of semiconductor materials such as silicon. To make PV plates, many of these cells are interconnected. Other equipment and supplies such as AC-toDC converters and energy storage devices such as batteries should also be included. PV panels can be installed or disconnected from the grid. In medium or small PV sites, grid electricity is used as a backup. The most important problem with this technology is its high cost that has only been used for desalination in small and remote areas. A PV system can produce $110-120 \mathrm{kWh}$ per square meter of energy collector, so the amount of collector area needed to produce 1 cubic meter of freshwater per day with a small desalination plant ( $8 \mathrm{~kW}$ hours per cubic meter) will be about 26.5-28 square meters of standard technology. The use of solar energy to power the RO process is a growing technology, especially for remote areas with low desalination capacities. Figure 29 indicates the defined system consisted of PV and RO.

High-efficiency PV cells are now more expensive per unit area than solar thermal collectors. PV cells can be used to power off-grid areas as well as high-capability portable devices, but are not competitive with the use of solar collectors to supply power for large units with high capacity. Currently, the cost of producing electricity with a PV system is about 0.12 USD per $\mathrm{kWh}$, which is about $2-3$ times more than the current methods of generating electricity in the US market. In other words, the PV system in its lifetime of generating electricity cannot make enough money to

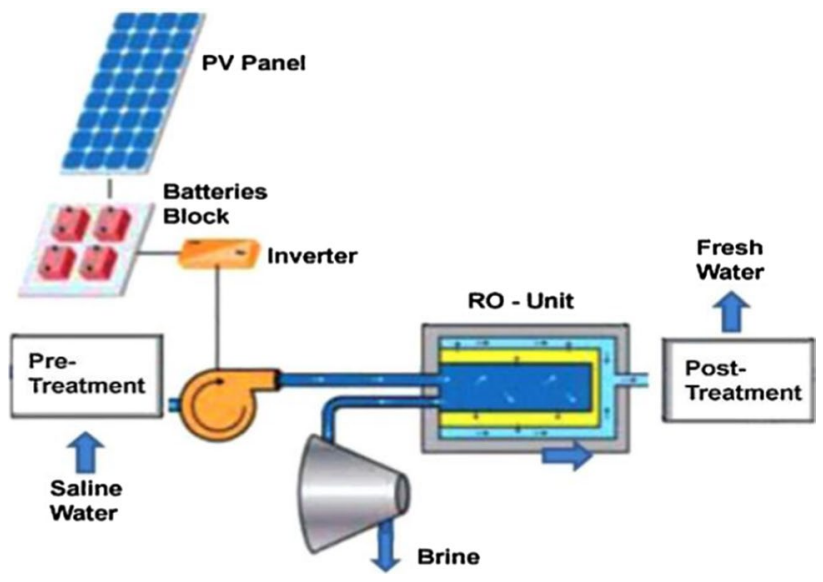

Fig. 29 The combination of a reverse osmosis system with photovoltaic (NREL 2016)

compensate for its initial investment costs. From these studies, it can be concluded that the use of electricity generated by the PV method for desalination is also much more costly than the use of electricity generated by power plants (NREL 2016). Due to the need for high-capacity batteries, the use of PV solar systems at large capacities for off-grid areas is very expensive. Although using these systems in grid connection mode can be cost-effective, a useful way to save solar energy is to use a PV system to generate hydrogen and store it for future use. In this case, stored hydrogen can be used in highefficiency fuel cells with low environmental impacts. Utilizing solar concentrators in RO desalination is an additional option for generating solar power (Verdier 2011).

High-pressure steam production technology is widely used in various industries, e.g., steam engines. In solar thermal systems, the pressure tank can be charged by the heat absorbed by the sun and then the high-pressure steam can be used to move the turbine and generate electricity. The same process can now be used to move the RO system. However, this cycle will require a steam cooling section for returning to the pressure tank. The pressure for RO desalination is 55 bar and for brackish water 10-15 bar. These pressures are much less than the pressures required driving the turbines (the pressure range of these turbines is 75-120 bar) (Reif and Alhalabi 2015). Solar collectors are basically divided into three categories based on the temperature:

1. Low-temperature solar collectors which increase the temperature slightly more than the ambient temperature. Uncoated flat collectors included this category. This low-temperature rise cannot be used as a source for operating thermal desalination systems.

2. Medium-temperature solar collectors that produce temperatures of more than $430{ }^{\circ} \mathrm{C}$, including flat-panel collectors and vacuum tube collectors. These collectors

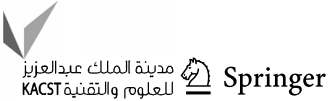


use water or air as a heat transfer. The heat of these collectors can be supplied indirectly by means of a heat exchanger for desalination.

3. High-temperature solar collectors that include parabolic trough collectors and central receivers. The heat generated in these types of collectors can be used directly in thermal desalination or indirectly through the electrical energy produced in membrane desalination. In order to achieve the highest efficiency in solar systems, the sun's tracking method should be used to stay perpendicular to the collectors by changing the location of the sun throughout the day and year. Large solar power plants will certainly require large desalination sites (Valdez Salas and Schorr Wiener 2012).

The main methods are concentrated solar power (CSP) technology, parabolic trough collector, Fresnel collector, solar tower and dish Stirling system. In these systems, solar radiation was collected from a large space and concentrated in a smaller area, so the concentration ratio is defined as the ratio of the area of energy collection to the area of concentrated solar radiation. Most concentrated solar power sites convert heat received into heat and then convert it into electricity in turbines. For concentrating processes, most of the mirrors are used to follow the sun continuously throughout the day. For working fluids, air, water, oil and molten salt can be used (Reif and Alhalabi 2015). Different types of solar concentration strategies are indicated in Fig. 30.

The parabolic trough and the Fresnel are very similar methods. Both have long reflectors, which play as a centralizing role in the system. In these devices, the reflection plates follow the solar radiation and concentrate the solar

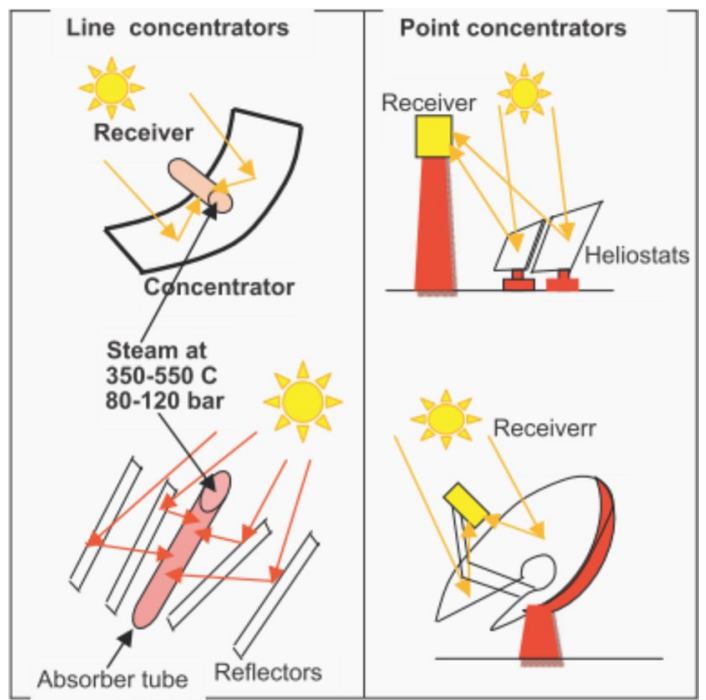

Fig. 30 Various types of solar concentrator methods (Reif and Alhalabi 2015) beams at any moment in the energy collector, and then the special fluid captures the heat of the sun and uses it in subsequent sections. The focal ratio for these systems is in the range of 1:60-1:80, which is somewhat weaker for generating electrical power compared to the solar tower, which generally has a focal ratio of 1:100. However, the concentration ratio of parabolic trough and linear Fresnel is suitable for producing heat for desalination. Fresnel linear collectors have been developed by various companies to achieve simpler and cheaper systems than parabolic trough collectors. The absorbent tube is at the center of this arrangement and does not need to be moved to follow the radiations. The structure of Fresnel collectors is very light (up to $80 \%$ per square meter lighter than parabolic trough collectors), which also helps reduce prices (Fig. 31). On the other hand, the simplicity of the Fresnel design reduces the optical efficiency of this type of collector, which will ultimately require additional strategies in order to obtain the same amount of energy (El-Ghonemy 2012)

The solar tower has a number of mirrors that track the sun and focus it on the central collector. The system uses parabolic reflectors to focus radiations on a motorized drive (Reif and Alhalabi 2015). The use of plate concentrators is not economical for large desalination complexes due to their low capacity in the range of a few kilowatts, although it can be used for freshwater production at limited capacities for off-grid areas. The two main candidates for the use of solar energy in high-capacity desalination are parabolic trough collectors and Fresnel collector (El-Ghonemy 2012). The use of a Fresnel collector is preferable to parabolic trough collectors. Firstly, the experience of using a parabolic trough system has more experience than Fresnel and the reliability of parabolic linear systems is much higher than Fresnel. But on the other hand, it should be kept in mind that the Fresnel collector also has many advantages including low cost and fewer materials for easier and lighter construction. Perhaps, Fresnel collectors can be considered the next generation of parabolic trough collectors provided they improve reliability (El-Ghonemy 2012). Parabolic trough collector, Fresnel and solar tower methods can be used to generate power in the range of 5-200 MW which the efficiency will be between 30 and $40 \%$. The dish Stirling system can be used to generate power in remote areas within the $10 \mathrm{~kW}$ power range. The efficiency of this method is about $10-15 \%$. The temperature in the solar tower can reach very high ranges of about $1000{ }^{\circ} \mathrm{C}$, which can be used directly by the hot air generated in the gas turbine. The heat absorbed by the sun during the day can be stored in melted salt tanks, ceramic or phase change materials, and can be used at night to save energy to make the process sustainable. A hybrid power plant consisted of parabolic trough collectors and salt storage tanks shown in Fig. 32. 
solar beam radiation

(a)

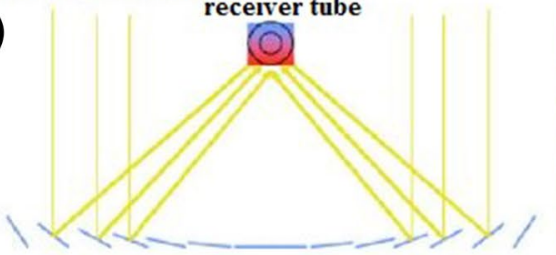

Fresnel Reflector Panels

\begin{abstract}
direct solar beam radiation
\end{abstract}
(b)

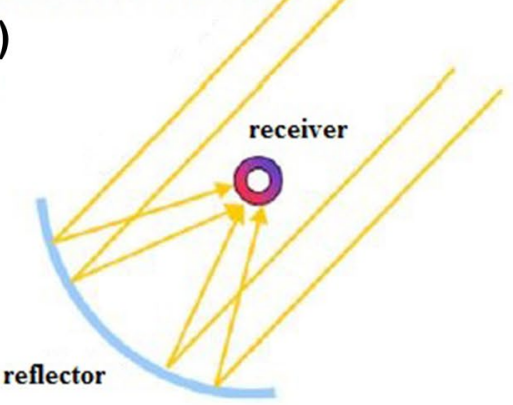

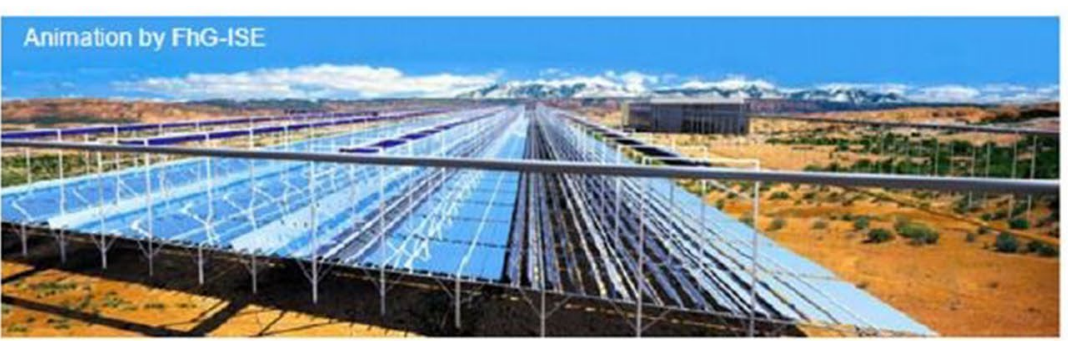

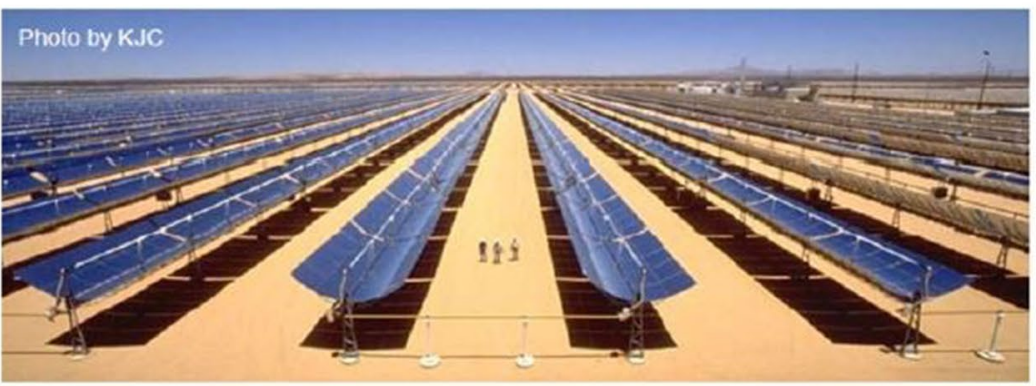

Fig. 31 Fresnel collectors (a) and parabolic trough (b) (El-Ghonemy 2012)

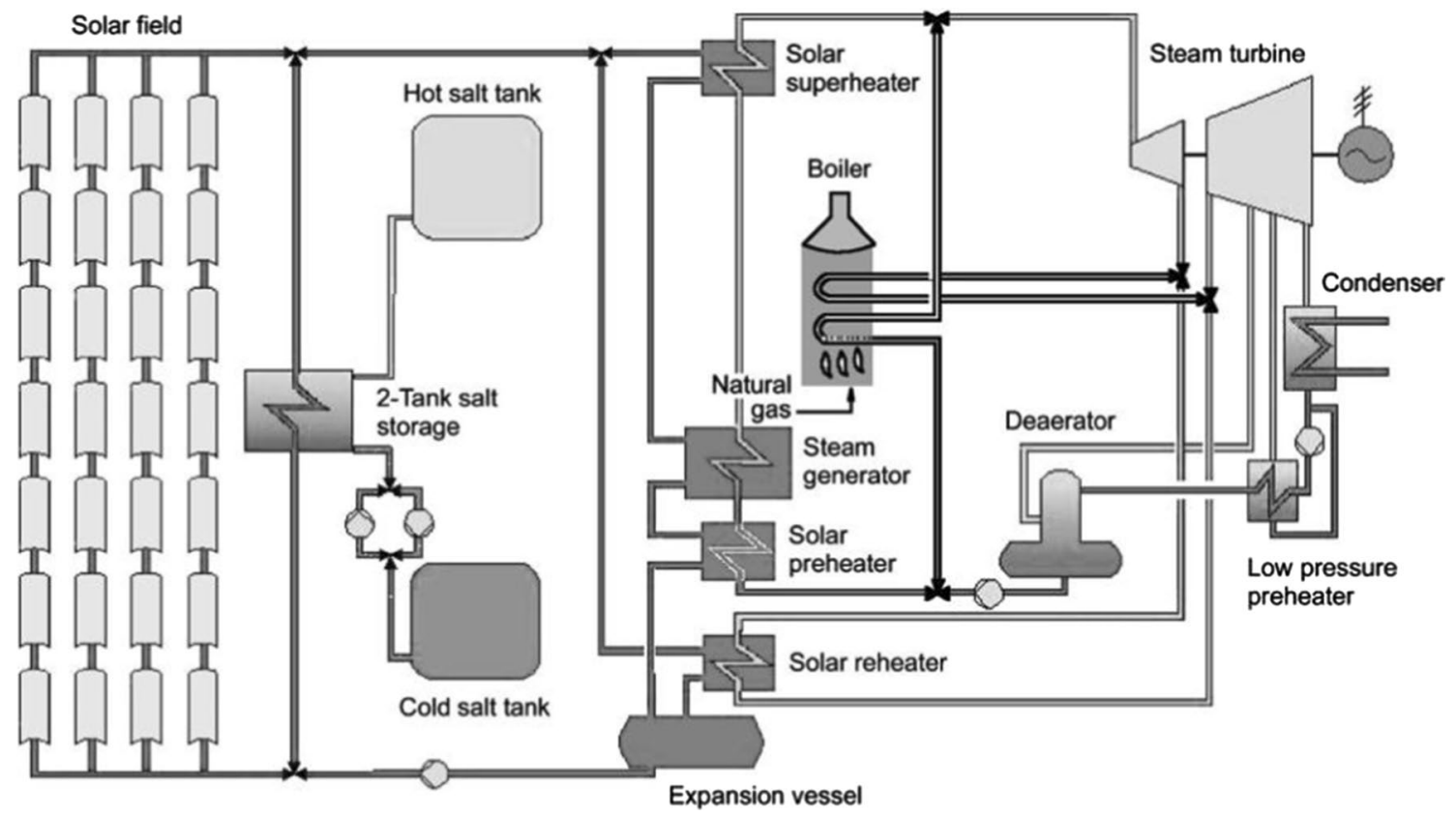

Fig. 32 The hybrid power plant with parabolic trough collectors and salt storage tanks (El-Ghonemy 2012)

Each year, the equivalent of 1.5 million bbl energy is received from the sun per kilometer of land in the Middle East and North Africa. The solar concentrator system, located within one square kilometer of the desert, can provide on average the energy required to desalt $165,000 \mathrm{~m}^{3} /$ year.
Solar-based systems have some disadvantages, such as requiring dynamic daylight tracking methods, which complicate the whole setup and maintenance procedure. So the total cost of construction and maintaining these systems is more expensive than flat-panel collectors. Some of the reasons 
that have raised the cost of using these sun-concentrated methods are:

1. All of these devices require infrastructures to withstand the climate and environmental conditions.

2. All reflecting and concentrating plates must be dynamically monitored throughout the day.

3. Expensive materials for manufacturing plates.

According to the US National Agency for renewable energy studies, return on investment for the concentrated method is $15-25$ years. The challenges of using these concentrated solar energy methods in the field of water desalination include:

1. To be used in arid areas to provide the required desalination energy, they must withstand extremely harsh environmental conditions such as high temperatures and high winds and sandstorms. Solar concentration systems developed in the USA and Europe are generally not designed for such environments. Therefore, the use in these environmental conditions will entail the cost of replacement and repair.

2. Current solar concentration systems are designed for steam generation to drive turbines, not for desalination. Therefore, these devices need to be redesigned for this process (so that the design costs and changes required for this purpose are unclear).

The operating temperature of the MED system is lower, so it requires steam at lower temperatures and pressures, so combining CSP with MED can work much better. A $40 \mathrm{~m}^{3} / \mathrm{d}$ low-temperature solar site has been installed on the La Desirade Island in the Caribbean region. The device consisted of 14 evaporation stages, operating at temperatures between 26 and $65^{\circ} \mathrm{C}$ (Yılmaz and Söylemez 2012). Another multi-stage solar distiller is installed on Takami Island, Japan, with an average annual capacity of $10 \mathrm{~m}^{3} / \mathrm{d}$. This unit has a minimum production capacity of $5 \mathrm{~m}^{3} / \mathrm{d}$ in winter and a maximum of $16.4 \mathrm{~m}^{3} / \mathrm{d}$ in summer. Alongside the complex, there is also a hot water storage tank of $38 \mathrm{~m}^{3}$ which automatically starts the distillation process when the temperature of the tank reaches $75^{\circ} \mathrm{C}$ in summer and $62{ }^{\circ} \mathrm{C}$ in winter.

A solar thermal desalination system built at Al-Azhar University uses PV cells to power the device. The complex contains 3-stage evaporation and is suitable for the desalination of brackish water. The maximum daily capacity of the system is $204.5 \mathrm{~L}$ in June and July, and the lowest daily capacity is $85 \mathrm{~L}$ in December (El-Ghonemy 2012). For situations that require power below $1 \mathrm{MW}$, solar concentrator systems, such as parabolic trough collectors, can hardly compete with the combination of PV cells and wind turbines. In low-capacity desalination markets such as remote and low populated areas, wind and solar power generation methods are well underway. Although the costs of producing freshwater due to solar power at low capacities are higher than those for transporting water to remote areas. It should be borne in mind that in remote areas the reliability of the access to fuel is low and therefore the costs of transport over long distances are high (Shatat et al. 2013). The most important features that make solar energy attractive to the Middle East and in Northern Africa are:

- The unlimited energy source is easily accessible.

- It can be used in combined cycles (electricity generation, cooling and desalination).

- Saving solar energy or working in combination with fossil fuels ensures continued use of this renewable resource.

- Solar concentrating plants can be produced in capacities from a few $\mathrm{kW}$ to several hundred MW.

\section{Wind energy}

Wind turbines use the kinetic energy of wind passing through their aerodynamic blades. The obtained energy from the mechanical state by a generator is converted into electrical energy. Wind turbines are usually divided into vertical and horizontal axis groups based on the direction of their axis. Most of the horizontal axis turbines are used to generate electricity (Yılmaz and Söylemez 2012). Wind energy has been enough to produce all the electricity needed by the world in 2005 . The wind is produced by the difference in atmospheric pressure due to solar energy effects. Of the 173,000 terawatts of solar energy that reaches the Earth, about 1200 terawatts consumed on the atmospheric pressure difference. Small desalination units can be combined with independent wind energy converters and have a high potential for converting saline and brackish water into freshwater. In this case, the supply of freshwater for the islands with wind energy is economically feasible and is more acceptable than the transmission of potable water to the consumers. In addition, wind turbines can be operated in an on-grid connection (Kalogirou 2005).

The Kwinana desalination unit in South Perth, Western Australia, is a successful example of the combination of RO and wind turbines. The site produces about $140 \mathrm{ML} / \mathrm{d}$ of freshwater. The electricity required for the unit is supplied by an $80-\mathrm{MW}$ wind power plant (Goosen et al. 2011). The ENERCON desalination unit is specifically designed to operate with a wind source. The system, combined with a RO desalination unit, can operate at variable capacities (from $12.5 \%$ to $100 \%$ ). Consequently, it can adapt well to changing weather conditions and wind fluctuations (Paulsen and Hensel 2005). The use of wind energy for the desalination of 
seawater, especially for coastal areas with high wind potential, is one of the promising approaches. Energy generated by wind turbines in both electrical and mechanical energy can be used for desalination processes (especially for RO and MVC methods). Different desalination units are installed around the world based on small wind turbines. As with solar energy, fluctuations in power output over time are one of its problems. By combining this system with other renewable energy resources and by using energy storage reservoirs such as batteries, we can observe the improvements in the operating conditions of this source (Ghaffour et al. 2014).

Park et al. investigated the efficiency and cost of water production by several small wind turbine models connected to the RO system in Ghana. The results showed that the $1-\mathrm{kW}$ wind turbine is the most efficient and the least costly unit. Therefore, it is the best option to power the RO system (Park et al. 2009). Impact of various factors on the pricing of each freshwater unit such as climatic conditions, site layout, turbine power, the concentration of saltwater, operating conditions, production capacity, cost of RO and wind turbine is reviewed in Garcia-Rodriguez et al. (Garcia-Rodriguez et al. 2001). Peñate et al. introduced a hybrid system for the use of wind energy by RO. The design has the variable capacity with a nominal production capacity of $1000 \mathrm{~m}^{3} / \mathrm{d}$ which the results are compared with constant production mode. The results showed that due to the variable nature of wind energy, the degassing units can gradually adapt to the energy supplied by the variable sources and maximize the amount of freshwater per year (Peñate et al. 2011). Segurado et al. have been exploring ways to increase the share of renewables on the island of Saint Vincent for combined systems. These methods have led to two scenarios for storing excessed wind energy. The main purpose of this system (Fig. 33) is to reduce costs by raising the share of wind energy in the integrated system (Segurado et al. 2015). The results demonstrated that the island's freshwater capacity is better to be provided by small desalination units. In addition by increasing the capacity of storage tank, the share of wind energy in the system can be increased (with the same installed wind turbine capacity), and the desalination capacity of the island can be $25 \%$ higher by 2020 . Also, it used wind power which provided $56 \%$ more freshwater by wind energy and overall expected costs would be reduced by about $7 \%$.

Gökçek and his colleagues have investigated the technical and economic use of small-scale wind energy to drive a RO unit. The results confirmed that the cost of producing freshwater for a stand-alone system varies from 2962 to 6457 USD per $\mathrm{m}^{3}$ based on the size of the turbine $(6 \mathrm{~kW}$ to $30 \mathrm{~kW}$ ). According to calculations using a $30-\mathrm{kW}$ turbine, $\mathrm{CO}_{2}$ reduction will be 80 tons per year (Gökçek and Gökçek 2016).

The solar energy is available during the day, not at night and, conversely, the wind speed is higher at night. To maximize the use of renewable energy, a hybrid system consisting of solar and wind resources recommended. Ismail et al. have studied and modeled the performance of MED and MVC desalination methods and used renewable resources for desalination at $100 \mathrm{~m}^{3} / \mathrm{h}$. The results showed that the location of the desalination unit, the intensity of solar radiation, wind speed, ambient temperature and water salinity are important factors in system performance (Ismail et al. 2016). Soshinskaya et al. have investigated the techno-economic potential of using renewable energy arrangements for industrial desalination in the Netherlands. Modeling shows that there is a great potential for electricity generation from renewable resources in the region, which can meet the electricity needs of the potable water production unit between $70 \%$ and $96 \%$ independently by using PV cells and wind turbines (Soshinskaya et al. 2014). Mentis et al. were

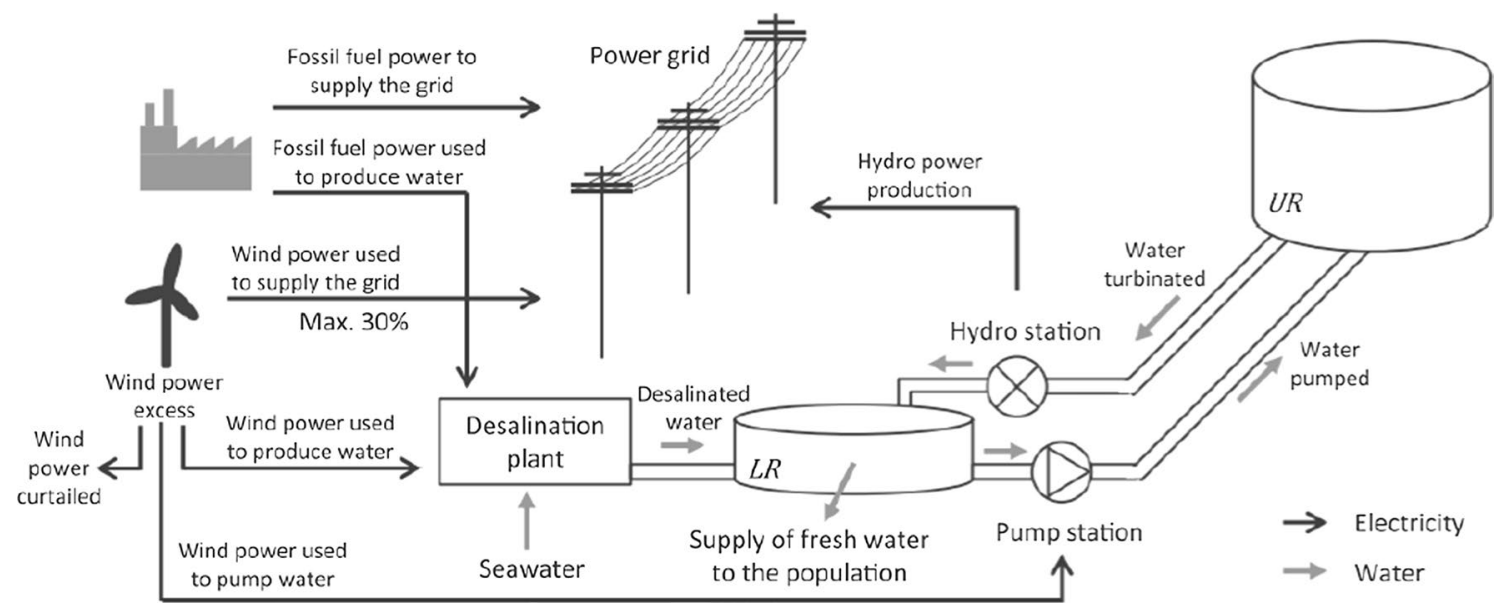

Fig. 33 Combining wind turbine, power grid and desalination plant for producing freshwater (Segurado et al. 2015) 
developed as a method for designing and optimizing desalination capacity with wind and solar renewable energy units in the Greek Islands. In this work, various parameters such as the demand water and the energy required for desalination have been considered. Information on technical performance, available resources and economic calculations has also been used. Modeling results showed that freshwater prices ranged from 1.45 euros per cubic meter for large islands to 2.6 euros per cubic meter for small islands, which is well below the current price of water in these areas (7-9 euros per cubic meter) (Mentis et al. 2016).

For large islands, wind turbines are preferred, while PV cells can also be added to the coupling system. In smaller islands, the computation is much more complex and the answer is not clear because the cost per kilowatt of small wind turbines is far higher than large wind turbines. In these islands, the use of PV cells is competitive and only restricts the design of the cells and their placement. Jordan is the right country for using solar and wind energy sources. The return on investment for some projects using wind energy is 6 years and for PV cells is 2.3 years (Mentis et al. 2016). The results show that the optimal use of renewable sources for electricity generation can be increased by up to $76 \%$, leading to a significant reduction in fossil fuel consumption and $\mathrm{CO}_{2}$ emissions. Studies demonstrated that the economic and environmental benefits of using a hybrid system for producing freshwater on an island can be up to $36 \%$. Smaoui et al. have been looking for a way to find the optimal size of an independent hybrid system including PV, wind and hydrogen, to provide the energy needed to desalinate seawater in the south of Tunisia (Fig. 34). When the electricity generated by wind and solar sources exceeds the load, this power is used in the electrolysis (EL) unit to generate hydrogen. In this case, as far as the integrated system faces a lack of inputted power,

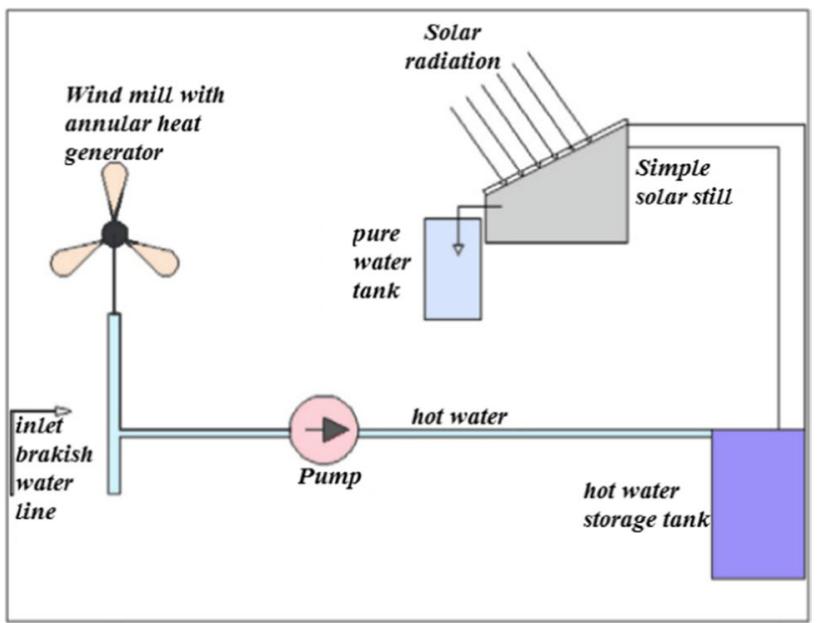

Fig. 35 Producing freshwater by combining solar and wind systems (Moh'd A et al. 2016)

fuel cells (FC) would provide demanded power for the desalination process. Hydrogen storage was selected because of low maintenance costs, low noise and the ability to operate in harsh conditions (Smaoui et al. 2015).

The introduced system provides freshwater for 14,400 person in winter. The mean annual water consumption is $193.6 \mathrm{~m}^{3} / \mathrm{hr}$, and the highest water consumption is $530 \mathrm{~m}^{3} /$ hr. Based on the results of this paper, the combination of wind and PV systems effectively increases the reliability of the power system and reduces the need for energy storage (thus reduces installation costs). An innovative wind energy system for the desalting process has been introduced by Moh'd A et al. They generated thermal energy by the wind system to preheat the water (Fig. 35). During winter as well as at night, the device relies on the thermal energy
Fig. 34 The hybrid system is driven by wind, PV and hydrogen for the desalination process (Smaoui et al. 2015)

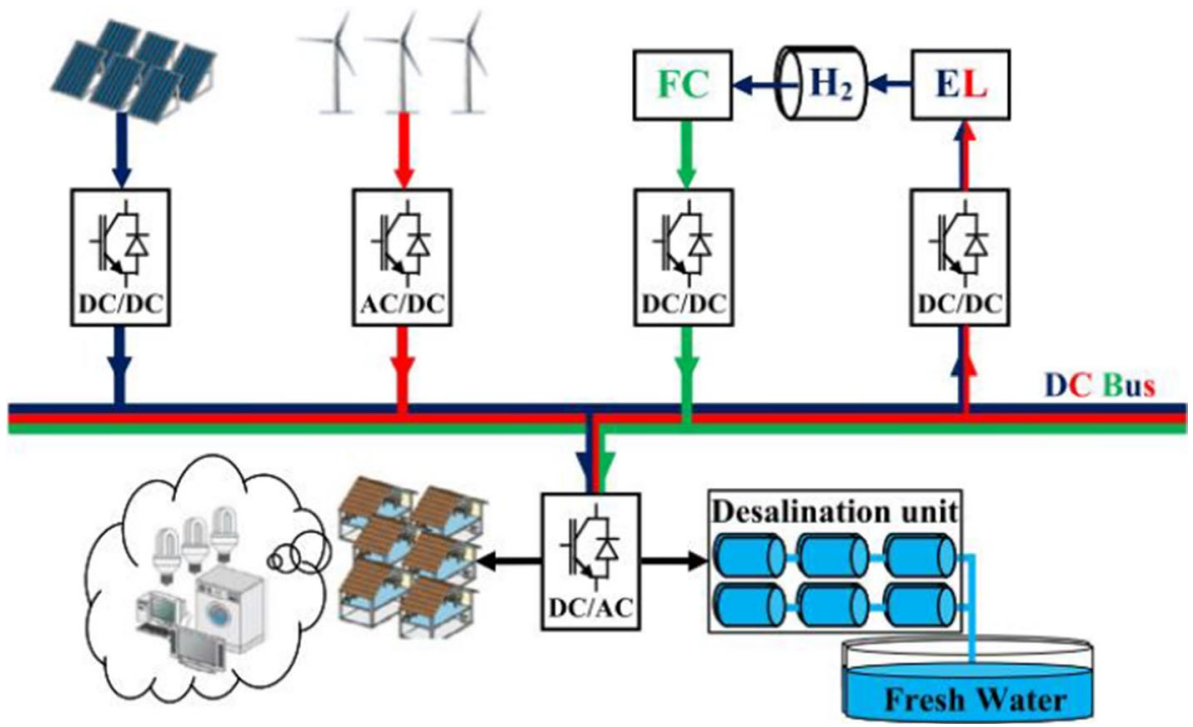


generated. In the summer and during the days, most of the energy is supplied by the sun (Moh'd A et al. 2016).

The ultimate aim of the project is to use a hybrid system to build an independent desalination plant in remote areas. In a wind turbine, the frictional heat energy raises the temperature of the oil, and then in heat exchanger its thermal energy transfers to seawater. The advantage of this method is to increase the desalination capacity and efficiency of the desalination plant as well as the ability to continue operating the desalination plant at night and cloudy days. Henderson et al. have studied the possibility of using a hybrid wind and diesel system that includes a water desalination unit in the Isle of Man area-New Hampshire. The system was designed to supply power during peak hours, to produce and to store potable water. The researchers noted that seawater desalination is technically an attractive option for long-term energy storage and power management (Henderson et al. 2009). There are numerous studies on the combination of wind energy and PV panels for freshwater production, and the results indicated that by using hybrid systems, power supply guaranteed through the year (Nagaraj et al. 2016) (Fig. 36).

\section{Geothermal energy}

Geothermal energy is widely distributed throughout the earth and can be used for heating and power generation that could be used in both thermal and membrane desalination processes. Geothermal resources can produce steam and hot water. The use of geothermal resources for energy production ranked third among all types of renewables. In Iceland, $86 \%$ of heating and $16 \%$ of demanded power are supplied by geothermal energy (Valdez Salas and Schorr Wiener 2012). By the end of 2004, geothermal energy provided $57 \mathrm{TWh}$ as electricity and $76 \mathrm{TWh}$ as heating. When geothermal energy is used for desalination, the need for heat storage resources disappears. On the other hand, the energy provided from this source is more stable than other renewable sources. Kalogirou showed that at a specified depth from the ground, the temperature remained constant throughout the year (Kalogirou 2005).

Geothermal resources are divided into three categories (based on temperature): the low temperature for sources with a temperature below $100{ }^{\circ} \mathrm{C}$, the average temperature for sources with a temperature between 100 and $150{ }^{\circ} \mathrm{C}$ and high-temperature sources with a temperature more than $150{ }^{\circ} \mathrm{C}$. Geothermal wells with a depth of 100 meters can be reasonably used for desalination purposes. Using geothermal energy resources can supply energy all day long. This energy source can be used continuously on the basis of two strategies. There are several ways of combining the geothermal system with desalination units. One of these strategies is the combination of the MED unit. In addition, the usual temperature of geothermal units is in the range of $70-90{ }^{\circ} \mathrm{C}$, which is ideal for the MED method (Gude et al. 2010). In another case, geothermal energy is first used to generate electricity, and then the electricity can be used to set up a RO desalination unit. There are other methods in which hot steam is extracted from the ground to circulate the power-generating turbine, and then, the steam released from the turbine comes into the MED desalination plant. This method can be used very efficiently to absorb geothermal energy and can be used for high water salinity areas such as the Persian Gulf and the Red Sea (Fig. 37).
Fig. 36 Producing freshwater by combining wind, $\mathrm{PV}$ and $\mathrm{RO}$ systems (Nagaraj et al. 2016)

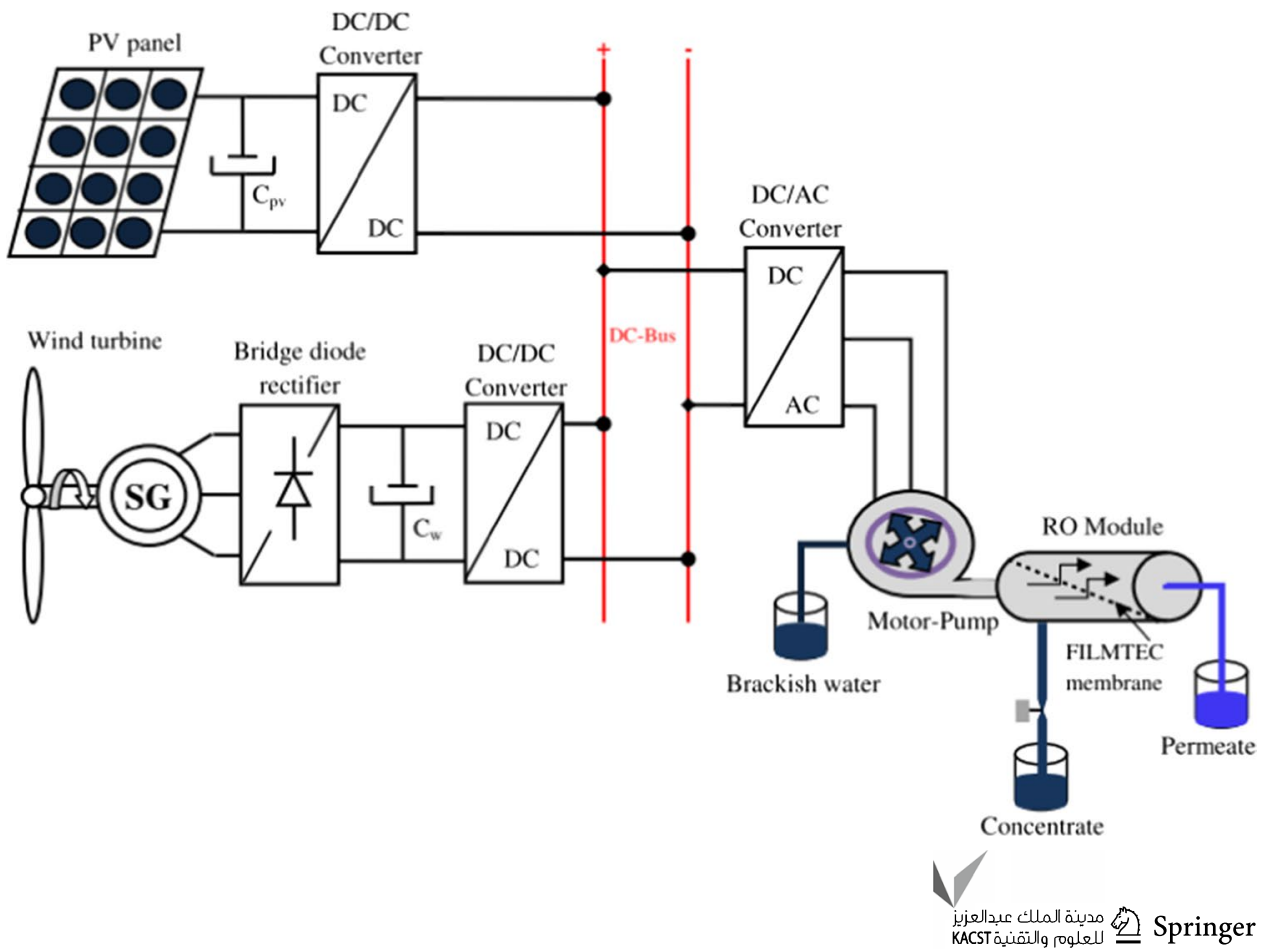




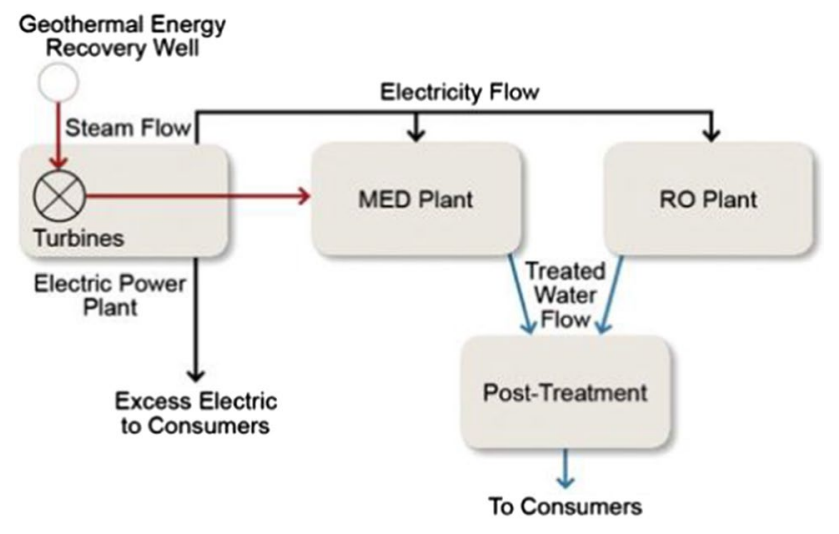

Fig. 37 The combined cycle consisted of RO, MED and geothermal plant for treating water (Gude et al. 2010)

The combinations of geothermal and desalting processes have been investigated in several theoretical and experimental studies (Bourouni and Chaibi 2005; Sarbatly and Chiam 2013; Tomaszewska and Bodzek 2013; Turchi et al. 2017). In particular, a detailed review of the use of geothermal energy for desalination has been carried out by Goosen et al. who examined examples of these systems in Greece, Algeria and Mexico. In this work, the conclusion represented that this type of energy can be very effective in some parts of the world (Goosen et al. 2010). A case study of a geothermal-desalination unit $\left(75-90{ }^{\circ} \mathrm{C}\right)$ with production capacity equaled to $600-800 \mathrm{~m}^{3} / \mathrm{d}$ has been investigated (Manenti et al. 2013). Calise et al. have studied the solar-geothermal system for analyzing the performance of the multipurpose hybrid system (power generation, heating, cooling and desalination). This multifunctional system included CSP, $\mathrm{PV}$, geothermal wells and MED desalination, as well as a set of lithium bromide absorption chillers and other accessories such as a water reservoir and a heat exchanger (Calise et al. 2014).

Solar collectors continuously receive electrical and thermal energy at $100{ }^{\circ} \mathrm{C}$ and are able to inject the surplus power into the grid. The absorbed heat energy can be used for a variety of purposes such as ambient heating as well as the supply of potable water. They also use this solar power to launch an absorption chiller in the summer. Finally, the rest of the thermal energy is combined with the low-temperature thermal energy of the geothermal well $\left(80^{\circ} \mathrm{C}\right)$ and used in the MED unit for desalination. Geothermal energy is also used to supply hot water at $45{ }^{\circ} \mathrm{C}$. In winter, solar energy reduced noticeably, resulting in less heat and electricity production. For this reason, much of the energy required for desalination comes from geothermal energy in winter. The results of the performance analysis of this system are acceptable, and from the economic point of view, the system's adaptability should be greatly enhanced by the increased

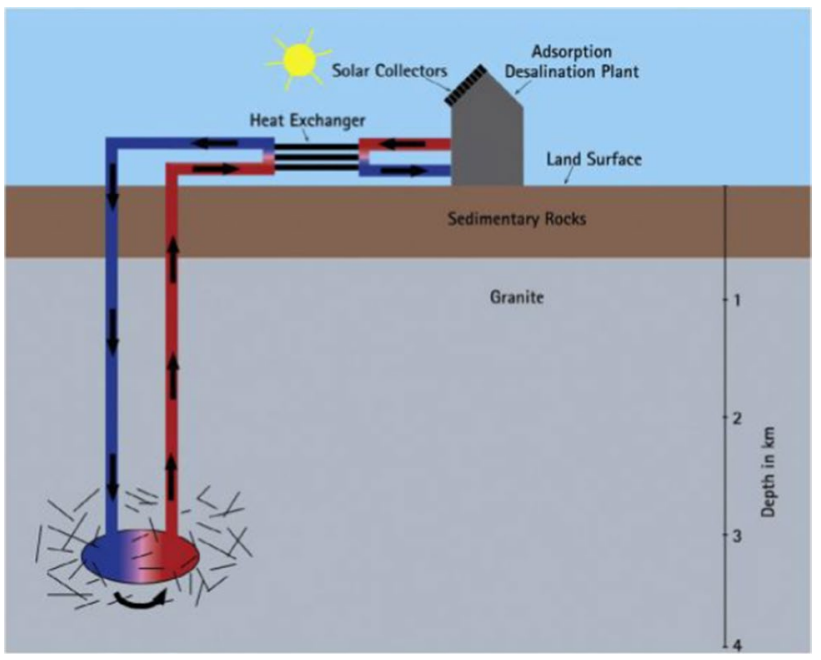

Fig. 38 The combined system consisted of solar and geothermal energies for freshwater production (Missimer et al. 2013)

use of hot water. Figure 38 displays the combined system by using geothermal and solar energy for the desalination process. The design requires a heat storage tank to meet the need for desalination units at night and geothermal energy at this time (Missimer et al. 2013).

\section{Wave energy}

Wave power use is developing technology with high investment costs, which has challenges in its implementation. Sustainable use of this energy requires new strategies to reduce the investment cost and enable the extraction of energy from small sources. With the help of this technology, produced power can be used in desalination units (especially RO). The total produced power by the waves in the world is estimated to be about 2 TW (Sharmila et al. 2004).

Studies by Davies in 2005 have been conducted to combine wave power with desalination plants. The research showed that along the arid and sunny beaches, the desalination unit with the power of the waves can optimally supply the water needed to irrigate a strip of land with $0.8 \mathrm{~km}$ width by waves with a minimum height of one meter. The amount of energy available to the waves varies from region to region. The ratio of available power to water scarcity in Morocco is $16 \%$ and Somalia is $100 \%$. It should be noted that the use of wave energy for desalination units has so far been limited to laboratory cases. The biggest problem with wave power is that it fluctuates over time (like wind energy), which is a failure in the sustainability of desalination units (Foteinis and Tsoutsos 2017; Falcão 2014; Burn et al. 2015; Davies 2005; Corsini et al. 2015).

A desalination pilot plant (DPP) based on wave power installed on Garden Island, Australia. The utilized device 
Fig. 39 The combined system consisted of CETO technology and DPP (Viola et al. 2016)

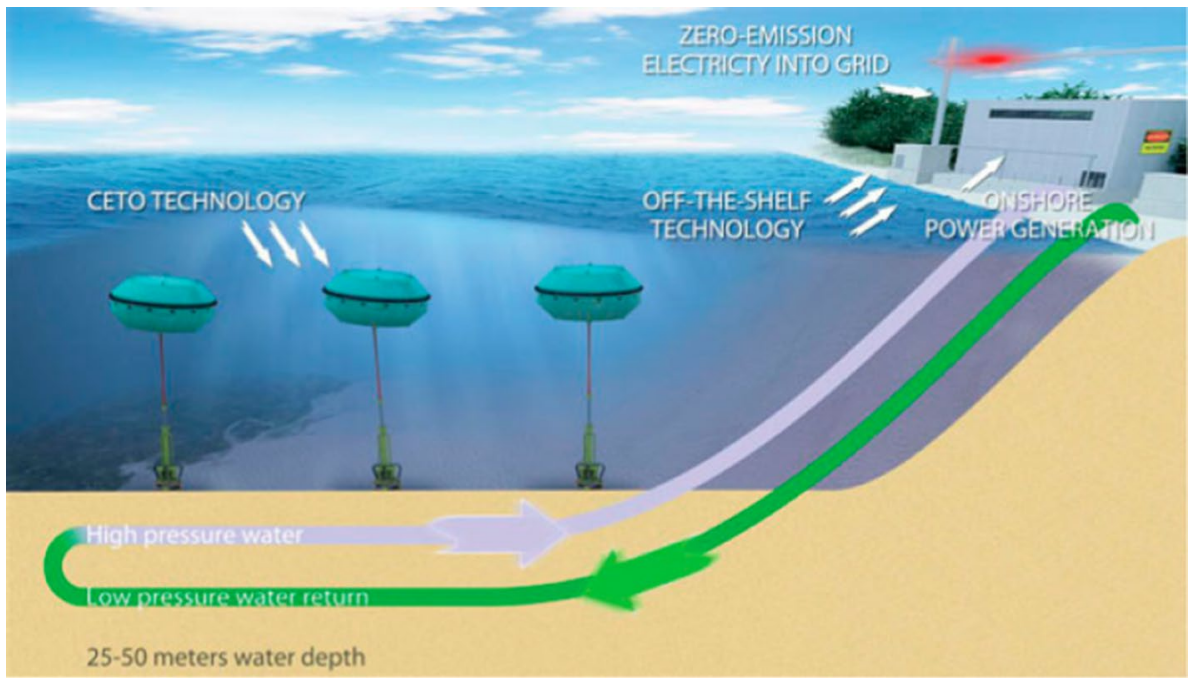

is called CETO. This innovative system uses numerous buoys to exploit the wave power to pump the seawater into a RO unit for producing freshwater, in which the production capacity is $150 \mathrm{~m}^{3} /$ day (Viola et al. 2016). Figure 39 indicates that the DPP-CETO system how it works.

The world's first commercial-scale wave energy was installed in Australia and connecting to the electricity grid uses produced power for the desalination process (Alkaisi et al. 2017). With the aid of DEIM converters, the production of electric power in Pantelleria Island in Italy with wave power potential equaled to $7 \mathrm{~kW} / \mathrm{m}$ became achievable. In this case, the consumption of diesel fuels (1391 tons) and $\mathrm{CO}_{2}$ emission (4406 tons) is eliminated, yearly. In this way, by integrating renewable sources with desalination processes, energy dependence on fossil fuels is avoided (Franzitta et al. 2016). Studying effective specifications in wave energy convertor (e.g., energy requirements and structure features) is carried out (Salter et al. 2010).

The deep-sea RO desalination facility to meet the needs of providing freshwater and reducing $\mathrm{CO}_{2}$ emission has been designed. In this system, energy consumption is significantly lower than in other systems. The introduced system has a longer membrane lifetime in comparison with other strategies (Dashtpour and Al-Zubaidy 2012).

\section{Performance analysis}

\section{Energy analysis}

In order to declare the system performance and indicate improvement potentials in considered component, energy and exergy analysis play remarkable roles. Obtained results from each one can illustrate the losses and ineffective parameters through the system function. Performed analysis on the amount of energy required for different desalination technologies, showed that humidification and dehumidification desalination has the highest value equaled to $12 \mathrm{kWh} / \mathrm{m}^{3}$ as thermal energy, while the most energy required as electrical energy belongs to freezing $\left(11.9 \mathrm{kWh} / \mathrm{m}^{3}\right.$ ) (Youssef et al. 2014). In 2011, energy analysis of the RO process has been performed. The final energy requirement in the cross-flow RO process is determined by Eq (2) (Liu et al. 2011).

$W=2.05 \times 10^{-5} \frac{C_{0}}{1-R}$

where $C_{0}$ is the initial salt concentration of feedwater and $R$ is the recovery defined as $\mathrm{Eq}(3)$.

$R=\frac{V}{V_{0}}$

That $V$ and $V_{0}$ are the initial volumes of feedwater and the volume of permeate produced, respectively.

The thermodynamic analysis of osmotic energy recovery at a $\mathrm{RO}$ unit has represented that substantial potential for additional reduction in energy consumption can be in the high chemical potential contained in RO concentrate using salinity gradient power technologies. So, osmotic energy recovery (OER) is presented as an auxiliary option. It is noteworthy to mention that by increasing the RO feed concentration, specific energy consumption for the considered system consisted of RO and OER will be increased (Feinberg et al. 2013). Equation (4) represents the impact of OER in coupling with $\mathrm{RO}$ in energy balance where $\mathrm{E}$ is the associated energy.

$E_{\text {net }}=\mathrm{ERO}-\mathrm{EOER}$

Energy analysis of a solar-powered low-temperature desalination system is performed in 2017. In this system, saline 
water is desalinated by evaporation at ambient temperatures under low pressures. For achieving demanded thermal energy, various heat resources were considered: direct solar energy, photovoltaic energy and low-grade heat source (Gude et al. 2017). The energy efficiency of the desalination system is as Eq. (5).

$\eta=\frac{\dot{m}_{\mathrm{f}} h_{\nu}}{\dot{Q}_{\text {in }}}$

where $m$ is the mass flow rate $(\mathrm{kg} / \mathrm{h}), \mathrm{h}$ is specific enthalpy $(\mathrm{kJ} / \mathrm{kg})$, and $Q$ is the heat transfer rate $(\mathrm{kW})$.

In other works, the energy analysis of a solar-driven cogeneration system has been studied (Kouta et al. 2017). In this system by defining a Brayton cycle that was combined with multiple-effect evaporation with thermal vapor compression, the desalination plant has powered. The results demonstrated that $6.25 \%$ of efficiency rise outcomes from utilizing the recompression cycle compared to the regeneration cycle.

The entropy generation provides useful results for analyzing desalination systems in order to determine the main sources of losses. However, it is noteworthy to mention that entropy generation analysis is principally beneficial for finding the improvement potentials. By evaluating second law efficiency for different process demonstrations which system is operating more reversible (Fig. 40), these results are useful for highlighting which processes have the potential for additional progress. By comparing second law efficiency for each by operating under various conditions, allows understanding the irreversibilities in the system (Mistry et al. 2011).

In Li 2011, reducing the specific energy consumption (SEC) in RO desalination is carried out. The cost of energy in the context of the RO process is usually described by
SEC (or the electrical energy demands per cubic meter of permeate). The modified SEC ( $\left.\mathrm{SEC}_{\mathrm{m}}\right)$ to reflect the pump efficiency for a single-stage RO is demonstrated in $\mathrm{Eq}(6)$.

$\mathrm{SEC}_{\mathrm{m}}=\eta_{\text {pump }} \mathrm{SEC}=\frac{Q_{\mathrm{f}} \Delta P}{Q_{\mathrm{p}}}$

In this case, $\eta_{\text {pump }}$ is pump efficiency, $Q_{\mathrm{f}}$ is the feed flow rate $\left(\mathrm{m}^{3} / \mathrm{s}\right)$, and $Q_{\mathrm{p}}$ is permeated flow rate $\left(\mathrm{m}^{3} / \mathrm{s}\right)$.

Obtained results from an innovative energy analysis represented that by increasing the salinity of seawater minimum energy consumption associated with considered process raises and by increasing the salt concentration in produced freshwater, this value will decrease. The minimum energy consumption based on the Gibbs free energy is shown in Eq (7) (Zhao et al. 2019).

$$
\begin{aligned}
W_{\text {Ideal }}= & G_{\mathrm{H}}-G_{\mathrm{L}}=n_{\mathrm{water}}\left(\mathrm{RT} \ln \left(\frac{c_{\mathrm{fw}}}{c_{\mathrm{fw}}+2 c_{\mathrm{fw}}} / \frac{c_{\mathrm{sw}}}{c_{\mathrm{sw}}+2 c_{\mathrm{sw}}}\right)\right. \\
& \left.+n_{\mathrm{salt}} \mathrm{RT} \ln \left(\frac{c_{\mathrm{fw}}}{c_{\mathrm{sw}}}\right)\right)
\end{aligned}
$$

where $G_{\mathrm{H}}$ and $G_{\mathrm{L}}$ represent the Gibbs free energy of freshwater (fw) and seawater (sw), $c$ is the molarity of salt and water, and $\mathrm{n}$ is the amount of considered substance in freshwater.

For calculating the thermal efficiency of the membrane distillation $\left(\eta_{\mathrm{T}}\right)$ process, which is the ratio of the quantity of inputted heat and the actual amount that used for the evaporation process is as $\mathrm{Eq}(8)$.

$\eta_{\mathrm{T}}=\frac{Q_{\mathrm{V}}}{Q_{\mathrm{V}}+Q_{\mathrm{C}}}$

where $Q_{\mathrm{c}}$ and $Q_{\mathrm{v}}$ are the thermal energy conducted through the membrane and the latent heat of vaporized molecules, respectively (Khayet 2013).
Fig. 40 Comparing the second law efficiency for various desalination processes which RO has a considerably higher value than the other processes (Mistry et al. 2011)

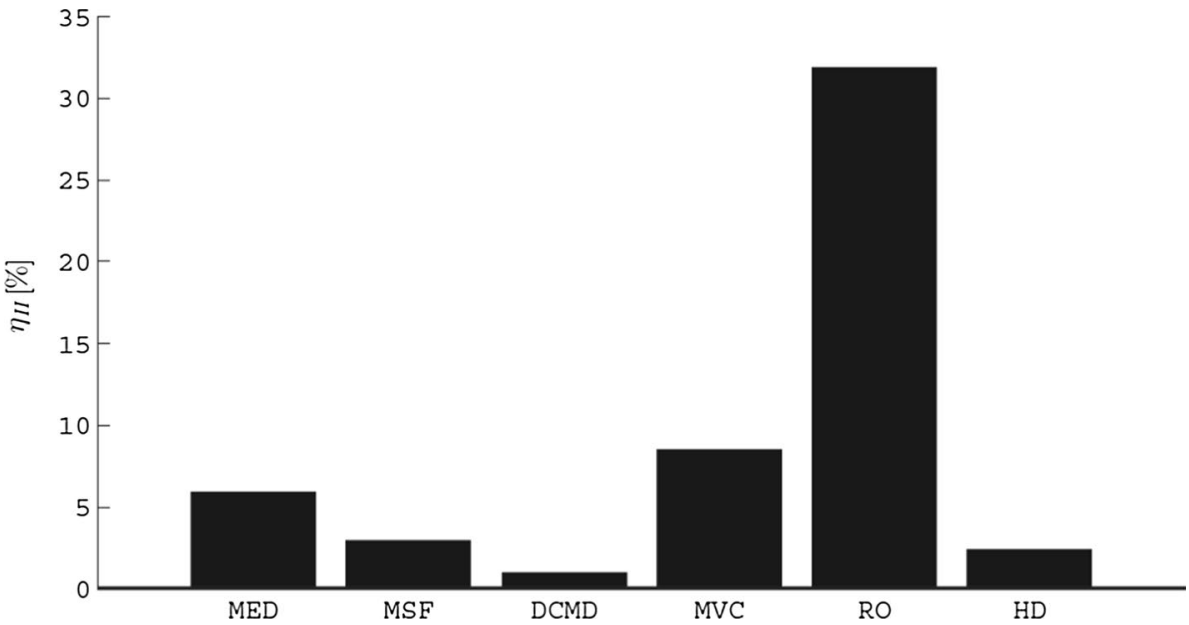

年 KACST Springer 


\section{Exergy analysis}

Energy and exergy are powerful tools for analyzing the power system. The energy formulations are derived from the first law of thermodynamics; however, the exergy equations are taken from both the first and second laws of thermodynamics. Furthermore, energy values cannot become absolute zero, but exergy quantity can reach to this value (Dincer and Rosen 2012). Exergy is a fundamental parameter for evaluating the performance of the power systems. In this field by computing the values of exergy destruction and irreversibility for various components, determining the optimal values for system design parameters becomes approachable (Behzadi et al. 2018; Ehyaei et al. 2019). The total exergy associated with a considered stream can be calculated as Eq (9).

$\mathrm{Ex}_{\mathrm{T}}=\mathrm{Ex}_{\mathrm{Ph}}+\mathrm{Ex}_{\mathrm{Ch}}+\mathrm{Ex}_{\mathrm{K}}+\mathrm{Ex}_{\mathrm{P}}$

where $\mathrm{Ex}_{\mathrm{K}}$ and $\mathrm{Ex}_{\mathrm{P}}$ are kinetic and potential exergy, respectively (that in most of the case are ignored). The physical exergy $\left(\mathrm{Ex}_{\mathrm{Ph}}\right)$ is defined as the maximum of useful theoretical work. The chemical exergy $\left(\mathrm{Ex}_{\mathrm{Ch}}\right)$ relates to the difference in the chemical composition of a chemical system to the reference environment and subsequent chemical exergy (Bejan and Tsatsaronis 1996).

$\mathrm{ex}_{\mathrm{ph}}=\left(h-h_{\mathrm{o}}\right)-T_{\mathrm{o}}\left(s-s_{o}\right)$

$\mathrm{ex}_{\text {mix }}^{\mathrm{ch}}=\left[\sum x_{i} \mathrm{ex}_{i}^{\mathrm{ch}}+\mathrm{RT}_{\mathrm{o}} \sum x_{i} \ln x_{i}\right]$

It is necessary to mention that in Eq. 10, $\mathrm{h}$ and s are enthalpy and entropy, respectively, and $\mathrm{T}_{\mathrm{o}}$ is ambient temperature $\left({ }^{\circ} \mathrm{K}\right)$.

By using the first and second laws of thermodynamics, the exergy balance could be achieved (Bejan and Tsatsaronis 1996).

$\dot{\mathrm{Ex}} \mathrm{Q}_{\mathrm{Q}}+\sum \dot{m}_{i} \mathrm{ex}_{i}=\sum \dot{m}_{\mathrm{e}} \mathrm{ex}_{\mathrm{e}}+\dot{\mathrm{Ex}} \mathrm{x}_{\mathrm{W}}+\dot{\mathrm{E}} \mathrm{x}_{\mathrm{D}}$

$\dot{\mathrm{Ex}}_{\mathrm{Q}}=\left(1-T_{\mathrm{o}} / T_{i}\right) \dot{Q}_{i}$

$\dot{\mathrm{E}} \mathrm{x}_{\mathrm{W}}=\dot{W}$

$\dot{\mathrm{Ex}} \mathrm{D}_{\mathrm{D}}=\sum \dot{\mathrm{Ex}} \mathrm{x}_{i}-\sum \dot{\mathrm{E}} \mathrm{x}_{\mathrm{e}}=\mathrm{T}_{\mathrm{o}} \dot{\mathrm{S}}_{\mathrm{gen}}$

where $T_{0}, T_{\mathrm{i}}, W, Q$ and $S_{\text {gen }}$ are ambient temperature $\left({ }^{\circ} \mathrm{K}\right)$, inlet temperature $\left({ }^{\circ} \mathrm{K}\right)$, rate of associated work $(\mathrm{kW})$, rate of inlet heat and the rate of entropy generation $(\mathrm{kW})$, respectively.

Obtained results from Al-Weshahi et al. 2013 depicted that by analyzing the MSF desalination plant in terms of exergy,
$55 \%$ of the exergy destruction belongs to the heat recovery stages. It was established that exergy efficiency has the potential to be optimized from $5.8 \%$ to $14 \%$ by recovering the hot distillate water from heat recovery stages. Theoretical and experimental exergy analysis for a solar desalination system has been performed. The outcomes represented that the designed system has high exergy efficiency. Also, there is a potential to increase overall exergy efficiency by shortening the length of humidification tower, decreasing temperature of entered air and increasing in diameter of the tower (Nematollahi et al. 2013).

In several studies, exergy content plays as a criterion for investigating the system performance, and examples include exergy and economic evaluations of combined solar organic rankine with RO process (Nafey and Sharaf 2010), exergy study of micro-organic rankine cycles for a small-scale solardriven RO system (Tchanche et al. 2010), exergy analysis of using phase change material (PCM) in heat storage system that combined with desalination unit (Asbik et al. 2016), energy and exergy analyses of a combined desalination and CCHP system driven by geothermal energy (Mohammadi and Mehrpooya 2017) and exergy analysis of a solar desalination unit with humidification (Deniz and Çınar 2016).

For expressing exergy terms, seawater has been modeled as a solution of different ionic species, which, with the aid of the Drioli model, exergy rates are calculated at the process stages (Drioli et al. 2006; Criscuoli and Drioli 1999; Macedonio and Drioli 2010).

$\dot{\mathrm{Ex}}=\dot{m}\left[c\left(T-T_{0}\right)-c T_{0} \ln \left(\frac{T}{T_{0}}\right)+\frac{P-P_{0}}{\rho}-N_{\text {solvent }} \mathrm{RT}_{0} \ln x_{\text {solvent }}\right]$

$N_{\text {solvent }}=\frac{\left(1000-\sum \frac{C_{i}}{\rho}\right)}{\mathrm{MW}_{\text {solvent }}}$

$x_{\text {solvent }}=\frac{N_{\text {solvent }}}{\left[N_{\text {solvent }}+\sum\left(\frac{\beta_{i} C_{i}}{\rho \mathrm{MW}_{i}}\right)\right]}$

where $c$ is the specific heat capacity $(\mathrm{kJ} / \mathrm{kg} \mathrm{K}), P$ is the pressure ( $\mathrm{kPa}), T$ is the temperature $(\mathrm{K}), \rho$ is the density of the solution, $N$ is number of moles, $x$ is mole fraction, $C_{\mathrm{i}}$ is concentration ( $\mathrm{g} / \mathrm{l}), M W$ is the molar mass, and $\beta$ is number of particles (Fitzsimons et al. 2015).

Finally, the suitability of a process can be evaluated by the exergy efficiency of the considered process. This value could be achieved as a ratio of outputted exergy to the inputted one. Equation (19) represents the mentioned relation for exergy efficiency.

$\varepsilon=\frac{\mathrm{Ex}_{\text {output }}}{\mathrm{Ex}_{\text {input }}} \times 100$ 
For optimizing energy systems, the value of exergy efficiency plays an important role. In this case, in the optimization procedure, the exergy efficiency could be considered as an objective function that maximizes its value is intended.

\section{Exergoeconomic analysis}

In conventional exergoeconomic analysis, the balance for a component that is working in a steady state is usually as Eq (20) (Bejan and Tsatsaronis 1996).

$\dot{C}_{\mathrm{P}, \text { tot }}=\dot{C}_{\mathrm{F}, \text { tot }}+\dot{Z}_{\mathrm{tot}}^{\mathrm{CI}}+\dot{Z}_{\mathrm{tot}}^{\mathrm{OM}}$

In Eq (20), $\dot{C}_{\mathrm{P}}, \dot{C}_{\mathrm{F}}, \dot{Z}^{\mathrm{CI}}$ and $\dot{Z}^{\mathrm{OM}}$ are cost rate of production, cost rate of fuel, rate of investment cost and rate of operating and maintenance cost, respectively. The cost balance represents that the cost of the system's production is equivalent to the rate of fuel cost, rate of the investment costs and rate of maintenance cost. $\dot{C}$ is the cost rate related to the exergy flow (mass flow, work or heat transfer). For that reason, for a component that receives heat and work, it could be presented as Eq. 21 (Bejan and Tsatsaronis 1996).

$\sum_{\mathrm{e}}\left(c_{\mathrm{e}} \dot{E}_{\mathrm{e}}\right)_{\mathrm{k}}+c_{\mathrm{w}, \mathrm{k}} \dot{W}_{\mathrm{k}}=c_{\mathrm{q}, \mathrm{k}} \dot{E}_{\mathrm{q}, \mathrm{k}}+\sum_{i}\left(c_{i} \dot{E}_{i}\right)_{\mathrm{k}}+\dot{Z}_{\mathrm{k}}$

In Eq. (21), $\dot{E}_{\mathrm{i}}, \dot{E}_{\mathrm{e}}, \dot{E}_{\mathrm{q}}$ and $\dot{W}$ are the rate of inputted exergy, the rate of outputted exergy, the rate of exergy transfer by heat and the rate of exergy transfer by production in the component, respectively. Furthermore, $\mathrm{c}$ is the cost per exergy. The function of defining the cost of technology is represented as Eq. 22.

$\dot{Z}_{\mathrm{K}}=\frac{\mathrm{PEC}_{\mathrm{K}} \times \Phi \times \mathrm{CRF}}{N \times 3600}$

While $\Phi$ is the maintenance factor and it is considered to be $1.06, \mathrm{CRF}$ is the recovery factor of capital and it is expressed by the annual interest rate $(i)$ and the time period for the annual repayment $(n)$ specified by operating hours of the plant per year.
$\mathrm{CRF}=\frac{i \cdot(1+i)^{n}}{(1+i)^{n}-1}$

In this field, exergoeconomic analysis of $\mathrm{HDH}$ desalination systems driven by heat pump (HP) has been carried out. Obtained results from this study declared that the cost of desalinated water evaluated for HP-HDH air-heated system and HP-HDH water-heated cycle varies from $4.61 \$ / \mathrm{m}^{3}$ to $5.49 \$ / \mathrm{m}^{3}$ and $6.00 \$ / \mathrm{m}^{3}$ to $7.14 \$ / \mathrm{m}^{3}$, respectively (Lawal et al. 2018). In another study, an exergoeconomic analysis of a forward-feed multi-effect mechanical VC desalination system has been performed. The quantities of specific energy consumption, exergy efficiency and cost of production for this analysis are calculated to be between 7.67 and $11.36 \mathrm{kWh} / \mathrm{m}^{3}, 7$ and $11 \%$ and $0.86-1.19 \$ / \mathrm{m}^{3}$, respectively (Jamil and Zubair 2017). In this study, the associated cost with each component is presented in Table 11:

In 2017, an exergoeconomic evaluation of a CSP plant in combination with a desalination system has been performed. In this study, two operational cases studied: (1) maximizing the water output and (2) maximizing the electricity output. The costs of electricity generation are estimated to $0.2051 \mathrm{USD} / \mathrm{kWh}$ and $0.2079 \mathrm{USD} / \mathrm{kWh}$. The costs of water generation are from $0.8464 \mathrm{USD} / \mathrm{m}^{3}$ to $0.3991 \mathrm{USD} / \mathrm{m}^{3}$ for the two cases (Wellmann et al. 2018). In optimum combination of site utility steam network with MED-RO desalination with the help of exergoeconomic analysis, it was found that the cost of fuel contributed the most at $88 \%$. Obtained results declare that the associated cost with investments and O\&M (operating and maintenance) contributed at 9\% and 3\%, respectively (Manesh et al. 2013). Exergoeconomic analysis for multi-effect evaporation-absorption heat pump desalination indicated that multi-effect evaporation has the maximum cost of product $1301 \$ / \mathrm{GJ}$, while the cost of fuel is $13.8 \$ / \mathrm{GJ}$ (Esfahani et al. 2015).
Table 11 Capital costs for facilities in the desalination system (Jamil and Zubair 2017; El-Mudir et al. 2004)

\begin{tabular}{lll}
\hline Component & Cost function & Variables \\
\hline Feed heater & $Z_{\mathrm{FH}}=1000\left(12.86+A_{\mathrm{HT}}^{0.8}\right)$ & $\begin{array}{l}A: \text { area }\left(\mathrm{m}^{2}\right) \\
\text { HT: horizontal tube }\end{array}$ \\
Evaporator & $Z_{\mathrm{EV}}=430 \times 0.582\left(\mathrm{UA}_{\mathrm{HT}} \Delta P_{\mathrm{t}}^{-0.01} \Delta P_{\mathrm{s}}^{-0.1}\right)$ & $\begin{array}{l}\text { : overall heat transfer } \\
\text { coefficient }(\mathrm{kW} / \\
\left.\mathrm{m}^{2} \cdot \mathrm{K}\right)\end{array}$ \\
& & $o:$ outlet condition \\
Compressor & $Z_{\text {comp }}=7364\left(\dot{m}_{\nu}\left(\frac{P_{0}}{P_{i}}\right)\left(\frac{\eta_{\text {Comp }}}{1-\eta_{\text {Comp }}}\right)^{0.7}\right)$ & $i:$ inlet condition \\
& & $\nu:$ vapor \\
Pump & $Z_{\text {pump }}=1000 \times 32 \times 0.000435 \times\left(\dot{m}_{\text {water }}\right) \Delta P^{0.55}\left(\frac{\eta_{\text {pump }}}{1-\eta_{\text {pump }}}\right)$ & $\eta:$ efficiency \\
& &
\end{tabular}




\section{Future prospects}

Researches trend represents that the desalination systems are improving and their progress is endless. Reducing fossil fuel reserves and raising concerns about environmental and economic aspects, have increased the focus on renewable energy. Investigating the researches and studies on desalination processes and renewable energy systems, the future prospects for these systems include the following:

- By considering the impact of bio-organic molecules on membrane materials adsorption would be caused in reducing the cost of desalination energy in the future, extending and lifetime, and improving cleaning techniques (Ridgway et al. 2017).

- Next examinations on membrane materials should focus on the actual applications of high-performance FO membranes for proving their performance in realistic desalination processes. The results show that future effort should pay attention to reducing pressure-retarded osmosis membrane fouling and realizing long-term performance stability. Furthermore, stability analysis of the hybrid system consisted of RO and RPO powered by renewables can represent invaluable outcomes (Wang et al. 2018).

- Achieving sustainability in the energy, economic and environmental sectors can be the foundation of future development. Sustainability entails state-of-the-art membrane materials. Conversely, thermally driven desalination systems can achieve efficiency at $25 \%$. The membrane sector needs about 15 years for gaining experience, but the thermal sector would be accomplished in 1 or 2 years (Shahzad et al. 2017). In this field producing more water and less greenhouse gas is a favorite (Fane 2018). Also, by eradicating the high energy consumption in desalination systems, approaching to the sustainability in the energy sector is more accessible (Lee et al. 2019).

- Future trends consider the use of hybrid renewables in addition to solar-powered FO and dewvaporation. Upcoming outlooks of solar desalination contain shifting to other less explored desalination methods. Dewvaporation is an innovative method in solar-powered desalination. In dewvaporation process, saturated steam is used as a carrier gas to vaporize water from the saline feed as distillate. Focusing on this process and utilizing it in hybrid renewables would increase the efficiency in desalination systems (Ahmed et al. 2019).

- Increasing the attention to FD systems can provide a new opportunity for increasing the efficiency of the desalination process. The main advantage of indirect freeze desalination is the production of refrigerant-free water, which determines the future usage of product water (Kalista et al. 2018).
- Using ocean thermocline energy for the desalination system is an innovative strategy for producing freshwater. In this method, by exploiting low-temperature differential between surface hot water and deep-sea cold water, freshwater would be produced (Ng and Shahzad 2018).

\section{Conclusion}

Nowadays, global demands for access to freshwater are increasing rapidly as its resources are decreasing due to increased use of natural resources and climate change, especially in arid areas. One way to address this challenge is desalinating seawater and brackish water to meet the needs of communities. Water desalination is a highly energy-intensive process that today almost all of this energy provides from fossil fuel sources. The use of these resources faces several major problems, such as the uneven distribution of these resources on the Earth, price fluctuations of energy carriers around the world, the difficulty of transporting these resources to remote areas and the environmental problems caused by the use of these fuels. Nowadays, most of the desalination plants are located in the Persian Gulf, where has suitable potentials with high availability and low cost of fossil fuels.

Finally, it is important to note that reverse osmosis and multi-effect distillation techniques are the leading methods in the desalination market and extensive studies are carried out to increase efficiency and reduce investment costs for these two processes. Additionally, most desalination plants in the world use solar and wind energy (in the renewable sector). Developments of energy networks across countries would be certainly costly and by supplying demanded energy for remote areas, the problem is multiplied. By using renewables such as solar, wind, geothermal or other forms of local energy resources, dealing with this problem becomes solvable. It is important to mention that renewable sources have variable behaviors in each region, whereas in some areas access to them is problematic. Therefore, utilizing a system that has been driven by an individual renewable source has a high risk in terms of cost and performance. A true combination of two or more energy systems with particular resources called a hybrid system is an authenticated option that would be suitable to face this problem. By focusing on different aspects of desalination systems and producing freshwater, this chapter provides the greatest details related to these issues: 1. comprehensive information about energy, exergy, economic and environmental analysis, 2. plenty of case studies that focused on the related issues and 3. practical data of innovative sites.

The most important outcomes of this chapter are as follows: 
- Desalination process is a hi-tech process that categorized as a high energy consumer; nonetheless, desalination is the only feasible solution in some areas, where the accessibility of freshwater is limited, while brackish water or seawater is available.

- As most of the energy generation processes entail significant amounts of water, and water requires energy for treatment and desalination, subsequently these two resources are inseparably connected.

- At present, desalination processes are very expensive with low energy efficiency, which suggesting innovative methods that will reduce the costs would make them more affordable and economical.

- Reverse osmosis is a practical and conventional method in this field. Reverse osmosis is the widely used method for producing freshwater that $69 \%$ of desalination plants use this system.

- Considered strategies in the fields of construction and development are expected to reach 20,000 desalination plants until 2020. In this case, increasing the attention on the renewables (especially hybrid plants) has economic and environmental benefits.

- In terms of energy and economic, the productivity of renewable energy systems in coupling with reverse osmosis depends on numbers of conditions, e.g., renewables sources, availability of components and economic restrictions.

- Batteries and energy storage devices are one of the important parameters for designing hybrid systems. These facilities have a direct impact on the economic aspects of the systems.

- Solar energy is a vital option for hybrid systems, but wind energy has the best performance.

- The geothermal has a very small contribution in the desalination process. However, due to the constant temperature at a specified depth, the energy provided from this source is more stable than other renewable sources.

- The design and deployment of hybrid systems are tailored to the area's potentials, economic conditions and technical capabilities.

- Regardless of the techno-economic conditions of hybrid renewables systems, these types of systems are crucial solutions for providing power and freshwater for remote areas.

\section{Compliance with ethical standards}

Conflicts of interest The author whose name is listed immediately below certifies that he has NO affiliations with any financial interest (such as honoraria; educational grants; membership, employment or other equity interest) in the subject matter or materials discussed in this manuscript. The author declares that he has no conflicts of interest.

Ethical approval All procedures followed were in accordance with the ethical standards, and this article does not contain any studies with human or animal subjects.

Open Access This article is licensed under a Creative Commons Attribution 4.0 International License, which permits use, sharing, adaptation, distribution and reproduction in any medium or format, as long as you give appropriate credit to the original author(s) and the source, provide a link to the Creative Commons licence, and indicate if changes were made. The images or other third party material in this article are included in the article's Creative Commons licence, unless indicated otherwise in a credit line to the material. If material is not included in the article's Creative Commons licence and your intended use is not permitted by statutory regulation or exceeds the permitted use, you will need to obtain permission directly from the copyright holder. To view a copy of this licence, visit http://creativecommons.org/licenses/by/4.0/.

\section{References}

Abdoelatef MG, Field RM, Lee Y-K (2015) Thermodynamic evaluation of coupling APR1400 with a thermal desalination plant. Int J Chem Mol Nucl Mater Metall Eng 9(11):1217-1225

Abrams RH (2018) Legal control of water resources cases and materials. West Academic, New York

Ahmadi A, Esmaeilion F, Esmaeilion A, Ehyaei MA, Silveira JL (2019) Benefits and limitations of Waste-to-energy conversion in Iran. Renewable Energy Res Appl 1(1):27-45

Ahmed FE, Hashaikeh R, Hilal N (2019) Solar powered desalination-Technology, energy and future outlook. Desalination 453:54-76

Al-Hallaj S, Parekh S, Farid MM, Selman JR (2006) Solar desalination with humidification-dehumidification cycle: review of economics. Desalination 195(1-3):169-186

Al-Hinai H, Al-Nassri MS, Jubran BA (2002) Effect of climatic, design and operational parameters on the yield of a simple solar still. Energy Convers Manag 43(13):1639-1650

Ali MEA, Wang L, Wang X, Feng X (2016) Thin film composite membranes embedded with graphene oxide for water desalination. Desalination 386:67-76

Ali A, Tufa RA, Macedonio F, Curcio E, Drioli E (2018) Membrane technology in renewable-energy-driven desalination. Renew Sustain Energy Rev 81:1-21

Al-Jasser AO (2007) Chlorine decay in drinking-water transmission and distribution systems: pipe service age effect. Water Res 41(2):387-396

Alkaisi A, Mossad R, Sharifian-Barforoush A (2017) A review of the water desalination systems integrated with renewable energy. Energy Procedia 110:268-274

Al-Karaghouli A, Renne D, Kazmerski LL (2009) Solar and wind opportunities for water desalination in the Arab regions. Renew Sustain Energy Rev 13(9):2397-2407

Al-Othman A, Tawalbeh M, Assad MEH, Alkayyali T, Eisa A (2018) Novel multi-stage flash (MSF) desalination plant driven by parabolic trough collectors and a solar pond: a simulation study in UAE. Desalination 443:237-244

Al-Othman A, Darwish NN, Qasim M, Tawalbeh M, Darwish NA, Hilal N (2019) Nuclear desalination: a state-of-the-art review. Desalination 457:39-61 
Al-Weshahi MA, Anderson A, Tian G (2013) Exergy efficiency enhancement of MSF desalination by heat recovery from hot distillate water stages. Appl Therm Eng 53(2):226-233

Amy G et al (2017) Membrane-based seawater desalination: present and future prospects. Desalination 401:16-21

Ang WS, Lee S, Elimelech M (2006) Chemical and physical aspects of cleaning of organic-fouled reverse osmosis membranes. J Membr Sci 272(1-2):198-210

Asbik M, Ansari O, Bah A, Zari N, Mimet A, El-Ghetany H (2016) Exergy analysis of solar desalination still combined with heat storage system using phase change material (PCM). Desalination 381:26-37

Ashok S (2007) Optimised model for community-based hybrid energy system. Renewable Energy 32(7):1155-1164

Askarzadeh A (2013) A discrete chaotic harmony search-based simulated annealing algorithm for optimum design of PV/wind hybrid system. Sol Energy 97:93-101

Ayoub GM, Malaeb L (2012) Developments in solar still desalination systems: a critical review. Crit Rev Environ Sci Technol 42(19):2078-2112

Balfaqih H, Al-Nory MT, Nopiah ZM, Saibani N (2017) Environmental and economic performance assessment of desalination supply chain. Desalination 406:2-9

Baxter R, Hastings N, Law A, Glass EJ (2008) Anim Genet 39(5):561-563

Be TO et al (2014) Freshwater resources

Behzadi A, Gholamian E, Ahmadi P, Habibollahzade A, Ashjaee M (2018) Energy, exergy and exergoeconomic (3E) analyses and multi-objective optimization of a solar and geothermal based integrated energy system. Appl Therm Eng 143:1011-1022

Bejan A, Tsatsaronis G (1996) Thermal design and optimization. Wiley, New York

Belessiotis V, Papanicolaou E, Delyannis E (2010) Nuclear desalination: a review on past and present. Desalin Water Treat 20(1-3):45-50

Belkaid A, Amzert SA, Bouaichaoui Y, Chibane H (2012) Economic study of nuclear seawater desalination for mostaganem site. Procedia engineering 33:134-145

Bennett A (2014) Current challenges in energy recovery for desalination. Filtration Separation 51(5):22-27

Bennett A (2015) Developments in desalination and water reuse. Filtration Separation 52(4):28-33

Bourouni K, Chaibi MT (2005) Application of geothermal energy for brackish water desalination in the south of Tunisia. Ground Water 2185(290):225

Brauns E (2010) An alternative hybrid concept combining seawater desalination, solar energy and reverse electrodialysis for a sustainable production of sweet water and electrical energy. Desalin Water Treat 13(1-3):53-62

Brauns E (2019) Salinity gradient power reverse electrodialysis. Current trends and future developments on (bio-) membranes. Elsevier, New York, pp 327-348

Burn S et al (2015) Desalination techniques-a review of the opportunities for desalination in agriculture. Desalination 364:2-16

Caldera U, Bogdanov D, Breyer C (2016) Local cost of seawater RO desalination based on solar PV and wind energy: a global estimate. Desalination 385:207-216

Calise F, Cipollina A, d'Accadia MD, Piacentino A (2014) A novel renewable polygeneration system for a small Mediterranean volcanic island for the combined production of energy and water: dynamic simulation and economic assessment. Appl Energy 135:675-693

Catrini P, Cipollina A, Micale G, Piacentino A, Tamburini A (2017) Exergy analysis and thermoeconomic cost accounting of a Combined Heat and Power steam cycle integrated with a Multi Effect
Distillation-Thermal Vapour Compression desalination plant. Energy Convers Manag 149:950-965

Chandrashekara M, Yadav A (2017) Water desalination system using solar heat: a review. Renew Sustain Energy Rev 67:1308-1330

Cheng A, Halhal D, Naji A, Ouazar D (2000) Pumping optimization in saltwater-intruded coastal aquifers. Water Resour Res 36(8):2155-2165

Cipollina A, Micale G, Rizzuti L (2009) Seawater desalination. Conventional and renewable energy processes. Springer, Berlin

Corsini A, Tortora E, Cima E (2015) Preliminary assessment of wave energy use in an off-grid minor island desalination plant. Energy Procedia 82:789-796

Cotruvo J, Voutchkov N, Fawell J, Payment P, Cunliffe D, Lattemann S (2010) Desalination technology: health and environmental impacts. CRC Press, Boca Raton

Council NR (2008) Desalination: a national perspective. National Academies Press, Washington

Criscuoli A, Drioli E (1999) Energetic and exergetic analysis of an integrated membrane desalination system. Desalination 124(1-3):243-249

Dahm K, Chapman M (2014) Produced water treatment primer: case studies of treatment applications. [US Department of the Interior], Bureau of Reclamation, Technical Service Center

Darre NC, Toor GS (2018) Desalination of water: a review. Curr Poll Rep 4(2):104-111

Darwish MA, Al-Awadhi FM, Darwish AM (2008) Energy and water in Kuwait Part I. A sustainability view point. Desalination 225(1-3):341-355

Darwish MA, Abdulrahim HK, Hassan AS, Mabrouk AA (2016) PV and CSP solar technologies \& desalination: economic analysis. Desalin Water Treat 57(36):16679-16702

Dashtpour R, Al-Zubaidy SN (2012) Energy efficient reverse osmosis desalination process. Int J Environ Sci Dev 3(4):339

Davies PA (2005) Wave-powered desalination: resource assessment and review of technology. Desalination 186(1-3):97-109

Delgado-Torres AM, García-Rodríguez L (2012) Design recommendations for solar organic Rankine cycle (ORC)-powered reverse osmosis (RO) desalination. Renew Sustain Energy Rev $16(1): 44-53$

Deniz E, Çınar S (2016) Energy, exergy, economic and environmental (4E) analysis of a solar desalination system with humidification-dehumidification. Energy Convers Manag 126:12-19

DeZuane J (1997) Handbook of drinking water quality. Wiley, New York

Dincer I, Rosen MA (2012) Exergy: energy, environment and sustainable development. Elsevier, Newnes

Ding LC, Akbarzadeh A, Tan L (2018) A review of power generation with thermoelectric system and its alternative with solar ponds. Renew Sustain Energy Rev 81:799-812

Dittmar M (2012) Nuclear energy: status and future limitations. Energy 37(1):35-40

Doukas H, Patlitzianas KD, Kagiannas AG, Psarras J (2006) Renewable energy sources and rationale use of energy development in the countries of GCC: myth or reality? Renewable Energy 31(6):755-770

Drioli E, Curcio E, Di Profio G, Macedonio F, Criscuoli A (2006) Integrating membrane contactors technology and pressuredriven membrane operations for seawater desalination: energy, exergy and costs analysis. Chem Eng Res Des 84(3):209-220

Ehyaei MA, Ahmadi A, Rosen MA (2019) Energy, exergy, economic and advanced and extended exergy analyses of a wind turbine. Energy Convers Manag 183:369-381

U. S. EIA (2019) Energy explained. Secondary Sources, Electricity, Electricity in the United States, Top, vol 10

El-Dessouky HT, Ettouney HM (2002) Fundamentals of salt water desalination. Elsevier, Amsterdam

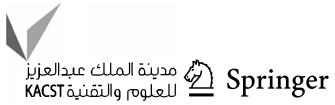


El-Ghonemy AMK (2012a) Future sustainable water desalination technologies for the Saudi Arabia: a review. Renew Sustain Energy Rev 16(9):6566

El-Ghonemy AMK (2012b) Retracted: water desalination systems powered by renewable energy sources, Review. Elsevier, Amsterdam

Elimelech M, Phillip WA (2011) The future of seawater desalination: energy, technology, and the environment. Science 333(6043):712-717

El-Mudir W, El-Bousiffi M, Al-Hengari S (2004) Performance evaluation of a small size TVC desalination plant. Desalination 165:269-279

El-Sebaii AA, Ramadan MRI, Aboul-Enein S, Khallaf AM (2011) History of the solar ponds: a review study. Renew Sustain Energy Rev 15(6):3319-3325

Eltawil MA, Zhengming Z, Yuan L (2009) A review of renewable energy technologies integrated with desalination systems. Renew Sustain Energy Rev 13(9):2245-2262

Esfahani IJ, Lee S, Yoo C (2015) Evaluation and optimization of a multi-effect evaporation-absorption heat pump desalination based conventional and advanced exergy and exergoeconomic analyses. Desalination 359:92-107

Falcão AFO (2014) Modelling of wave energy conversion. Universidade Técnica de Lisboa, Instituto Superior Técnico

Falkenmark M, Berntell A, Jägerskog A, Lundqvist J, Matz M, Tropp $\mathrm{H}$ (2007) On the verge of a new water scarcity: a call for good governance and human ingenuity. Stockholm International Water Institute (SIWI), Stockholm

Fane AGT (2018) A grand challenge for membrane desalination: more water, less carbon. Desalination 426:155-163

Feinberg BJ, Ramon GZ, Hoek EMV (2013) Thermodynamic analysis of osmotic energy recovery at a reverse osmosis desalination plant. Environ Sci Technol 47(6):2982-2989

Fiorenza G, Sharma VK, Braccio G (2003) Techno-economic evaluation of a solar powered water desalination plant. Energy Convers Manag 44(14):2217-2240

Fitzsimons L, Corcoran B, Young P, Foley G (2015) Exergy analysis of water purification and desalination: a study of exergy model approaches. Desalination 359:212-224

Foster R, Ghassemi M, Cota A (2009) Solar energy: renewable energy and the environment. CRC Press, Boca Raton

Foteinis S, Tsoutsos T (2017) Strategies to improve sustainability and offset the initial high capital expenditure of wave energy converters (WECs). Renew Sustain Energy Rev 70:775-785

Franzitta V, Curto D, Milone D, Viola A (2016) The desalination process driven by wave energy: a challenge for the future. Energies 9(12): 1032

García-Rodríguez L (2007) Assessment of most promising developments in solar desalination. Solar desalination for the 21 st century. Springer, Berlin, pp 355-369

Garcia-Rodriguez L, Romero-Ternero V, Gomez-Camacho C (2001) Economic analysis of wind-powered desalination. Desalination 137(1-3):259-265

Ghaffour N, Lattemann S, Missimer T, Ng KC, Sinha S, Amy G (2014) Renewable energy-driven innovative energy-efficient desalination technologies. Appl Energy 136:1155-1165

Ghaffour N, Bundschuh J, Mahmoudi H, Goosen MFA (2015) Renewable energy-driven desalination technologies: a comprehensive review on challenges and potential applications of integrated systems. Desalination 356:94-114

Gielen D, Boshell F, Saygin D, Bazilian MD, Wagner N, Gorini R (2019) The role of renewable energy in the global energy transformation. Energy Strategy Reviews 24:38-50
Gilau AM, Small MJ (2008) Designing cost-effective seawater reverse osmosis system under optimal energy options. Renewable Energy 33(4):617-630

Gökçek M, Gökçek ÖB (2016) Technical and economic evaluation of freshwater production from a wind-powered small-scale seawater reverse osmosis system (WP-SWRO). Desalination 381:47-57

Goosen M, Mahmoudi H, Ghaffour N (2010) Water desalination using geothermal energy. Energies 3(8):1423-1442

Goosen M, Mahmoudi H, Ghaffour N, Sablani SS (2011) Application of renewable energies for water desalination. Desalination, trends and technologies 1:89-118

Greenlee LF, Lawler DF, Freeman BD, Marrot B, Moulin P (2009) Reverse osmosis desalination: water sources, technology, and today's challenges. Water Res 43(9):2317-2348

Gude VG, Nirmalakhandan N, Deng S (2010) Renewable and sustainable approaches for desalination. Renew Sustain Energy Rev 14(9):2641-2654

Gude VG, Mummaneni A, Nirmalakhandan N (2017) Emergy, energy and exergy analysis of a solar powered low temperature desalination system. Desalin Water Treat 74:21-34

He W, Wang Y, Shaheed MH (2015) Stand-alone seawater RO (reverse osmosis) desalination powered by PV (photovoltaic) and PRO (pressure retarded osmosis). Energy 86:423-435

Henderson CR, Manwell JF, McGowan JG (2009) A wind/diesel hybrid system with desalination for Star Island, NH: feasibility study results. Desalination 237(1-3):318-329

Hernandez A, Muñoz R, Ventura S, Büscher W, Christoph R (2018) Study of low cost materials for the enhancement of solar seawater desalination. Periodico Tche Quimica 15(29):300-308

Hosseini R, Soltani M, Valizadeh G (2005) Technical and economic assessment of the integrated solar combined cycle power plants in Iran. Renew Energy 30(10):1541-1555

Ismail TM, Azab AK, Elkady MA, Elnasr MMA (2016) Theoretical investigation of the performance of integrated seawater desalination plant utilizing renewable energy. Energy Convers Manag 126:811-825

Jamil MA, Zubair SM (2017) Design and analysis of a forward feed multi-effect mechanical vapor compression desalination system: an exergo-economic approach. Energy 140:1107-1120

Jones E, Qadir M, van Vliet MTH, Smakhtin V, Kang S (2019) The state of desalination and brine production: a global outlook. Sci Total Environ 657:1343-1356

Jung D, Kang D, Kang M, Kim B (2015) Real-time pump scheduling for water transmission systems: case study. KSCE J Civ Eng 19(7):1987-1993

Kadaj E, Bosleman R (2018) Energy recovery devices in membrane desalination processes. Renewable energy powered desalination handbook. Elsevier, New York, pp 415-444

Kalista B, Shin H, Cho J, Jang A (2018) Current development and future prospect review of freeze desalination. Desalination 447:167-181

Kalogirou SA (2005) Seawater desalination using renewable energy sources. Prog Energy Combust Sci 31(3):242-281

Kalogirou SA (2018) Introduction to renewable energy powered desalination. Renewable energy powered desalination handbook. Elsevier, Amsterdam, pp 3-46

Karagiannis IC, Soldatos PG (2008) Water desalination cost literature: review and assessment. Desalination 223(1-3):448-456

Karameldin A, Shamloul MM, Shaalan MR, Esawy MH (2007) Dynamics of reverse osmosis in a standalone cogenerative nuclear reactor (Part I: reactivity changes). Int J Nucl Desalin 2(3):219-233

Kavvadias KC, Khamis I (2010) The IAEA DEEP desalination economic model: a critical review. Desalination 257(1-3):150-157 
Khan SU-D et al (2017) Development and techno-economic analysis of small modular nuclear reactor and desalination system across Middle East and North Africa region. Desalination 406:51-59

Khan SU-D, Khan SU-D, Danish SN, Orfi J, Rana UA, Haider S (2018) Nuclear energy powered seawater desalination. Renewable energy powered desalination handbook. Elsevier, New York, pp 225-264

Khayet M (2013) Solar desalination by membrane distillation: dispersion in energy consumption analysis and water production costs (a review). Desalination 308:89-101

Kim HS, No HC (2012) Thermal coupling of HTGRs and MED desalination plants, and its performance and cost analysis for nuclear desalination. Desalination 303:17-22

Kim B et al (2016) Purification of high salinity brine by multi-stage ion concentration polarization desalination. Sci Rep 6:31850

Kouta A, Al-Sulaiman FA, Atif M (2017) Energy analysis of a solar driven cogeneration system using supercritical $\mathrm{CO} 2$ power cycle and MEE-TVC desalination system. Energy 119:996-1009

Koutroulis AG, Tsanis IK, Daliakopoulos IN, Jacob D (2013) Impact of climate change on water resources status: a case study for Crete Island, Greece. J Hydrol 479:146-158

Koutsou CP, Kritikos E, Karabelas AJ, Kostoglou M (2020) Analysis of temperature effects on the specific energy consumption in reverse osmosis desalination processes. Desalination 476:114213

Kucera J (2019) Desalination: water from water. Wiley, New York

Kummu M et al (2016) The world's road to water scarcity: shortage and stress in the 20th century and pathways towards sustainability. Sci Rep 6:38495

Kusangaya S, Warburton ML, Van Garderen EA, Jewitt GPW (2014) Impacts of climate change on water resources in southern Africa: a review. Phys Chem Earth Parts A/B/C 67:47-54

Kwon DY, Yoon JS (2017) Study on the assessment of environmental impact indicators on concentrated effluent from desalination facility. Desalination Water Treat 96:201-210

Latorre FJG, Báez SOP, Gotor AG (2015) Energy performance of a reverse osmosis desalination plant operating with variable pressure and flow. Desalination 366:146-153

Latteman S (2010) Development of an environmental impact assessment and decision support system for seawater desalination plants. CRC Press, Boca Raton

Lattemann S, Kennedy MD, Schippers JC, Amy G (2010) Global desalination situation. Sustain Sci Eng 2:7-39

Lawal DU, Zubair SM, Antar MA (2018) Exergo-economic analysis of humidification-dehumidification $(\mathrm{HDH})$ desalination systems driven by heat pump (HP). Desalination 443:11-25

Lee S, Choi J, Park Y-G, Shon H, Ahn CH, Kim S-H (2019) Hybrid desalination processes for beneficial use of reverse osmosis brine: current status and future prospects. Desalination 454:104-111

Li M (2011) Reducing specific energy consumption in Reverse Osmosis (RO) water desalination: an analysis from first principles. Desalination 276(1-3):128-135

Lior N (2017) Sustainability as the quantitative norm for water desalination impacts. Desalination 401:99-111

Liu L, Wang Z (2009) The development and application practice of wind-solar energy hybrid generation systems in China. Renew Sustain Energy Rev 13(6-7):1504-1512

Liu C, Rainwater K, Song L (2011) Energy analysis and efficiency assessment of reverse osmosis desalination process. Desalination 276(1-3):352-358

Ludwig H (2010) Energy consumption of reverse osmosis seawater desalination-possibilities for its optimisation in design and operation of SWRO plants. Desalin Water Treat 13(1-3):13-25

Lund H, Østergaard PA, Stadler I (2011) Towards 100\% renewable energy systems. Appl Energy 88(2):419-421
Macedonio F, Drioli E (2010) An exergetic analysis of a membrane desalination system. Desalination 261(3):293-299

Madaeni SS, Samieirad S (2010) Chemical cleaning of reverse osmosis membrane fouled by wastewater. Desalination 257(1-3):80-86

Maleki A, Askarzadeh A (2014) Comparative study of artificial intelligence techniques for sizing of a hydrogen-based standalone photovoltaic/wind hybrid system. Int J Hydrogen Energy 39(19):9973-9984

Manenti F, Masi M, Santucci G, Manenti G (2013) Parametric simulation and economic assessment of a heat integrated geothermal desalination plant. Desalination 317:193-205

Manesh MHK, Ghalami H, Amidpour M, Hamedi MH (2013) Optimal coupling of site utility steam network with MED-RO desalination through total site analysis and exergoeconomic optimization. Desalination 316:42-52

Manios T, Tsanis IK (2006) Evaluating water resources availability and wastewater reuse importance in the water resources management of small Mediterranean municipal districts. Resour Conserv Recycl 47(3):245-259

Mansouri NY, Ghoniem AF (2017) Does nuclear desalination make sense for Saudi Arabia? Desalination 406:37-43

Mentis D et al (2016) Desalination using renewable energy sources on the arid islands of South Aegean Sea. Energy 94:262-272

Mezher T, Fath H, Abbas Z, Khaled A (2011) Techno-economic assessment and environmental impacts of desalination technologies. Desalination 266(1-3):263-273

Micale G, Rizzuti L, Cipollina A (2009) Seawater desalination: conventional and renewable energy processes. Springer, Berlin

Miller JE (2003) Review of water resources and desalination technologies. Sandia national labs unlimited release report SAND-2003-0800

Miller S, Shemer H, Semiat R (2015) Energy and environmental issues in desalination. Desalination 366:2-8

Misra BM (2003) Advances in nuclear desalination. Int J Nucl Desalin $1(1): 19-29$

Misra BM, Kupitz J (2004) The role of nuclear desalination in meeting the potable water needs in water scarce areas in the next decades. Desalination 166:1-9

Missimer TM, Maliva RG (2018) Environmental issues in seawater reverse osmosis desalination: intakes and outfalls. Desalination 434:198-215

Missimer TM, Kim Y-D, Rachman R, Ng KC (2013) Sustainable renewable energy seawater desalination using combinedcycle solar and geothermal heat sources. Desalin Water Treat 51(4-6):1161-1170

Mistry KH, McGovern RK, Thiel GP, Summers EK, Zubair SM, Lienhard JH (2011) Entropy generation analysis of desalination technologies. Entropy 13(10):1829-1864

Moh'd A A-N, Kiwan SM, Talafha S (2016) Hybrid solar-wind water distillation system. Desalination 395:33-40

Mohammadi A, Mehrpooya M (2017) Energy and exergy analyses of a combined desalination and CCHP system driven by geothermal energy. Appl Therm Eng 116:685-694

Mokheimer EMA, Sahin AZ, Al-Sharafi A, Ali AI (2013) Modeling and optimization of hybrid wind-solar-powered reverse osmosis water desalination system in Saudi Arabia. Energy Convers Manag 75:86-97

Munia H, Guillaume JHA, Mirumachi N, Porkka M, Wada Y, Kummu M (2016) Water stress in global transboundary river basins: significance of upstream water use on downstream stress. Environ Res Lett 11(1):14002

Nafey AS, Sharaf MA (2010) Combined solar organic Rankine cycle with reverse osmosis desalination process: energy, exergy, and cost evaluations. Renewable Energy 35(11):2571-2580 
Nafey AS, Sharaf MA, García-Rodríguez L (2010) Thermo-economic analysis of a combined solar organic Rankine cycle-reverse osmosis desalination process with different energy recovery configurations. Desalination 261(1-2):138-147

Nagaraj R, Thirugnanamurthy D, Rajput MM, Panigrahi BK (2016) Techno-economic analysis of hybrid power system sizing applied to small desalination plants for sustainable operation. Int J Sustain Built Environ 5(2):269-276

Nematollahi F, Rahimi A, Gheinani TT (2013) Experimental and theoretical energy and exergy analysis for a solar desalination system. Desalination 317:23-31

Ng KC, Shahzad MW (2018) Sustainable desalination using ocean thermocline energy. Renew Sustain Energy Rev 82:240-246

NREL (2016) National Renewable Energy Laboratory, Best Research Cell-efficiencies. http://www.nrel.gov/ncpv/images/efficiency _chart

Ortega-Delgado B, Garcia-Rodriguez L, Alarcón-Padilla D-C (2017) Opportunities of improvement of the MED seawater desalination process by pretreatments allowing high-temperature operation. Desalin Water Treat 97:94-98

Pal A, Gin KY-H, Lin AY-C, Reinhard M (2010) Impacts of emerging organic contaminants on freshwater resources: review of recent occurrences, sources, fate and effects. Sci Total Environ 408(24):6062-6069

Park GL, Schäfer AI, Richards BS (2009) Potential of wind-powered renewable energy membrane systems for Ghana. Desalination 248(1-3):169-176

Paulsen K, Hensel F (2005) Introduction of a new Energy Recovery System-optimized for the combination with renewable energy. Desalination 184(1-3):211-215

Peñate B, Castellano F, Bello A, García-Rodríguez L (2011) Assessment of a stand-alone gradual capacity reverse osmosis desalination plant to adapt to wind power availability: a case study. Energy 36(7):4372-4384

Pérez-González A, Ibáñez R, Gómez P, Urtiaga AM, Ortiz I, Irabien JA (2015) Nanofiltration separation of polyvalent and monovalent anions in desalination brines. J Membr Sci 473:16-27

Pietruszko SM, Gradzki M (2003) Performance of grid connected small PV system in Poland. Appl Energy 74(74):177-184

Pinto FS, Marques RC (2017) Desalination projects economic feasibility: a standardization of cost determinants. Renew Sustain Energy Rev 78:904-915

Proskynitopoulou V, Katsoyiannis IA (2018) Review of recent desalination developments for more efficient drinking water production across the world. New Mater Compd Appl 2(3):179-195

Rajaseenivasan T, Murugavel KK, Elango T, Hansen RS (2013) A review of different methods to enhance the productivity of the multi-effect solar still. Renew Sustain Energy Rev 17:248-259

Raucher RS, Tchobanoglous G (2014) The opportunities and economics of direct potable reuse. WateReuse Res Found, Alexandria

Reddy KV, Ghaffour N (2007) Overview of the cost of desalinated water and costing methodologies. Desalination 205(1-3):340-353

Reif JH, Alhalabi W (2015) Solar-thermal powered desalination: its significant challenges and potential. Renew Sustain Energy Rev 48:152-165

Resch G, Held A, Faber T, Panzer C, Toro F, Haas R (2008) Potentials and prospects for renewable energies at global scale. Energy policy 36(11):4048-4056

Ridgway HF, Orbell J, Gray S (2017) Molecular simulations of polyamide membrane materials used in desalination and water reuse applications: recent developments and future prospects. J Membr Sci 524:436-448
Salata F, Coppi M (2014) A first approach study on the desalination of sea water using heat transformers powered by solar ponds. Appl Energy 136:611-618

Saleh A, Qudeiri JA, Al-Nimr MA (2011) Performance investigation of a salt gradient solar pond coupled with desalination facility near the Dead Sea. Energy 36(2):922-931

Salter SH, Cruz JMBP, Lucas JAA, Pascal RCR (2010) Wave powered desalination. Macro-engineering Seawater in Unique Environments. Springer, Berlin, pp 657-674

Šály V, Ružinský M, Baratka S (2006) Photovoltaics in Slovakia-status and conditions for development within integrating Europe. Renewable Energy 31(6):865-875

Sanza MA, Bonnélyea V, Cremerb G (2007) Fujairah reverse osmosis plant: 2 years of operation. Desalination 203(1-3):91-99

Sarbatly R, Chiam C-K (2013) Evaluation of geothermal energy in desalination by vacuum membrane distillation. Appl Energy 112:737-746

Sauvet-Goichon B (2007) Ashkelon desalination plant—a successful challenge. Desalination 203(1-3):75-81

Scruggs CE, Thomson BM (2017) Opportunities and challenges for direct potable water reuse in arid inland communities. J Water Resour Plan Manag 143(10):4017064

Segurado R, Costa M, Duić N, Carvalho MG (2015) Integrated analysis of energy and water supply in islands. Case study of S. Vicente, Cape Verde. Energy 92:639-648

Shahzad MW, Burhan M, Ang L, Ng KC (2017) Energy-water-environment nexus underpinning future desalination sustainability. Desalination 413:52-64

Sharmila N, Jalihal P, Swamy AK, Ravindran M (2004) Wave powered desalination system. Energy 29(11):1659-1672

Shatat M, Riffat SB (2012) Water desalination technologies utilizing conventional and renewable energy sources. Int J Low-Carbon Technol 9(1):1-19

Shatat M, Worall M, Riffat S (2013a) Opportunities for solar water desalination worldwide. Sustain Cities Soc 9:67-80

Shatat M, Worall M, Riffat S (2013b) Economic study for an affordable small scale solar water desalination system in remote and semiarid region. Renew Sustain Energy Rev 25:543-551

Shemer H, Semiat R (2017) Sustainable RO desalination-Energy demand and environmental impact. Desalination 424:10-16

Sleem M (2010) Environmental impact assessment of nuclear desalination plant at KANUPP. Nucleus (Islamabad) 47(4):313-322

Smaoui M, Abdelkafi A, Krichen L (2015) Optimal sizing of standalone photovoltaic/wind/hydrogen hybrid system supplying a desalination unit. Sol Energy 120:263-276

Sommariva C, Hogg H, Callister K (2004) Environmental impact of seawater desalination: relations between improvement in efficiency and environmental impact. Desalination 167:439-444

Soshinskaya M, Crijns-Graus WHJ, van der Meer J, Guerrero JM (2014) Application of a microgrid with renewables for a water treatment plant. Appl Energy 134:20-34

Spyrou ID, Anagnostopoulos JS (2010) Design study of a stand-alone desalination system powered by renewable energy sources and a pumped storage unit. Desalination 257(1-3):137-149

Sterling SM, Ducharne A, Polcher J (2013) The impact of global landcover change on the terrestrial water cycle. Nat Clim Change 3(4):385

Subramani A, Jacangelo JG (2015) Emerging desalination technologies for water treatment: a critical review. Water Res 75:164-187

Sukhatme SP, Nayak JK (2017) Solar energy. McGraw-Hill Education, New York

Tabak J (2009) Solar and geothermal energy. Infobase Publishing, New York

Tado K, Sakai F, Sano Y, Nakayama A (2016) An analysis on ion transport process in electrodialysis desalination. Desalination 378:60-66 
Tchanche BF, Lambrinos G, Frangoudakis A, Papadakis G (2010) Exergy analysis of micro-organic Rankine power cycles for a small scale solar driven reverse osmosis desalination system. Appl Energy 87(4):1295-1306

Tomaszewska B, Bodzek M (2013) Desalination of geothermal waters using a hybrid UF-RO process. Part I: boron removal in pilotscale tests. Desalination 319:99-106

Tufa RA, Curcio E, Brauns E, van Baak W, Fontananova E, Di Profio G (2015) Membrane distillation and reverse electrodialysis for near-zero liquid discharge and low energy seawater desalination. J Membr Sci 496:325-333

Tufa RA et al (2019) Integrated membrane distillation-reverse electrodialysis system for energy-efficient seawater desalination. Appl Energy 253:113551

Turchi C, Akar S, Cath T, Vanneste J, Gustafson E, Akerley J (2017) Desalination of impaired water using geothermal energy. National Renewable Energy Lab, Golden

U. R. Energy (2012) Water desalination using renewable energy. IRENA, Abu Dhabi

Ummel K, Wheeler D (2008) Desert power: the economics of solar thermal electricity for Europe, North Africa, and the Middle East. Center for Global Development Working Paper, no. 156

Urmee T, Harries D, Schlapfer A (2009) Issues related to rural electrification using renewable energy in developing countries of Asia and Pacific. Renewable Energy 34(2):354-357

Valdez Salas B, Schorr Wiener M (2012) Desalination, trends and technologies. Taylor \& Francis, Abingdon

Veldkamp TIE et al (2015) Changing mechanism of global water scarcity events: impacts of socioeconomic changes and inter-annual hydro-climatic variability. Glob Environ Change 32:18-29

Velmurugan V, Srithar K (2008) Prospects and scopes of solar pond: a detailed review. Renew Sustain Energy Rev 12(8):2253-2263

Verdier F (2011) MENA regional water outlook part II desalination using renewable Energy task 1-desalination potential. Fichtner Stuttgart

Vermaas DA, Guler E, Saakes M, Nijmeijer K (2012) Theoretical power density from salinity gradients using reverse electrodialysis. Energy Procedia 20:170-184

Viola A, Franzitta V, Trapanese M, Curto D, Viola D (2016) Nexus water \& energy: a case study of wave energy converters (WECs) to desalination applications in Sicily. Int J Heat Technol 34(2):S379-S386

Vörösmarty CJ, Hoekstra AY, Bunn SE, Conway D, Gupta J (2015) Fresh water goes global. Science 349(6247):478-479

Voutchkov N (2012) Desalination engineering: planning and design. McGraw Hill Professional, New York

Voutchkov N (2016) Desalination-past, present and future. International Water Association 17:1

Voutchkov N (2018) Energy use for membrane seawater desalinationcurrent status and trends. Desalination 431:2-14

Wang Z et al (2018a) Nanoparticle-templated nanofiltration membranes for ultrahigh performance desalination. Nat Commun 9(1):2004

Wang Y-N, Goh K, Li X, Setiawan L, Wang R (2018b) Membranes and processes for forward osmosis-based desalination: recent advances and future prospects. Desalination 434:81-99
Wellmann J, Meyer-Kahlen B, Morosuk T (2018) Exergoeconomic evaluation of a CSP plant in combination with a desalination unit. Renewable Energy 128:586-602

Wetterau G (2011) Desalination of seawater: M61, vol 61. American Water Works Association, Denver

Widiasa IN, Paramita V, Kusumayanti H (2009) BWRO Desalination for potable water supply enhancement in coastal regions. J Coast Dev 12(2):81-88

World Health Organization (1993) Guidelines for drinking-water quality. World Health Organization, Geneva

Wright JD (1982) Selection of a working fluid for an organic Rankine cycle coupled to a salt-gradient solar pond by direct-contact heat exchange. J SolEnergy Eng 104(4):286-292

Wu S, Zhang Z (2003) An approach to improve the economy of desalination plants with a nuclear heating reactor by coupling with hybrid technologies. Desalination 155(2):179-185

Wu S, Zheng W (2002) Coupling of nuclear heating reactor with desalination process. Desalination 142(2):187-193

Wu S, Dong D, Zhang D, Wang X (2000) Seawater desalination plant using nuclear heating reactor coupled with MED process. Nucl Sci Tech 11(1):6-12

Xevgenos D, Moustakas K, Malamis D, Loizidou M (2016) An overview on desalination \& sustainability: renewable energydriven desalination and brine management. Desalin Water Treat 57(5):2304-2314

Yearbook IDAD (2010) Yearbook 2010-2011. Media analytics Ltd, Oxford

Yılmaz İH, Söylemez MS (2012) Design and computer simulation on multi-effect evaporation seawater desalination system using hybrid renewable energy sources in Turkey. Desalination 291:23-40

Younos T (2005) The economics of desalination. J Contemp Water Res Educ 132(1):39-45

Youssef PG, Al-Dadah RK, Mahmoud SM (2014) Comparative analysis of desalination technologies. Energy Procedia 61:2604-2607

Yuan Y et al (2017) Enhanced desalination performance of carboxyl functionalized graphene oxide nanofiltration membranes. Desalination 405:29-39

Zhao S, Zou L, Mulcahy D (2012) Brackish water desalination by a hybrid forward osmosis-nanofiltration system using divalent draw solute. Desalination 284:175-181

Zhao D, Deng S, Shao Y, Zhao L, Lu P, Su W (2019) A new energy analysis model of seawater desalination based on thermodynamics. Energy Procedia 158:5472-5478

Zhou Y, Tol RSJ (2005) Evaluating the costs of desalination and water transport. Water Resour Res 41(3):1-10

Publisher's Note Springer Nature remains neutral with regard to jurisdictional claims in published maps and institutional affiliations. 